LEANDRA NAVARRO BENATTI

Estudo da força gerada pelo grupo muscular isquiotibial em exercícios resistidos

São Carlos - SP 


\section{Estudo da força gerada pelo grupo muscular isquiotibial em exercícios resistidos}

\begin{abstract}
Dissertação apresentada ao Programa de Pós-Graduação Interunidades em Bioengenharia, Escola de Engenharia de São Carlos, Faculdade de Medicina de Ribeirão Preto, Instituto de Química de São Carlos da Universidade de São Paulo, para a obtenção do título de Mestre em Bioengenharia.
\end{abstract}

Área de concentração: Biomecânica.

ORIENTADOR: Prof ${ }^{\circ}$ Dr. Neri Alves 
Dedico este trabalho aos meus pais ANA e BENEDITO, que sempre confiaram em mim e nunca mediram esforços para sustentar e apoiar com todo carinho cada etapa da minha vida. Amo vocês e divido a emoção de mais um sonho concretizado... 


\section{AGRADECIMENTOS ESPECIAIS}

Ao meu orientador Prof ${ }^{\circ}$ Dr. Neri Alves, pela credibilidade e entusiasmo para o desenvolvimento deste trabalho, mostrando-me com muita simplicidade a arte de se fazer ciência. Muito obrigada por sua dedicação e amizade!!

Ao meu amigo Fábio Mícolis de Azevedo pelo incentivo e pela gentil doação e colaboração desde o início deste trabalho. Valeu por tudo!! 


\section{AGRADECIMENTOS}

A Deus que nos presenteia sempre com um novo dia, me abençoou e conduziu cada minuto deste trabalho com Sua sabedoria e Seu amor. Amém!

Aos meus pais e ao meu irmão Danilo pelo amor e carinho oferecido a cada momento da minha vida, pela compreensão de tantos momentos nos quais estive ausente e, principalmente, por todos os nossos momentos de contagiante alegria, pois estes, além de estarem acima de toda e qualquer dificuldade, levarei sempre em minha lembrança.

Aos meus amigos baririenses Renata e Gustavo, Fernanda, Regiane, Pércia e Alex, pela união de tanto tempo, por nossas incansáveis conversas e confidências e pelo apoio integral, que serviram de encorajamento para que eu seguisse em frente. Obrigada pessoal!

À Ana Paula Rebucci Lirani pela prazerosa amizade e companhia em todos os momentos vividos em São Carlos, e também, aos seus pais João Lirani e Lurdinha e seus irmãos João Paulo e Heloísa pela calorosa acolhida.

Ao Profo Dr. Orivaldo Lopes da Silva pela amizade e por todas as conversas esclarecedoras para nossos trabalhos.

Ao Prof $^{\circ}$ Dr. José Carlos Pereira pela sua constante disposição para ajudar.

Ao Prof $^{\circ}$ Dr. Fábio Viadanna Serrão, da Universidade Federal de São Carlos, pela gentil disposição para conhecer o nosso trabalho.

Aos colegas do Laboratório de Fisioterapia Aplicada ao Movimento Humano da FCT/UNESP, Luciana, Emanuelle, Fábio, Diego e Milene, pela colaboração na coleta dos dados e pelos momentos de descontração.

Aos professores Aldo e Fábio do Departamento de Física da FCT/UNESP pela gentileza em ceder o EMIC e pela ajuda na realização dos ensaios.

Aos voluntários que participaram da fase experimental deste trabalho, pela disposição e paciência.

Aos meus professores da graduação do Departamento de Fisioterapia da Universidade Estadual Paulista pela minha formação, especialmente ao Profo $^{\circ}$ Dr. Luiz Carlos Marques Vanderlei por sua prazerosa amizade e pelo 
incentivo constante para a pesquisa, ao Profo Augusto Cesinando de Carvalho por sua contagiante dedicação à Fisioterapia e sua gentil disposição nos momentos difíceis, ao Profo Dr. Rúben de Faria Negrão Filho pela atenção dada neste trabalho e por ceder um espaço no laboratório para a realização do mesmo e ao Profo José Carlos de Camargo Filho pela sua adorável maneira de ser mestre.

Às secretárias da diretoria da FCT/UNESP de Presidente Prudente, Cleide, Carmen Lúcia e Dirce pela dedicação e paciente ajuda sempre que precisei.

À Aline, Beatriz e Cássia, amigas e companheiras de república, por acolherem esta etapa da minha vida com carinho e compreensão. Sucesso meninas!

À Patrícia Ferraz Braz, Graziela Garrido Mori e Fernanda Figueirôa Sanchez, grandes amigas de trabalho e companheiras, por todos os momentos enriquecedores e descontraídos que passamos juntas. Adoro vocês!

A toda minha família, principalmente aos irmãos Fernando e Felipe, meus graciosos primos, pela diversão de todos esses anos e a minha tia Vera Lúcia e ao meu tio Diogenes pela alegre presença em todos os momentos da minha vida.

Aos meus alunos do curso de graduação em Fisioterapia das Faculdades Adamantinenses Integradas pela troca de experiências dentro e fora das salas de aula e, principalmente, por serem o estímulo para a incansável busca do novo.

Um abraço carinhoso a todos!!

Leandra Navarro Benatti 
"Mas é preciso ter manha, É preciso ter graça, É preciso ter sonho, sempre. Quem traz na pele essa marca, Possui a estranha mania de ter fé na vida".

(Milton Nascimento) 


\section{RESUMO}

\section{BENATTI, L. N. (2005). Estudo da força gerada pelo grupo muscular} isquiotibial em exercícios resistidos. Dissertação (Mestrado) - Escola de Engenharia de São Carlos/Faculdade de Medicina de Ribeirão Preto/ Instituto de Química de São Carlos, Universidade de São Paulo, São Carlos, 2005.

O desenvolvimento de protocolos de fortalecimento muscular, tanto na reabilitação quanto no treinamento, é realizado por exercícios resistidos, os quais envolvem a aplicação de sobrecargas externas ao músculo exercitado. Estas sobrecargas podem ser do tipo constante ou variável. Dentre os recursos existentes para a aplicação da resistência variável, os tubos elásticos são amplamente utilizados por sua versatilidade e viabilidade econômica. No entanto, é um material que ainda não possui parâmetros de aplicação claramente delineados. Alguns estudos realizaram a caracterização biomecânica dos materiais elásticos e as formas de aplicação nos diferentes tipos de exercícios, mas poucos registraram o comportamento do músculo quando exercitado por esse tipo de resistência. Neste contexto, o objetivo deste trabalho foi caracterizar o comportamento do grupo muscular isquiotibial, no que se diz respeito a sua geração de força interna e a atividade eletromiográfica (EMG), durante exercícios resistidos, com tubo elástico e peso fixo. E, envolveu: o estudo das propriedades de tubos elásticos nacionais e importados, por meio de ensaios mecânicos realizados no EMIC; a avaliação da força exercida pelos isquiotibiais em exercícios resistidos, com o indivíduo em diferentes posições, utilizando-se simulações realizadas no Origin 6.0 e MatLab 6.5 e baseadas no modelo biomecânico; e análise do sinal EMG do músculo bíceps femoral, o qual correlacionado com a força e o torque dos isquiotibiais, durante ensaios experimentais. Estes ensaios foram realizados em 10 voluntários do sexo masculino, os quais foram posicionados no sistema mecânico de exercício em decúbito dorsal para a realização de movimentos de flexo-extensão do joelho, com resistência elástica e fixa. A captação do sinal EMG foi feita no módulo condicionador de sinais modelo EMG1000. Registrouse também, a posição angular da perna por meio do eletrogoniômetro e a força aplicada, por uma célula de carga. Os dados foram tratados em rotina desenvolvida em MatLab 6.5. Os resultados mostraram que não existem diferenças significativas na relação tensão-deformação entre os tubos elásticos nacionais e importados. A otimização da escolha do tipo de resistência, baseada na resposta de força muscular, depende também da escolha da posição adotada pelo indivíduo para realizar a flexão do joelho. A relação entre a força dos isquiotibiais e o sinal EMG da cabeça longa do bíceps femoral foi independente do tipo de sobrecarga utilizada. O sinal EMG dos exercícios realizado com peso foi menos harmônico e o músculo agiu numa menor extensão do movimento. E, por fim, o torque foi proporcional ao sinal EMG, nos casos de resistência constante e elástica.

Palavras-chave: biomecânica, tubos elásticos, exercícios resistidos, eletromiografia, força muscular, músculos isquiotibiais, torque. 
ABSTRACT

BENATTI, L. N. (2005) Study of the force by hamstrings in resisted exercises. M.Sc. Dissertation - Escola de Engenharia de São Carlos/Faculdade de Medicina de Ribeirão Preto/ Instituto de Química de São Carlos, Universidade de São Paulo, São Carlos, 2005.

The development of protocols of strengthening, as in the rehabilitation as in the training, it is carried through resistives exercises, which involve the application of external overloads to the exercised muscle. These overloads can be of the constant or variable type. Among the existing resources for the application of the variable resistance, the elastic tubing are widely used by its versatility and economic viability. However, it is a material that still haven t possess parameters of application delineated clearly. Some studies had carried through the biomechanic characterization of the elastic materials and the forms of application in the different types of exercises, but few had registered the behavior of the muscle when exercised by this type of resistance. In this context, the aim of this work was to characterize the behavior of the hamstrings, connected to generation of internal force and the electromyography (EMG) activity, during resisted exercises, with elastic tubing and constant weight. This work involved: the study of the properties of national and imported elastic tubing, during the experiments in the EMIC; the evaluation of the force exerted for hamstrings in resisted exercises, with the individual in different positions, through simulations realized by 6,0 Origin and MatLab 6,5, based in the biomechanic model; analysis of EMG activity of the femoral biceps, which was correlated with the force and torque of the hamstrings, during the experiments. These experiments had been carried out $n 10$ voluntaries of the masculine gender, that had been located in the mechanical system of exercise in supino position for the accomplishment knee of flexion-extension of the knee, with elastic and constant resistance. The captation of EMG activity was made by conditioning module of signals model EMG1000. It was also registered the angular position of the leg through goniometer and the applied force through a load cell. The data had been treated in routine developed in MatLab 6.5. The results had shown no significant differences in the tension-deformation relation between the national and imported elastic tubes. The improvement of the choice of type of resistance, based on the reply of muscular force, also depends on the choice of the position adopted for the individual to carry out the knee flexion. The relation between the force of the hamstrings and EMG signal of the long head of the femoral biceps was independent of the type of used overload. The EMG activity of the exercises carried out with weight was less harmonic and the muscle acts in a less extension of the movement. Finally, the torque was proportional to EMG signal in the cases of constant and elastic resistance.

Key-Words: biomechanics, elastic tubes, resisted exercises, electromyography, force, hasmtrings, torque. 


\section{LISTA DE FIGURAS}

Figura 1 - Princípio da sobrecarga para desenvolvimento de força muscular (Adaptado de Barbanti (2002)) .............................................22

Figura 2 - Estrutura da unidade motora (Adaptado de Pozzo; Farina e Merletti

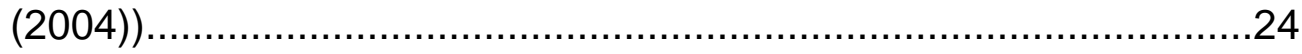

Figura 3 - Relação força-velocidade de um músculo isolado..........................28

Figura 4 - Princípio da especificidade na curva força-velocidade (Adaptado de Barbanti (2002))

Figura 5 - Exemplos de resistências constantes e de suas formas de aplicação. A) Conjunto de anilhas (1) e halteres (2). B) Conjunto de caneleiras. C) Equipamento de musculação para membros superiores $\mathrm{e}$ inferiores. D) Aplicação de resistência constante em membros inferiores. E) Aplicação de resistência constante em membros superiores.

Figura 6 - Exemplos de resistências variáveis. A) Tubos elásticos de diferentes espessuras da Thera-Band $(\AA$. B) Faixas elásticas Thera-Band $($. C) Tubos de látex nacionais de diferentes espessuras. D) Sistema de molas (Método Pilates)....

Figura 7 - Dinamômetro isocinético (Biodex Medical System®, Inc, 2003).....32

Figura 8 - Diagrama da correlação entre os métodos de medidas e as grandezas de interesse na análise biomecânica do movimento humano (BAUMANN, 1995). .35

Figura 9 - Representação esquemática da geração do potencial de ação da unidade motora (Adaptado de De Luca (1979))...........................38

Figura 10 - Representação esquemática da geração do sinal mioelétrico. A) Aspecto anatômico. B) Modelo fisiológico e instrumentação (Adaptado de De Luca (1979)).

Figura 11 - Amplificação diferencial, onde n representa o ruído do sistema e do ambiente e $\mathrm{m} 1$ - $\mathrm{m} 2$ o SME resultante.

Figura 12 - (A) Anatomia de superfície das regiões do glúteo, da coxa e do joelho (vista posterior). (B) Dissecção superficial da face posterior destas regiões. Destaca-se a localização dos músculos isquiotibiais e dos tendões do bíceps femoral (1) e do semimembranoso e semitendinoso (2). (Adaptado de Netter (1999) e Moore (1994))......42

Figura 13 - Dissecção profunda da face posterior das regiões do glúteo, da coxa e do joelho. Destaca-se a localização da tuberosidade isquiática 
e dos Músculos semimembranoso e da cabeça curta do bíceps femoral (Adaptado de Netter (1999) e Moore (1994))......................43

Figura 14 - A) Dissecção superficial da face lateral das regiões do glúteo, da coxa e do joelho. Destaca-se a localização do músculo bíceps femoral (vista lateral). B) Anatomia de superfície correspondente destas regiões (Adaptado de Netter (1999) e Moore (1994)).....

Figura 15 - Vista sagital das estruturas ósseas que compõem a articulação do joelho: A) Côndilos femurais; B) Platô tibial; C) Patela; D) Cabeça proximal da fíbula (Adaptado de Primal Pictures ${ }^{\circledR 2003) . ~}$ .45

Figura 16 - Representação simplificada da linha de força dos isquiotibiais $\left(F_{i}\right)$ e seu respectivo braço de momento $\left(\mathrm{bm}_{\mathrm{i}}\right)$ (Adaptado de Kellis, 1998)

Figura 17 - Caracterização mecânica das cordas elásticas no EMIC 50

Figura 18 - Gráfico representativo da distribuição dos valores de braço de momento dos isquiotibiais durante flexão do joelho numa amplitude de movimento de 0 a $90^{\circ}$ (Adaptado de Kellis e Baltzopoulos (1999))

Figura 19 - Sistema mecânico de exercício para uso da resistência elástica como tipo de sobrecarga.

Figura 20 - Relação entre a força de resistência e a força aplicada pelo membro na roda.

Figura 21 - Corda elástica utilizada nos ensaios experimentais.

Figura 22 - A) Sistema adaptado para o uso da resistência fixa. B) Sistema adaptado para a realização de contrações isométricas. 58

Figura 23 - Módulo condicionador de sinais da marca Lynx, modelo BioEMG 1000. (1) Canais biopotenciais para eletrodos bipolar ativo; (2) Canais de instrumentação.

Figura 24 - A) Módulo condicionador de sinais (1. Eletrodo de referência; 2. Eletrodo ativo). B) Par de eletrodos ativos utilizados para a captação do sinal eletromiográfico. Destaca-se o circuito pré-amplificador e a distância de $20 \mathrm{~mm}$ dos centros de cada eletrodo 60

Figura 25 - Célula de carga 61

Figura 26 - Eletrogoniômetro. 61

Figura 27 - Esquema representativo do local de colocação dos eletrodos sobre o músculo bíceps femoral (HERMENS et al., 2002). 
Figura 28 - Posicionamento do voluntário no sistema mecânico de exercício.

Figura 29 - Valores de tensão oferecidos por diferentes números de cordas elástica de acordo com ângulo de flexão do joelho. 65

Figura 30 - (1) Ciclos de sinais sem nenhum tratamento da intensidade eletromiográfica, da posição angular da perna e da força registrada na célula de carga. (2) Exemplo de seqüência de tratamento de EMG no domínio do tempo. A) sinal de EMG bruto durante um ciclo de flexo-extensão; B) RMS do sinal (sinal retificado); C) Envoltória do sinal retificado sobreposta ao sinal e; C) Envoltória do sinal..... 66

Figura 31 - Esquema ilustrando o sinal de eletromiografia, a posição angular da perna e a força registrada na célula de carga na base de tempo normalizada.

Figura 32 - Curvas de tensão-deformação durante ensaios com amostras das cordas elástica Lengruber e Thera-Band $®$.

Figura 33 - Ensaio com corda elástica (204) Lengruber no sistema de tração (condição estática)......

Figura 34 - Gráfico logarítmico da tensão da corda e a deformação relativa....73

Figura 35 - Diagrama de corpo livre representando a perna de um indivíduo em decúbito dorsal.

Figura 36 - Diagrama de corpo livre representando a perna de um indivíduo em decúbito ventral.

Figura 37 - Diagrama de corpo livre representando a perna de um indivíduo em pé.

Figura 38 - Diagrama de corpo livre representando a perna de um indivíduo sentado.

Figura 39 - Diagrama de corpo livre representando a perna de um indivíduo em decúbito lateral.

Figura 40 - Simulação da força dos isquiotibiais em exercícios de flexão do joelho, considerando o indivíduo em decúbito dorsal, utilizando-se diferentes números de cordas. .84

Figura 41 - Simulação da força dos isquiotibiais em exercícios de flexão do joelho, considerando o indivíduo em decúbito dorsal, utilizando-se diferentes pesos. 
Figura 42 - Simulação da força dos isquiotibiais em exercícios de flexão do joelho, considerando o indivíduo em decúbito dorsal, utilizando-se diferentes tipos de resistências.

Figura 43 - Simulação da força dos isquiotibiais em exercícios de flexão do joelho, considerando o indivíduo em decúbito lateral, utilizando-se diferentes tipos de resistências.

Figura 44 - Simulação da força dos isquiotibiais em exercícios de flexão do joelho, considerando o indivíduo em pé, utilizando-se diferentes tipos de resistências.

Figura 45 - Simulação da força dos isquiotibiais em exercícios de flexão do joelho, considerando o indivíduo em decúbito ventral, utilizando-se diferentes tipos de resistências.

Figura 46 - Simulação da força dos isquiotibiais em exercícios de flexão do joelho, considerando o indivíduo em diferentes posições e a corda elástica como resistência.

Figura 47 - Simulação da força dos isquiotibiais em exercícios de flexão do joelho, considerando o indivíduo em diferentes posições e o peso fixo como resistência.

Figura 48 - Força interna dos isquiotibiais, intensidade do sinal EMG, posição angular da perna e tensão da corda elástica normalizados na base do tempo.

Figura 49 - Velocidade e aceleração angular durante o movimento de flexoextensão do joelho com a corda elástica como resistência......

Figura 50 - Curvas de força dos isquiotibiais, de torque e de sinal EMG, normalizadas pela contração voluntária isométrica máxima em 90 graus, de movimentos de flexo-extensão do joelho com a corda elástica como resistência.

Figura 51 - Relação da força dos isquiotibiais e da intensidade do sinal EMG com o ângulo de flexão do joelho $(\theta)$, nas fases concêntrica e excêntrica de exercícios com corda elástica como resistência.

Figura 52 - Relação entre a intensidade do sinal EMG normalizado e a força dos isquiotibiais normalizada nas fases concêntrica e excêntrica de exercício realizado com corda elástica como resistência.

Figura 53 - Relação do torque e da intensidade do sinal EMG com o ângulo de flexão do joelho $(\theta)$, nas fases concêntrica e excêntrica de exercícios realizados com corda elástica como resistência... 
Figura 54 - Relação entre a intensidade do sinal EMG normalizado e o torque normalizado, nas fases concêntrica e excêntrica de exercício realizado com corda elástica como resistência.

Figura 55 - Força interna dos isquiotibiais, intensidade do sinal EMG, posição angular da perna e peso fixo normalizados na base do tempo..... 96

Figura 56 - Velocidade e aceleração angular obtidas pela derivação da curva da posição angular da perna, durante o movimento de flexo-extensão do joelho com o peso fixo como resistência.

Figura 57 - Curvas de força dos isquiotibiais, torque e sinal EMG, normalizados pela contração voluntária isométrica máxima em 90 graus, obtidas durante a flexo-extensão do joelho com o peso fixo como resistência.

Figura 58 - Relação da força dos isquiotibiais e da intensidade do sinal EMG com o ângulo de flexão do joelho $(\theta)$, nas fases concêntrica e excêntrica de exercício com peso fixo como resistência. .98

Figura 59 - Relação entre a intensidade do sinal EMG normalizado e a força dos isquiotibiais normalizada, nas fases concêntrica e excêntrica de exercício realizado com peso fixo como resistência. .98

Figura 60 - Relação do torque e da intensidade do sinal EMG com o ângulo de flexão do joelho $(\theta)$, nas fases concêntrica e excêntrica de exercício realizado com peso fixo como resistência. 99

Figura 61 - Relação entre a intensidade do sinal EMG normalizado e o torque normalizado, nas fases concêntrica e excêntrica de exercício realizado com peso fixo como resistência.

Figura 62 - Relação NIEMG-Torque durante flexão do joelho (Adaptado de Onishi et al. (2002)). 


\section{LISTA DE TABELAS}

Tabela 1 - Valores do braço de momento dos isquiostibiais descritos por Kellis e Baltzopoulos (1999) para intervalos de ângulos de flexão do joelho de $0^{\circ}$ a $90^{\circ}$.

Tabela 2 - Parâmetros da função polinomial do $4^{\circ}$ grau utilizada para o ajuste dos valores dos braços de momento dos isquiotibiais.

Tabela 3 - Características antropométricas dos voluntários submetidos aos ensaios experimentais...................................................54

Tabela 4 - Posicionamento e orientação dos eletrodos na cabeça longa do bíceps femoral, segundo padronização proposta pela SENIAM (HERMENS et al., 2002).....

Tabela 5 - Áreas de secção transversal das cordas estudadas e seus respectivos valores de histerese e tensão máxima a 300\% de deformação.

Tabela 6. Equação da força do grupo muscular isquiotibial para diferentes posições do indivíduo na realização da flexo-extensão do joelho.....81

Tabela 7. Valores médios de força da contração voluntária isométrica máxima (CVIM), da resistência fixa, da resistência elástica e do RMS do sinal de EMG em $90^{\circ}$. 


\section{SUMÁRIO}

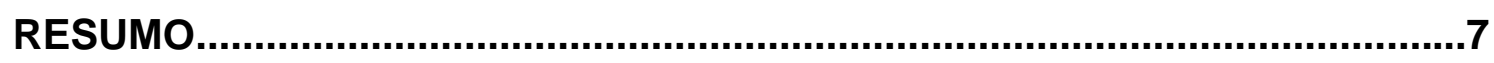

ABSTRACT

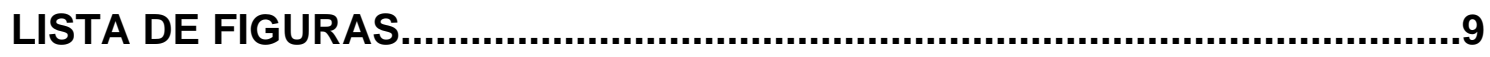

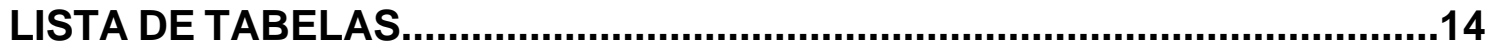

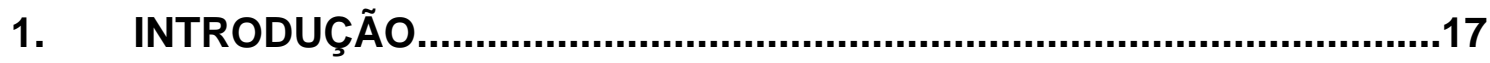

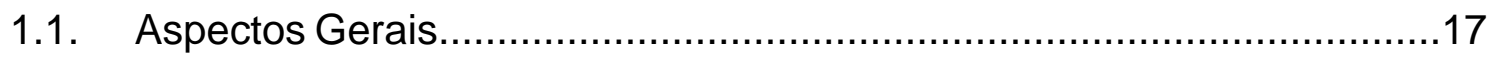

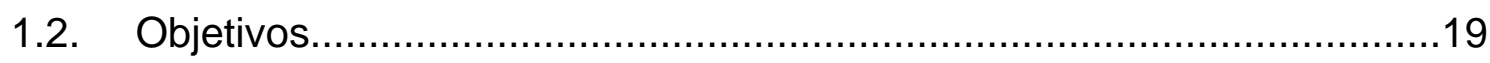

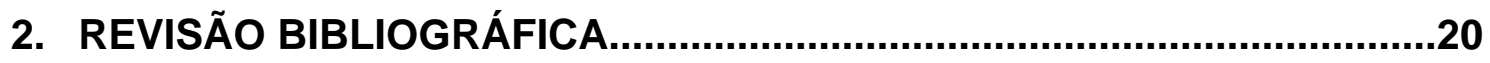

2.1. Exercício físico aplicado à reabilitação e ao treinamento.......................20

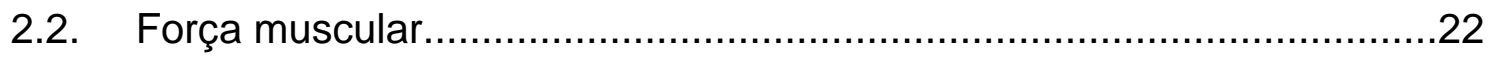

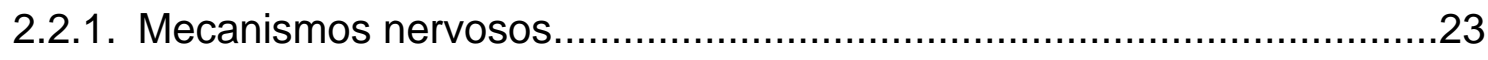

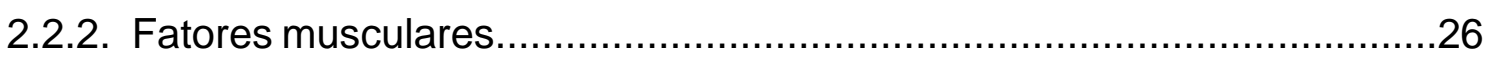

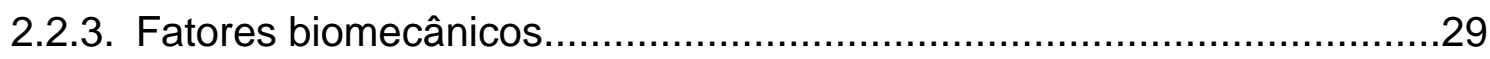

2.4. A resistência elástica..................................................................

2.5. Biomecânica aplicada ao movimento humano..................................34

2.5.1. Métodos de medição em biomecânica.........................................35

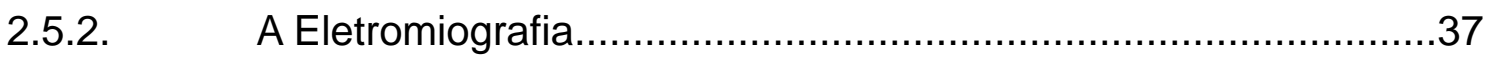

2.6. O grupo muscular isquiotibial..................................................

2.7. O modelo biomecânico do joelho..................................................46

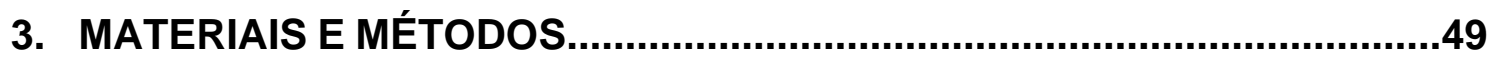

3.1. Estudo das propriedades da corda elástica.......................................49

3.2. Modelo biomecânico da atuação dos isquiotibiais.................................51

3.3. Simulação da força dos isquiotibiais..................................................52

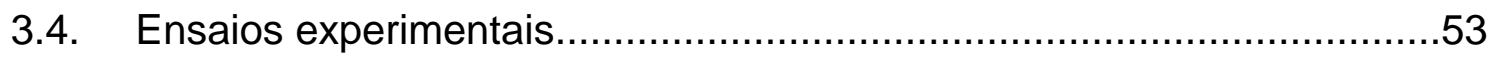




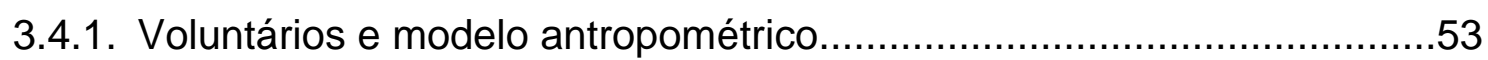

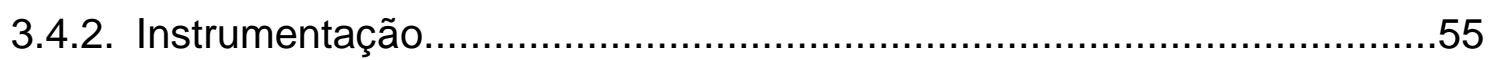

3.4.2.1. Sistema mecânico de exercício, corda elástica e peso fixo...................55

3..4.2.2. Instrumentos de medição...........................................................58

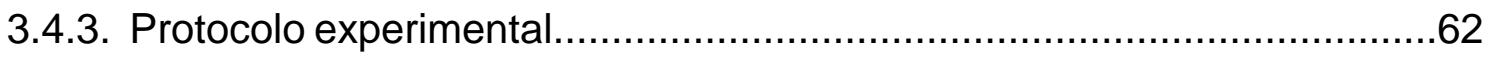

3.4.3.1 Fixação dos eletrodos para captação dos sinais de EMG......................62

3.4.3.2. Posicionamento no sistema mecânico de exercício................................63

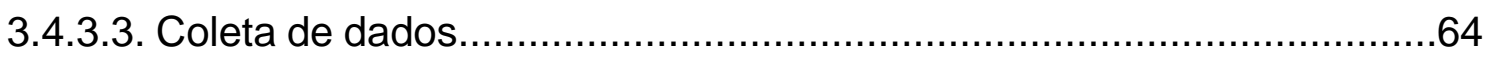

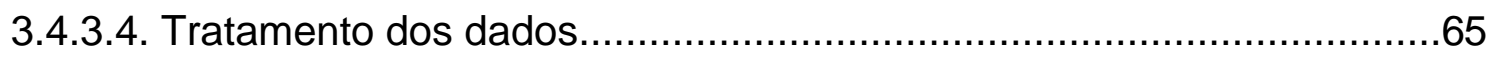

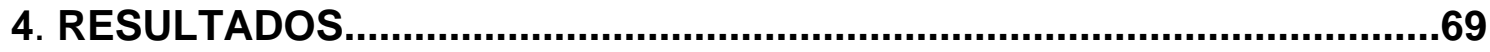

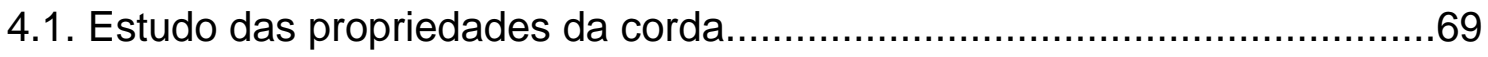

4.2. Modelo biomecânico da atuação dos isquiotibiais.....................................73

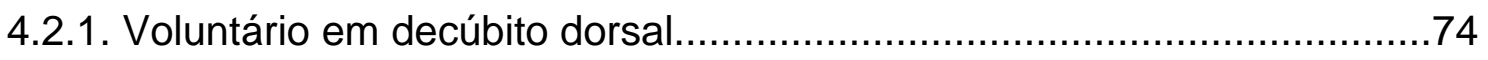

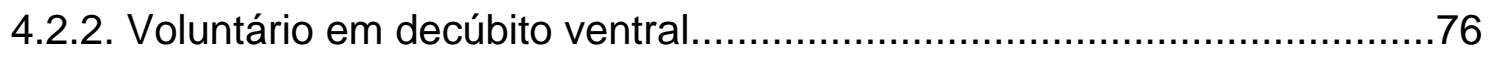

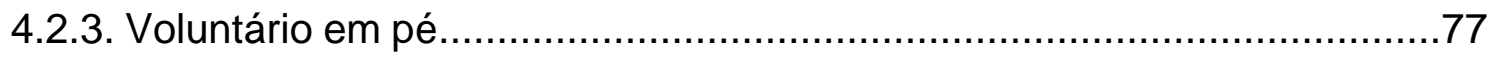

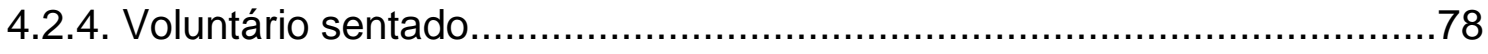

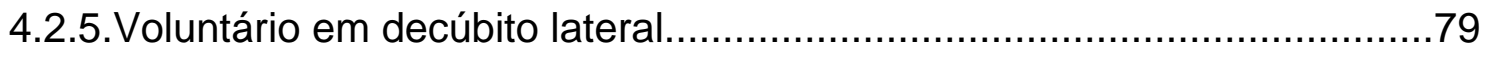

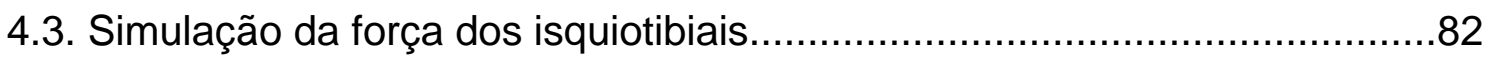

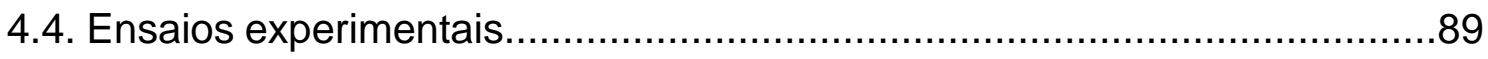

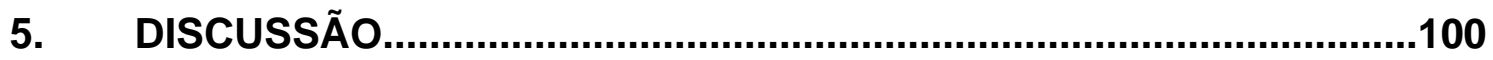

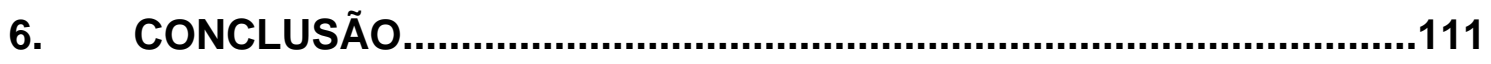

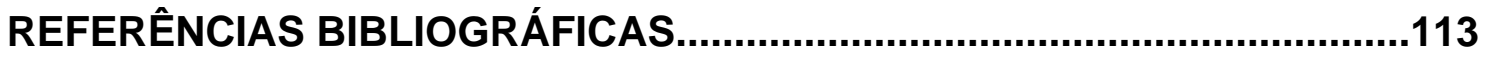

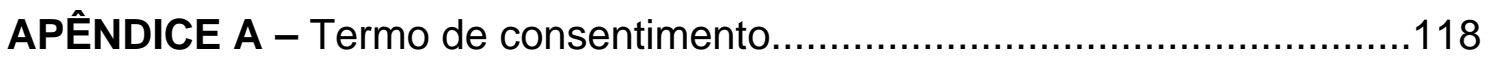

APÊNDICE B - Resultados individuais dos experimentos com corda

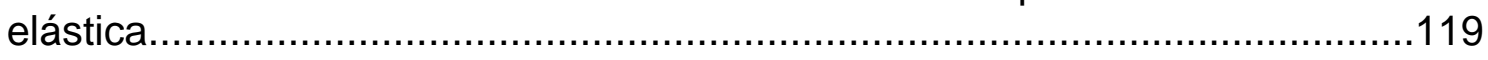

APÊNDICE C - Resultados individuais dos experimentos com peso fixo.......128 


\section{INTRODUÇÃO}

\subsection{Aspectos Gerais}

A importância dos músculos isquiotibiais para a realização da flexão do joelho e, principalmente, para a estabilização dinâmica desta articulação durante a locomoção humana já é bem definida na literatura. Este papel estabilizador é potencializado nos casos de lesão do ligamento cruzado anterior (LCA), cujo papel é evitar a anteriorização da tíbia em relação fêmur (LI et al., 1999; LIU; MAITLAND, 2000). Assim, os músculos isquiotibiais são reconhecidos como importantes elementos compensatórios durante a marcha, quando há uma diminuição da estabilização da articulação do joelho de indivíduos com lesão de LCA, o que pode, nestes casos, ser confirmado pelo aumento da atividade eletromiográfica do músculo bíceps femoral (SOLOMORROW et al., 1987; KALUND et al., 1990; CICCOTTI et al., 1994; YANAGAWA et al., 2002).

Os indivíduos que apresentam este tipo de perda de estabilidade articular, normalmente passam por um processo de reabilitação específico, o qual envolve em uma das suas etapas a fase de fortalecimento dos músculos isquiotibiais (YANAGAWA et al., 2002). Para o desenvolvimento dos protocolos de fortalecimento, tanto nos processos de reabilitação quanto nos de treinamento, aplica-se uma sobrecarga ao músculo exercitado a fim de se obter um ganho de força muscular e resistência à fadiga (BARBANTI, 2002).

A sobrecarga oferecida ao músculo é obtida por meio da aplicação de resistências externas ao movimento. Estas resistências podem ser do tipo constante ou variável, sendo a corda elástica um recurso bastante utilizado para oferecer resistência variável ao músculo exercitado, devido à sua versatilidade e, também, por sua viabilidade econômica (KISNER; COLBY, 1998; AZEVEDO et al., 2003;). No entanto, diferente do que ocorre nos protocolos que utilizam as resistências fixas e o dinamômetro isocinético, aqueles que utilizam a corda elástica como tipo de resistência externa, não possuem parâmetros de aplicação bem definidos (AZEVEDO et al., 2003). 
Existem poucos estudos que envolvam a caracterização das propriedades das cordas elásticas, a sua forma de aplicação nos diferentes tipos de exercícios e, principalmente, como o músculo, quando exercitado por esse tipo de resistência, comporta-se durante o arco de movimento no que se diz respeito a sua geração de força e atividade mioelétrica (HINTERMEISTER et al, 1998; PATTERSON et al., 2001; AZEVEDO et al., 2003).

Neste contexto, determinou-se o objetivo principal desta dissertação, 0 qual consistiu no estudo do comportamento da força gerada pelo grupo muscular isquiotibial em exercícios resistidos sob resistência elástica e resistência fixa, durante a flexão do joelho. 


\subsection{Objetivos}

\section{Objetivo Geral}

Este trabalho tem como objetivo quantificar a força interna do grupo muscular isquiotibial durante exercício resistidos, utilizando-se sobrecarga elástica e fixa.

\section{Objetivos específicos}

São objetivos específicos deste trabalho:

- $\quad$ Realizar estudo sobre as propriedades dos tubos de elásticos utilizados como resistência externa em exercícios;

- Avaliar as forças exercidas pelos músculos isquiotibiais nos exercícios com corda elástica e peso fixo, considerando o indivíduo em diferentes posições;

- Analisar o sinal eletromiográfico do músculo bíceps femoral, coletado durante ensaios experimentais, procurando identificar o padrão de ativação do mesmo e as correlações com as grandezas biomecânicas, especialmente a força muscular e o torque. 


\section{REVISÃO BIBLIOGRÁFICA}

\subsection{Exercício físico aplicado à reabilitação e ao treinamento}

O termo exercício físico, segundo o dicionário Houaiss (HOUAISS et al., 2001), é entendido como uma atividade corporal que tem por fim manter ou aperfeiçoar a forma física, aprimorar a saúde, corrigir alguma imperfeição do corpo ou prepará-lo para uma competição esportiva. Ou seja, é aplicado tanto na reabilitação quanto no treinamento esportivo, e exige que se tenha uma orientação e evolução programada. Sua aplicação tem como metas principais a prevenção de disfunções, o desenvolvimento da força muscular e a manutenção da condição cardiorrespiratória, da flexibilidade, da coordenação, do equilíbrio e das habilidades motoras funcionais (KISNER; COLBY, 1998; FRONTERA; DAWSON; SLOVIK, 2001).

Para a aplicação de exercícios físicos, com metas específicas de reabilitação ou de treinamento, deve-se adotar alguns protocolos de acordo com os objetivos pretendidos. Os programas de reabilitação são preparados, basicamente, para prevenir complicações e otimizar a função musculoesquelética. Tais objetivos são alcançados, freqüentemente, com a aplicação de diferentes tipos de exercícios físicos, pois a maioria das condições incapacitantes limita a mobilidade, interferindo na função dos músculos, dos ossos, do coração e dos pulmões (KISNER; COLBY, 1998; FRONTERA; DAWSON; SLOVIK, 2001). A aplicação de exercícios físicos específicos no treinamento esportivo, por sua vez, tem por objetivo alcançar o preparo físico, intelectual, psíquico e moral dos atletas (WEINECK, 1991).

Tanto nos programas de reabilitação quanto no treinamento esportivo, 0 uso adequado do exercício requer a compreensão dos princípios básicos para a sua prescrição, os quais são fundamentados em respostas fisiológicas e correlações biomecânicas; bem como no conhecimento dos diversos equipamentos existentes. Os profissionais responsáveis pela reabilitação de 
um indivíduo ou pelo treinamento de um atleta, podem adequar um programa de exercícios com a disfunção ou a deficiência que requer tratamento e/ou a melhora do rendimento físico. Garantindo assim, a segurança e as adaptações fisiológicas benéficas durante a realização desses exercícios (BARBANTI, 1992; POWERS; HOWLEY, 2000; FRONTERA; DAWSON; SLOVIK, 2001).

Para a prescrição de atividades físicas devem ser observadas, principalmente, a individualidade biológica, a especificidade dos exercícios, a reversibilidade das alterações fisiológicas e a efetividade da sobrecarga. Estas observações são fundamentadas nos princípios da prescrição do exercício, que são os Princípios da Individualidade Biológica, da Especificidade, da Reversibilidade, da Continuidade e da Sobrecarga (WEINECK, 1991; POWERS; HOWLEY, 2000).

Embora cada princípio especifique uma característica importante, conforme descrito a seguir, estes não devem ser considerados isoladamente. Pelo Princípio da Individualidade Biológica o indivíduo deverá ser sempre considerado como a junção do seu genótipo e do seu fenótipo. Assim, um mesmo exercício propiciará diferentes efeitos de treinamento dependendo de fatores como sexo, idade, capacidade aeróbica e experiência prévia. O Princípio da Especificidade determina que as adaptações induzidas sejam dependentes do tipo de exercício executado, do segmento corporal exercitado e das coordenações psicomotoras utilizadas. Já a natureza transitória das mudanças funcionais e morfológicas adquiridas pelo treinamento físico descreve o Princípio da Reversibilidade. Ou seja, após uma possível paralisação do treinamento ocorre um retorno às condições iniciais. Além disso, pode-se citar o Princípio da Continuidade que determina a importância de se ter uma continuidade de trabalho ao longo do tempo, respeitando o período de repouso entre as aplicações da sobrecarga. E, por fim, para induzir modificações num organismo, o exercício deve ser realizado com uma intensidade de carga, freqüência e duração do exercício, nas quais o indivíduo não está habituado, o que descreve o importante Princípio da Sobrecarga (POWERS; HOWLEY, 2000; BARBANTI, 2002).

Com respeito à intensidade do exercício, este deve ser realizado na denominada "zona de treinamento", ou seja, cargas entre 50 e 100\% da força voluntária máxima. Assim, quanto maior a carga de treinamento, maior será o 
aumento da força, por outro lado, se os níveis de atividade regular forem mais baixos que os habituais, a capacidade de força diminui (figura1) (BARBANTI, 2002).

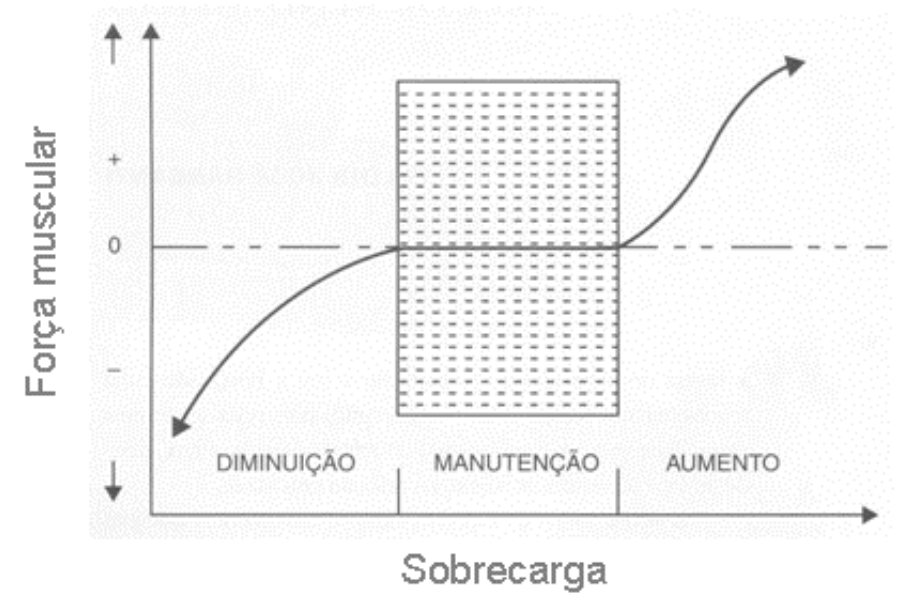

Figura 1 - Princípio da sobrecarga para desenvolvimento de força muscular (Adaptado de Barbanti (2002)).

No contexto da teoria do treinamento e do princípio da sobrecarga, os conceitos que envolvem a produção de força muscular consistem num tópico muito importante a ser estudado, pois, trata-se de uma capacidade motora fundamental da motricidade humana. Além disso, o treinamento de força quando planejado e executado corretamente proporciona resultados positivos tanto para a reabilitação de pacientes quanto para o condicionamento de atletas, bem como para melhorar a forma física de não-atletas (FLECK; KRAEMER, 1995; FRONTERA; DAWSON; SLOVIK, 2001).

\subsection{Força muscular}

No organismo humano, o elemento responsável pela geração de força é o músculo; todos os movimentos exigem força e/ou suas variações, como a potência e a força resistente. O termo força muscular expressa a capacidade dos músculos de gerar tensão. A potência muscular refere-se à capacidade de produzir força de natureza explosiva e a força resistente, ou resistência de 
força, à capacidade de executar movimentos durante um tempo prolongado (BARBANTI, 2002).

As modalidades de exercícios que envolvem o ganho de força muscular, além de serem as mais difundidas, consistem em um importante objeto de estudo. Suas aplicações visam benefícios como: hipertrofia muscular, resistência à fadiga, potência muscular e visam ainda a melhora do desempenho motor, como por exemplo, a capacidade para correr, para saltar ou para jogar um objeto (FLECK; KRAEMER, 1995; BARBANTI, 2002).

Em indivíduos normais, a força muscular pode ser aumentada por vários métodos, desde que se respeite o princípio da sobrecarga para 0 desenvolvimento da força, conforme descrito anteriormente. Entretanto, um dos desafios dos profissionais envolvidos no processo de reabilitação consiste na seleção da forma mais segura para realizar um treinamento de força muscular, com intensidade, freqüência, duração e tipo de sobrecarga adequados e suficientes para atingir os benefícios desejados. Isto se deve ao fato de que as definições de tais parâmetros para a obtenção de um alto nível de desempenho atlético são diferentes das necessárias para melhorar um resultado relacionado à manutenção da saúde de um indivíduo a ser reabilitado (FLECK; KRAEMER, 1995; POWERS; HOWLEY, 2000; FRONTERA; DAWSON; SLOVIK, 2001; BARBANTI, 2002).

Para entender tais diferenças, torna-se necessário abordar as características que envolvem a produção de força muscular, as quais podem ser divididas em mecanismos nervosos e fatores musculares e biomecânicos.

\subsubsection{Mecanismos nervosos}

Dentre os mecanismos nervosos que influenciam a capacidade do músculo produzir força, pode-se distinguir os que derivam do sistema nervoso central (SNC) e do sistema nervoso periférico. O SNC fornece o estímulo necessário para que um determinado grupo de músculos desenvolva tensão muscular enquanto o sistema nervoso periférico está associado às inervações 
sensitivas do músculo que faz a comunicação das informações com o SNC (FOSS; KETEYIAN, 2000).

Cada célula do músculo esquelético, chamada de fibra muscular, está conectada ao ramo de uma fibra originária de uma célula nervosa, que partiu da medula espinhal e é denominado motoneurônio. O conjunto formado pelo motoneurônio e todas as fibras musculares que ele inerva é denominado unidade motora, a qual regula os mecanismos responsáveis pela contração destas fibras musculares (Figura 2), (FOSS; KETEYIAN, 2000; POZZO; FARINA; MERLETTI; 2004).

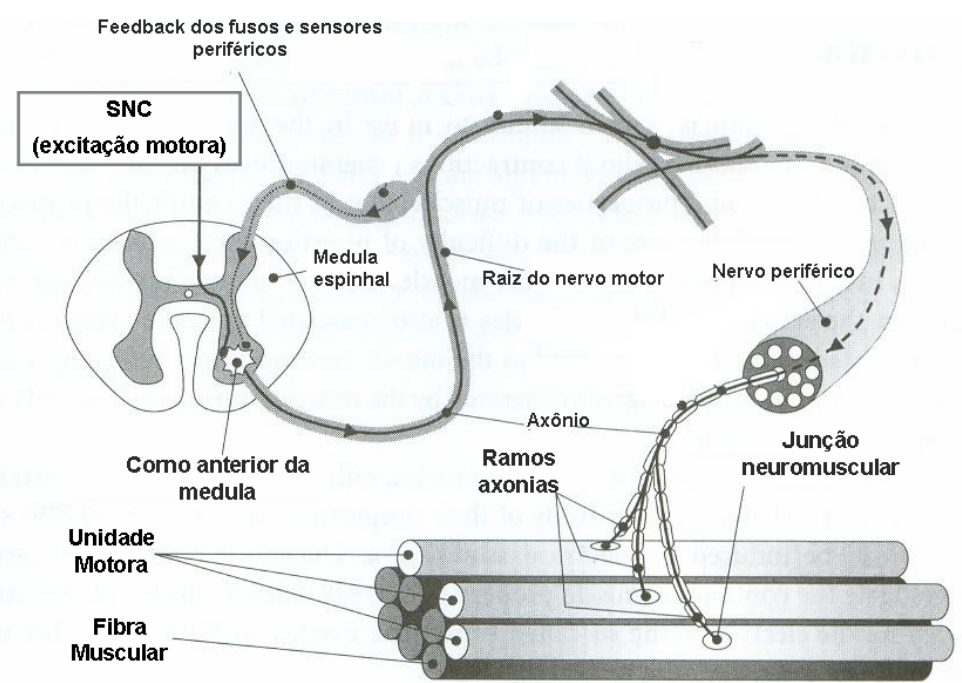

Figura 2. Estrutura da unidade motora (Adaptado de Pozzo; Farina e Merletti (2004)).

O SNC dispõe de três mecanismos fundamentais para regular a força produzida por uma contração muscular: o número das unidades motoras recrutadas, a freqüência e a sincronização da ativação das unidades motoras (FOX; KETEYIAN, 2000; ROBINSON, 2001; POZZO; FARINA; MERLETTI; 2004).

As unidades básicas de geração de força são os diferentes tipos de fibras musculares. A força pode ser regulada pelo controle do número e do tipo de fibras acionadas, que, por sua vez, está relacionado com o limiar de excitabilidade das mesmas. As unidades motoras de menores dimensões possuem limiares de excitabilidade mais baixos e, conseqüentemente, são as primeiras a serem recrutadas. À medida que a necessidade de produção de 
força aumenta, as unidades motoras de maiores dimensões são recrutadas progressivamente. Desta forma, a partir do momento que o limiar é alcançado todas as fibras constituintes se contraem (FOSS; KETEYIAN, 2000; FRONTERA; DAWSON; SLOVIK, 2001; ROBINSON, 2001).

A freqüência de ativação das unidades motoras está relacionada com a velocidade de contração e é um dos mecanismos responsável pelo controle da força produzida. Durante a ativação neural do músculo uma série de potenciais de ação muscular é produzida. Em resposta ao primeiro potencial de ação muscular, o elemento contrátil do músculo é ativado e a força de uma contração é produzida. Se um segundo potencial de ação é disparado antes que todo cálcio liberado seja reafastado, mais cálcio é liberado e o ciclo de pontes cruzadas actina -miosina continua. Como resultado, a força mensurada do segmento muscular ativado cresce novamente. Assim, quando a freqüência de ativação do musculoesquelético é incrementada, a força muscular também aumenta de forma que as suas oscilações vão gradualmente desaparecendo até tornarem-se uniformes (FRONTERA, 2001; FOSS; KETEYIAN, 2000; BARBANTI, 2002).

A sincronização da ativação das unidades motoras pode ser definida como a coincidência temporal dos impulsos de duas ou mais unidades motoras. Assim, quanto maior for a capacidade de recrutar unidades motoras simultaneamente, num dado momento, maior será a força produzida pelo músculo (FOSS; KETEYIAN, 2000; FRONTERA; DAWSON; SLOVIK, 2001; BARBANTI, 2002).

Os mecanismos nervosos periféricos envolvem as terminações sensoriais dos músculos, tendões e articulações cuja função principal é de veicular as informações sensitivas para o SNC. O processo de produção de força muscular depende também das informações geradas no sistema nervoso periférico pelos proprioceptores. Entre os proprioceptores, o fuso neuromuscular, os órgãos tendinosos de Golgi e os receptores articulares são aqueles que mais se relacionam e interagem no processo de produção de força. 


\subsubsection{Fatores musculares}

Os fatores musculares que influenciam a capacidade do músculo em produzir força são: a área da secção transversal do músculo, os tipos de fibras musculares e o tipo de contração muscular.

A força de um músculo é proporcional a sua área da secção transversal fisiológica. Inclusive, uma das formas de melhorar a capacidade de produção de força de um dado músculo, na reabilitação e no treinamento, é produzir hipertrofia muscular por meio de exercícios físicos (ONISHI et al., 2002).

A força produzida por um determinado músculo depende também dos tipos de fibras predominantes. O músculo esquelético compreende diferentes tipos de fibras que variam estrutural, histoquímica e metabolicamente. Existem duas categorias principais: as fibras do tipo I e do tipo II. As fibras do tipo I são mais adequadas para contrações sustentadas ou repetidas que requerem tensão relativamente baixa, tais como caminhar ou ficar de pé. A rota principal para produção de energia nessas fibras é a fosforilação oxidativa. As fibras do tipo II são subdivididas em tipos Ila e Ilb. As fontes de energia metabólica são para as fibras do tipo IIb, usadas para atividades que requerem desenvolvimento rápido e alta tensão, como por exemplo o levantamento de peso. Estas fibras são primariamente anaeróbicas, a partir da glicólise. As fibras do tipo lla são intermediárias, ou seja, usam rotas aeróbicas e anaeróbicas. Assim, as fibras do tipo II são mais facilmente fatigadas que as do tipo I (POWERS, HOWLEY, 2000).

Existe uma estreita relação entre a força e o tipo de contração muscular, ou seja, sempre que ativados os músculos desenvolvem tensão e tendem a encurtar-se podendo, ou não, ocorrer deslocamento dos segmentos ósseos que Ihes estão associados. O tipo de resistência exterior determinará a existência ou não desta contração.

Classicamente, existem três tipos de ações musculares: a concêntrica, a excêntrica e a isométrica. A ação muscular concêntrica ocorre quando a tensão desenvolvida pelo músculo é superior à resistência que ele tem de vencer, ocorrendo o seu encurtamento. Já a ação muscular excêntrica, desenvolve-se quando a tensão produzida pelo músculo é inferior à resistência a ele imposta. Neste caso, apesar do músculo tentar encurtar-se, ocorre um alongamento das 
fibras musculares. E, por fim, a ação muscular isométrica ocorre se a tensão desenvolvida pelo músculo é igual a resistência externa, ou seja, o membro permanece imóvel e, assim, o comprimento das fibras musculares mantém-se inalterado (KISNER; COLBY, 1998; FRONTERA, 2001).

A capacidade de produção de força de um músculo, numa dada posição, depende do seu alongamento. A força desenvolvida pelo músculo é maior no seu comprimento de repouso, já que o número de pontes cruzadas entre a actina e a miosina é maior nesta posição. À medida que o músculo se encurta ocorre uma diminuição das ligações entre as proteínas contráteis porque ocorre alguma sobreposição dos filamentos, com uma diminuição da tensão que pode ser desenvolvida. Contudo, quando um músculo é alongado há um acréscimo de força devido aos fatores elásticos (ROBINSON, 2001).

A potência muscular pode ser expressa pelo produto da força pela velocidade de contração, por isso, é importante entender a relação entre força e velocidade. A figura 3 mostra a variação típica da força em função da velocidade de contração muscular. A capacidade de um músculo gerar força é mais elevada numa situação isométrica (velocidade de contração igual a zero) do que numa contração concêntrica, sendo que, esta capacidade diminui à medida em que se aumenta a velocidade de contração. Tal fato ocorre devido à ação da viscosidade das fibras musculares, que resiste ao movimento de forma proporcional ao aumento da velocidade de contração. As condições de produção de força são reduzidas também, pela ação das pontes cruzadas, pois, para que ocorra o deslizamento dos filamentos, é necessário um aumento da velocidade de contração. No entanto, durante uma contração excêntrica, o músculo é capaz de desenvolver tensões maiores do que no caso isométrico, e neste caso a força aumenta com a velocidade de contração muscular (BARBANTI, 2002). 


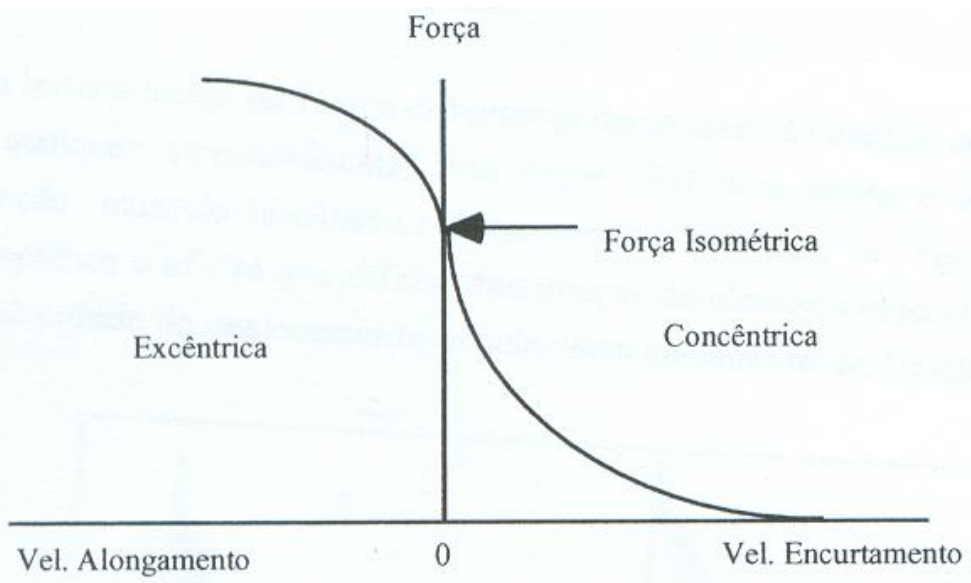

Figura 3. Relação força-velocidade de um músculo isolado.

Para um melhor delineamento de um protocolo de treinamento, pode-se aplicar à relação força-velocidade o princípio da especificidade. A figura 4 ilustra este exemplo, indicando que, se o objetivo do exercício aplicado for desenvolver maior força muscular, o mesmo deve ser realizado com sobrecargas mais elevadas, mas com uma velocidade pequena, justamente pela ação da própria sobrecarga preconizada. Porém, se o efeito desejado estiver relacionado às características do ganho de velocidade de contração, o exercício deve ser aplicado com sobrecargas menores (BARBANTI, 2002).
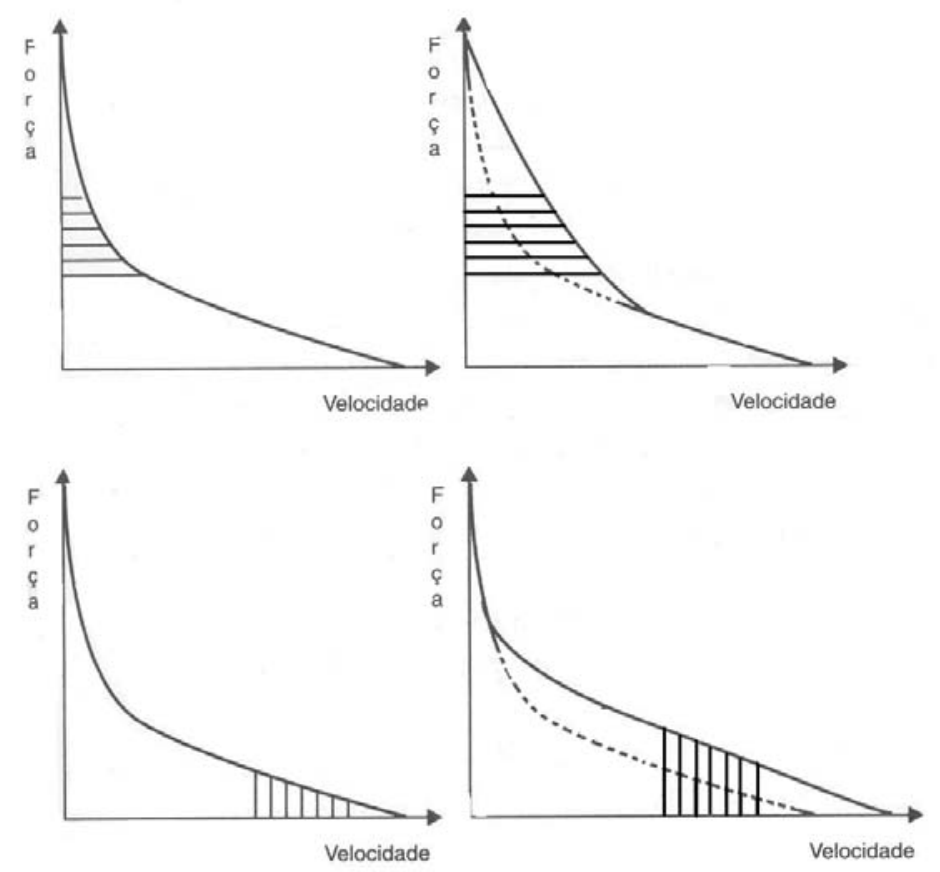

Figura 4. Princípio da especificidade na curva força-velocidade (Adaptado de Barbanti (2002)). 
O produto da força e da velocidade desenvolvida determinará a potência, a qual o músculo pode realizar um movimento, com uma determinada sobrecarga. A potência máxima que um músculo desenvolve é obtida, geralmente, quando a força atinge de 35 a 45\% da força máxima e de 30 a $35 \%$ da velocidade máxima de encurtamento (BOSCO et al., 1982)

\subsubsection{Fatores biomecânicos}

Os fatores biomecânicos que interferem na quantidade de força produzida por um determinado músculo são a alavanca muscular, a alavanca da resistência externa e o tipo de resistência externa.

A alavanca muscular é definida como a distância perpendicular entre 0 eixo da articulação e a linha de ação do tendão. A modificação do ângulo articular produz uma alteração no braço de alavanca muscular. Quando o braço da alavanca é maior a vantagem mecânica é mais elevada, por outro lado, se o braço de alavanca diminui a capacidade do membro em produzir força também diminui (KELLIS, 1998).

A alavanca da resistência exterior é à distância entre o eixo articular e o ponto de aplicação da resistência. Esta distância é alterada quando o ângulo articular é modificado, que significa dizer que o momento da resistência sofre alterações de acordo com o ângulo articular (KELLIS, 1998).

As diferenças entre os tipos de sobrecargas impostas ao músculo, durante a execução de um determinado exercício, podem ser produzidas pela resistência externa combinada com a relação entre a magnitude do braço da força e do braço de resistência ao longo do arco de movimento (KELLIS, 1998; KISNER; COLBY, 1998).

Durante a fase de fortalecimento muscular, tanto em programas de reabilitação quanto de treinamento, pode-se fazer uso de resistências constante ou variável. Para produzir uma resistência constante, aplica-se os pesos livres (ou fixo) a um determinado segmento do corpo a ser exercitado. Nestes casos, são usados barras, halteres, caneleiras, anilhas, sacos de areia e outros. Estes podem ser segurados pela mão ou fixados nos membros inferiores ou, ainda, podem interagir com o segmento do indivíduo por meio de 
equipamentos de ginástica específicos (figura 5) (KISNER; COLBY, 1998; AZEVEDO et al. 2003).
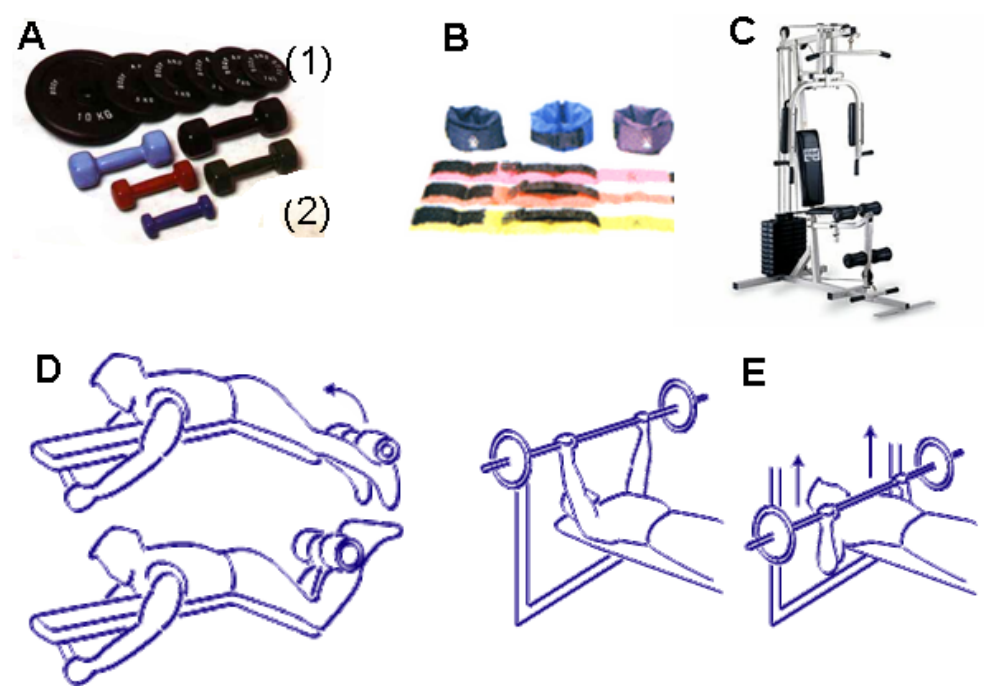

Figura 5. Exemplos de resistências constantes e de suas formas de aplicação. A) Conjunto de anilhas (1) e halteres (2). B) Conjunto de caneleiras. C) Equipamento de musculação para membros superiores e inferiores. D) Aplicação de resistência constante em membros inferiores.

E) Aplicação de resistência constante em membro superiores.

As resistências variáveis podem ser produzidas pelo uso de materiais elásticos como as molas, as faixas e tubos Thera- Band ${ }^{1}$ e os tubos de látex nacionais (figura 6). Estas resistências funcionam de forma a oferecer uma maior resistência na amplitude final do movimento. Outra forma de aplicação de resistência variável é por meio de algumas máquinas de musculação que fazem variar de forma crescente o braço de resistência oferecendo uma maior resistência na parte final do movimento (HINTERMEISTER et al., 1998; SIMONEAU et al., 2001; FRONTERA; DAWSON; SLOVIK, 2001).

\footnotetext{
${ }^{1}$ Thera-band $\AA$ The Hygienic Corporation. Akron - OH - USA.
} 

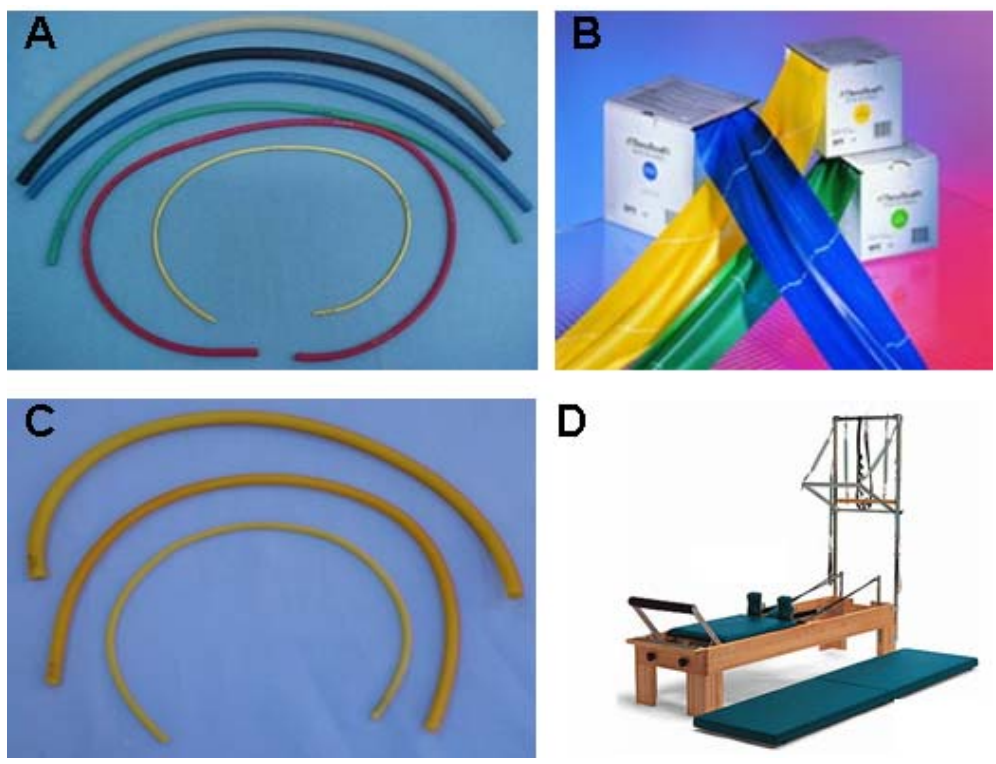

Figura 6. Exemplos de resistências variáveis. A) Tubos elásticos de diferentes espessuras da Thera-Band $\left(\circledR\right.$. B) Faixas elásticas da Thera-Band $\left({ }^{\circledR}\right.$. C) Tubos de látex nacionais de diferentes espessuras. D) Sistema de molas (Métodos Pilates).

Quando uma resistência variável é aplicada de forma a manter a velocidade do membro exercitado constante tem-se o chamado exercício isocinético. Esta é uma forma de aplicação de resistência variável amplamente explorada. Os equipamentos denominados dinamômetros isocinéticos oferecem uma resistência proporcional à força desenvolvida pelo indivíduo. Quando o individuo aumenta a velocidade angular o equipamento oferece uma maior resistência fazendo com que ele não ultrapasse a velocidade préselecionada (figura 7) (HISLOP; PERRIN, 1967; PERRIN, 1993; DVIR, 2002).

Os protocolos que envolvem a utilização tanto da resistência isocinética ${ }^{2}$ quanto das resistências constantes possuem parâmetros de aplicação padronizados. Tal fato permite que o profissional responsável pelo condicionamento do atleta e/ou pela reabilitação de um indivíduo tenha subsídio para avaliar e reavaliar as respostas fisiológicas e biomecânicas frente ao protocolo proposto. Já, os protocolos que envolvem a aplicação de materiais elásticos para a obtenção de resistência variável, apesar de serem amplamente utilizados, não apresentam delineações fundamentadas.

${ }^{2}$ O termo resistência isocinética é usado para especificar a resistência aplicada por um dinamômetro isocinético. 


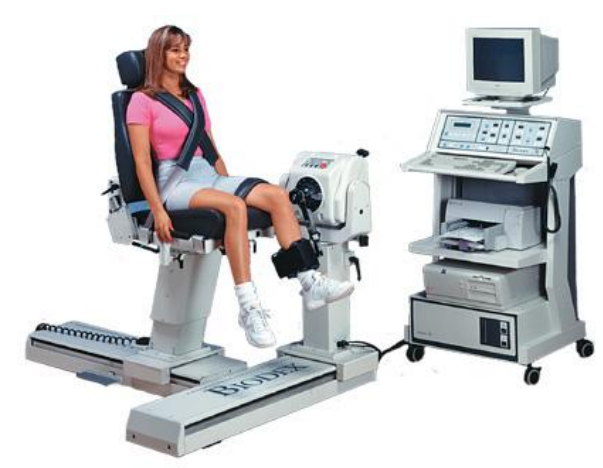

Figura 7. Dinamômetro isocinético (Biodex Medical Systems ${ }^{\circledR}$, Inc, 2003).

\subsection{A resistência elástica}

Os protocolos de reabilitação são subdivididos em atividades específicas que levam em conta a patologia apresentada pelo paciente. Uma das suas subdivisões é a fase de fortalecimento muscular, em que o paciente é submetido a um programa de exercícios resistidos, visando aumentar, principalmente, a força muscular e a resistência à fadiga (HOLLMANN; HETTINGER, 1989; KISNER; COLBY, 1998).

Quando num exercício se aplica uma resistência variável por meio de um material elástico, como as cordas ou faixas elásticas, a resistência imposta ao membro é denominada de resistência elástica. Essa ferramenta é amplamente utilizada devido a sua versatilidade e viabilidade econômica (KISNER; COLBY, 1998; AZEVEDO; NEGRÃO FILHO; CARVALHO, 1999), principalmente na fase de fortalecimento muscular dos protocolos de reabilitação.

Na prática clínica, utilizam-se os tubos e as faixas elásticas importadas Thera-Band $®$ e os tubos de látex nacionais disponíveis em várias espessuras, sendo que, quanto mais espesso o material elástico, maior a resistência aplicada ao músculo em contração. Para a execução do exercício, coloca-se, normalmente, uma extremidade do material elástico presa a um objeto fixo e a outra extremidade ao membro do indivíduo (KISNER; COLBY, 1998; BENATTI et al., 2003; PAGE, 2004). 
Com a proposta de conseguir um método para a padronização do uso da resistência elástica durante os protocolos de fortalecimento muscular, foi desenvolvido no Laboratório de Fisioterapia Aplicada ao Movimento Humano ${ }^{3}$, um sistema mecânico de exercício (AZEVEDO et al., 2003). Este sistema permite que o indivíduo realize tanto contrações isométricas, quando o eixo da roda é travado, quanto contrações isotônicas. Ressaltando que, para as contrações isotônicas o sistema pode ser usado com resistência elástica, pelo uso da corda, ou com peso fixo, por meio de anilhas. E, também, permite que os exercícios sejam realizados com membros superiores e inferiores (AZEVEDO; NEGRÃO FILHO; CARVALHO, 1999; AZEVEDO et al., 2003; AZEVEDO, 2003)

Dentro do processo de reabilitação, o tubo elástico é utilizado de maneira intensa e, conseqüentemente, após algumas sessões, pode-se observar a perda da sua eficiência com relação à geração de força. Portanto, para a obtenção de bons resultados terapêuticos com o uso das cordas elásticas, é importante o conhecimento das características mecânicas das mesmas. Como, por exemplo, a força empregada para o seu estiramento, a tensão gerada em função da porcentagem de estiramento e a deformação do tubo (SIMONEAU et al., 2001; BENATTI et al., 2003).

Os tubos Thera-band $®$ são comercializados em oito cores diferentes de acordo com a sua resistência. Alguns estudos foram desenvolvidos a fim de estudar as propriedades dos tubos e faixas elásticas fabricados por essa marca, especificamente para uso em programas de reabilitação.

conhecimento de suas propriedades possibilita um monitoramento quantitativo dos protocolos de tratamento, permitindo, ainda, adaptá-los de acordo com as características de cada indivíduo (HINTERMEISTER et al., 1998; SIMONEAU et al., 2001; PATTERSON, et al., 2001; PAGE, 2004).

No Brasil, usa-se em larga escala os tubos de látex fabricados a partir de borracha sintética polimerizada. Esta borracha é conhecida quimicamente como butadieno-estireno (VLACK, 1970). Mesmo não sendo um material fabricado para fins terapêuticos, o seu uso foi massificado dentro das clínicas de reabilitação, pois, além de ser uma ferramenta de baixo custo, é muito

\footnotetext{
${ }^{3}$ Laboratório de Fisioterapia Aplicada ao Movimento Humano, Departamento de Fisioterapia da Faculdade de Ciências e Tecnologia - UNESP, Presidente Prudente - SP.
} 
prática tanto no seu manuseio quanto no seu transporte, além de produzir bons resultados durante os protocolos de reabilitação (BENATTI et al., 2003; AZEVEDO et al., 2003; AZEVEDO, 2003).

\subsection{Biomecânica aplicada ao movimento humano}

A biomecânica pode ser conceituada como uma ciência que trata de análises físico-matemáticas de sistemas biológicos e, conseqüentemente, também dos movimentos humanos, os quais são analisados por meio de leis e conceitos mecânicos com relação a parâmetros específicos do sistema biológico (AMADIO, 1996).

Um dos objetos de estudo da biomecânica são as forças internas do corpo humano. Nesta abordagem, investigam-se as forças que se originam dentro do corpo como, por exemplo, as forças musculares, as forças de compressão articular e as forças ligamentares. Assim, a biomecânica interna preocupa-se com a determinação dessas forças e suas conseqüências sobre as estruturas biológicas envolvidas na sua interação (AMADIO, 1996).

A medida direta de forças internas é um processo inviável, principalmente devido a questões éticas em relação a procedimentos invasivos e de experimentação com seres humanos, que seriam inerentes a este tipo de abordagem. No entanto, estas forças podem ser calculadas por intermédio de parâmetros da cinemática e da dinâmica do movimento, bem como pelas características mecânicas do aparelho locomotor e suas estruturas funcionais. A biomecânica externa refere-se às características observáveis exteriormente ao corpo estudado, como por exemplo, o seu deslocamento no espaço, as forças aplicadas externamente e a atividade elétrica muscular (AMADIO, 1996).

$\mathrm{Na}$ maioria dos casos, há necessidade de medidas de parâmetros externos como posição, velocidade, aceleração e forças de reação, os quais são obtidas por diferentes métodos. Tais medidas são necessárias inclusive, para a elaboração de estudos das grandezas internas, como por exemplo, a força muscular, conforme citação anterior (BAUMANN, 1995). 


\subsubsection{Métodos de medição em biomecânica}

Os métodos de avaliação utilizados pela biomecânica para abordar as diversas formas de movimento são: antropometria, cinemetria, dinamometria, e eletromiografia (EMG), cujas correlações estão ilustradas figura 8 (BAUMANN, 1995). Utilizando-se destes métodos o movimento pode ser descrito e modelado matematicamente, permitindo uma melhor compreensão dos mecanismos internos reguladores e executores do movimento do corpo humano.

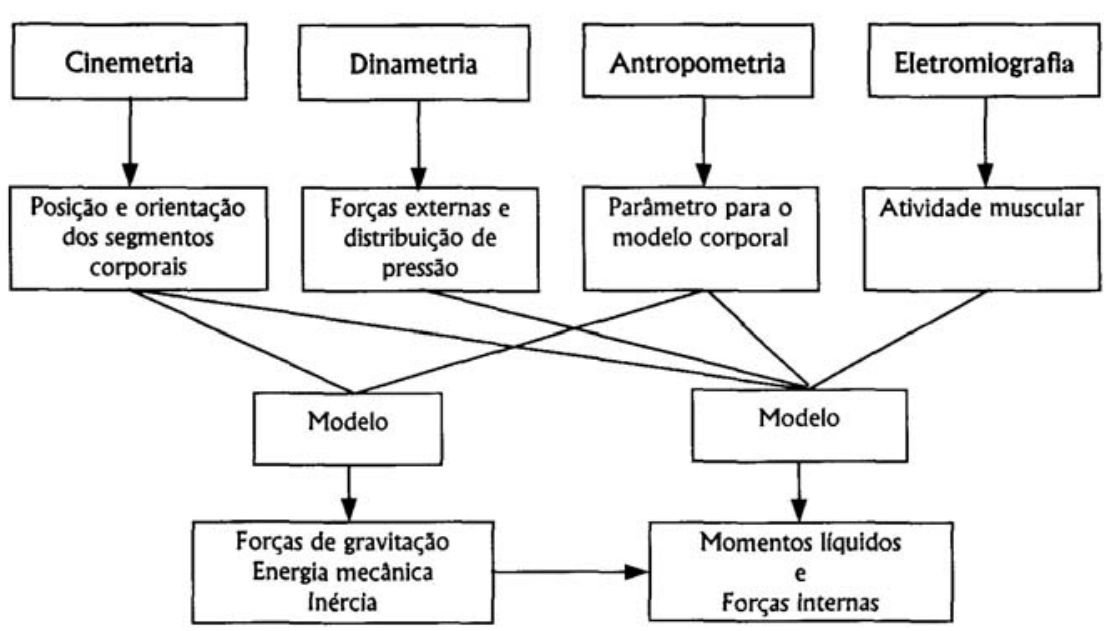

Figura 8. Diagrama da correlação entre os métodos de medidas e as grandezas de interesse na análise biomecânica do movimento humano (BAUMANN, 1995).

A cinemetria determina os parâmetros cinemáticos do movimento, ou seja, posição e orientação espacial. Para o estudo da cinemetria é necessário definir um sistema de coordenadas para descrever o movimento de cada segmento, ou seja, a posição, a velocidade e a aceleração. O sistema de coordenadas pode ser fixado com relação ao centro de massa ou outro ponto do corpo que tenha relação com as propriedades funcionais. Para a utilização deste método, pode-se utilizar equipamentos de vídeo para o registro de imagens por meio de luz visível ou infravermelha, associados com procedimentos para reconstrução de coordenadas dos pontos anatômicos de interesse. Além disso, são utilizados dispositivos que permitem medir as variáveis cinemáticas, como o acelerômetro, o goniômetro e os sensores de 
ultra-som (AMADIO, 1996).

A dinamometria consiste na verificação das variáveis dinâmicas externas por transdutores de força. É um método que se ocupa em medir tanto as forças externas de reação do solo como as forças dos membros, as quais são de particular interesse nas atividades motoras estáticas ou dinâmicas que envolvam alguma fase de apoio. Para isso, podem ser utilizados plataforma de força, célula de carga e o sistema f-scan (AMADIO, 1996).

As grandezas derivadas da anatomia humana são objetos de estudo da antropometria. Além de determinar os parâmetros geométricos e inerciais do corpo humano, a antropometria também fornece a segmentação da estrutura adequadamente dividida para a análise matemática. Assim, pode-se determinar: a forma geométrica de cada segmento, as posições das articulações entre os segmentos, a posição do centro de massa de cada segmento corporal, bem como os pontos de origem e inserção dos músculos para determinação das linhas de ação das forças musculares e os braços de alavanca, e os parâmetros inerciais, ou seja, a massa de cada segmento, o momento de inércia e o raio de giro (AMADIO, 1996).

As variáveis antropométricas fundamentais, dentre elas a massa, 0 centro de massa e o momento de inércia dos segmentos, bem como a localização dos pontos de ação das forças é conhecida na literatura específica (De LEVA, 1996).

A Eletromiografia é o termo que expressa o método de registro da atividade elétrica de um músculo quando este realiza contração. O traçado eletromiográfico representa o resultado do estímulo neural para o sistema muscular e fornece importantes informações para a modelagem do sistema dinâmico musculoesquelético (De LUCA, 1997; AMADIO, 1996; POZZO; FARIAN; MERLETTI, 2004). Além disso, permite obter informações a respeito dos processos fisiológicos ocorrentes no músculo durante a contração. Um exemplo importante da aplicação da EMG é o monitoramento do processo de fadiga muscular (AMADIO, 1996).

Durante o desenvolvimento do protocolo experimental deste trabalho, a EMG foi utilizada para o registro da atividade elétrica do músculo bíceps femoral. Assim, por consistir numa importante ferramenta para as coletas dos 
dados, as características que envolvem esse método de medição na biomecânica foram detalhadas no tópico seguinte.

\subsubsection{A Eletromiografia}

A eletromiografia possui inúmeras aplicações e, especialmente na biomecânica, para avaliação de fenômenos relacionados com a geração de força muscular. Além disso, é aplicada também na clínica médica para diagnóstico de doenças neuromusculares; na reabilitação, para a reeducação da ação muscular (biofeedback eletromiográfico); e na anatomia, com o intuito de revelar a ação muscular em determinados movimentos (AMADIO, 1996). No entanto, o estudo da eletromiografia merece uma atenção especial, pois se trata de uma ferramenta que ainda apresenta metodologias de aplicação muito controversas. Além da questão metodológica, outra dificuldade de aplicação da técnica é a individualidade dos resultados. Ressalta-se, portanto, que a EMG é um indicativo indireto de processos fisiológicos do músculo, os quais são extremamente individualizados (ALMEIDA, 1997; PEREIRA; AZEVEDO, 2002).

$\mathrm{Na}$ biomecânica, a utilização da EMG tem como propósitos fundamentais: (a) de servir como indicador de estresse muscular; (b) de ser um identificador de padrões de movimentos e (c) de identificar parâmetros de controle do sistema nervoso (MORITANI; HERBERT, 1978; MOHAMED; PERRY; HISLOP, 2002). No contexto deste trabalho, busca-se uma melhor compreensão da relação entre a força gerada pelo músculo durante diferentes exercícios com o sinal eletromiográfico captado.

Os músculos esqueléticos são constituídos por células aproximadamente paralelas, as fibras musculares, que constitui a unidade estrutural contrátil; ou seja, a unidade elementar geradora de força (POZZO; FARINA; MERLETTI, 2004). Estas fibras musculares são ativadas pelo sistema nervoso central através de sinais elétricos transmitidos pelo motoneurônio. Sob condições normais, um sinal elétrico, denominado potencial de ação, se propaga por um motoneurônio e ativa todos os seus ramos (ramos axoniais). Estes ramos, por sua vez, ativam todas as fibras musculares de uma unidade motora (Figura 2) (POZZO; FARINA; MERLETTI, 2004; DE LUCA, 1997). 
Quando a membrana pós-sináptica de uma fibra muscular é despolarizada, essa despolarização propaga em ambas as direções ao longo da fibra. A despolarização de membrana, acompanhada por um movimento de íons, gera um campo eletromagnético na redondeza das fibras musculares. Um eletrodo localizado neste campo irá detectar um potencial (com respeito a uma referência) cuja variação no tempo é conhecida como um potencial de ação (DE LUCA, 1997).

A figura 9 apresenta um esquema desta geração de potencial pela unidade motora. No diagrama, $n$ representa o número total de fibras musculares de uma unidade motora que está suficientemente perto do eletrodo para os potenciais de ação serem registrados por ele. Os potenciais de ação associados com cada fibra muscular são apresentados do lado direito. O sinal detectado no local do eletrodo é, na verdade, a soma de todos os potenciais individuais de ação de cada fibra muscular (De LUCA, 1979).

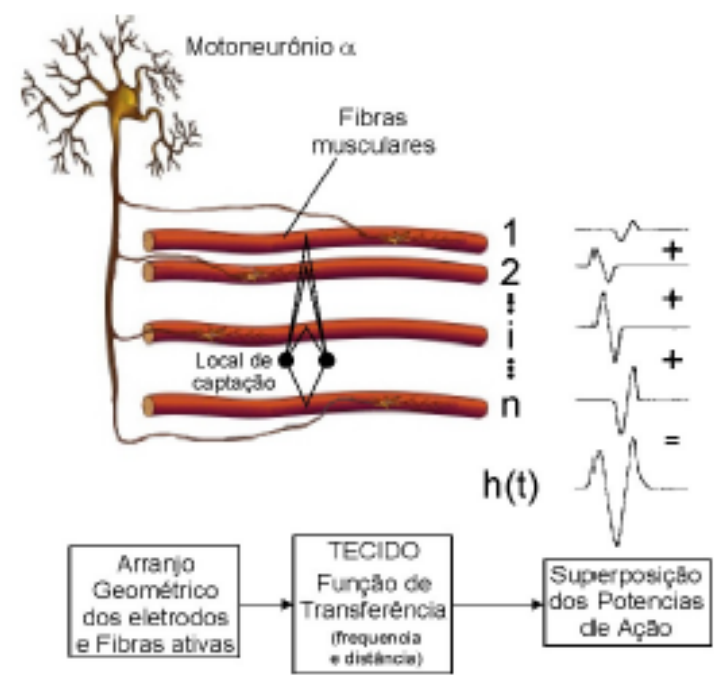

Figura 9. Representação esquemática da geração do potencial de ação da unidade motora (Adaptado de De LUCA (1979)).

Por razões técnicas, o eletrodo captador é tipicamente bipolar e o sinal é amplificado diferencialmente. A forma do potencial de ação observado dependerá da orientação dos contatos do eletrodo com relação às fibras ativas. Para exemplificar, na figura 9 os contatos do eletrodo estão alinhados em paralelo com as fibras musculares. Com este arranjo, os potenciais de ação 
das fibras musculares terão uma forma bifásica e o sinal das fases dependerá da direção na qual a despolarização de membrana muscular se propaga (GUEDES, 1972).

As formas e o espectro de freqüência dos potenciais de ação serão afetados pelo tecido existente entre a fibra muscular e o local do eletrodo. A presença deste tecido cria um efeito de filtro passa-baixa cuja largura de banda diminui com o aumento da espessura. Este "efeito filtro" do tecido é muito mais pronunciado para as captações de sinais usando eletrodos de superfície que para as captações usando eletrodos invasivos, pois estes ficam situados juntos às fibras musculares ativas (LINDSTRON, 1970).

Os potenciais de ação produzidos pelas fibras musculares são considerados eventos individuais distinguíveis. Porém, como as despolarizações das fibras musculares de uma mesma unidade motora se sobrepõem no tempo o sinal resultante do potencial de ação, presente no local da captação, constitui uma superposição espaço-temporal das contribuições individuais (figura 9). Para manter o músculo contraído, o sistema nervoso envia uma seqüência de estímulos, para que as unidades motoras sejam repetitivamente ativadas, resultando em um trem de potenciais de ação. Portanto, o sinal mioelétrico é a somatória dos potenciais de ação produzidos por todas as unidades motoras (figura 10) (POZZO; FARINA; MERLETTI, 2004; DE LUCA, 1997).

Eletrodos de fio ou agulha, chamados eletrodos invasivos, são capazes de detectar o potencial de ação de uma única unidade motora. Por isso, os sinais captados apresentam maiores amplitudes e menor efeito de filtro sendo que, o espectro de potência atinge freqüências de até $10 \mathrm{kHz}$ (WEBSTER, 1998). No entanto, estes eletrodos apresentam vários inconvenientes, como a necessidade de excelente esterilização, o perigo da quebra dos fios dentro do músculo e, sobretudo, o desconforto para o paciente. Para evitar estes inconvenientes, na biomecânica experimental são utilizados, frequentemente, eletrodos de superfície não invasivos. Com a utilização destes eletrodos, o sinal de EMG captado apresenta freqüências de até cerca de $500 \mathrm{~Hz}$ e amplitudes variando entre $5 \mu \mathrm{V}$ e $50 \mu \mathrm{V}$ dependendo do músculo analisado e da configuração do eletrodo utilizado (ALMEIDA, 1997). 

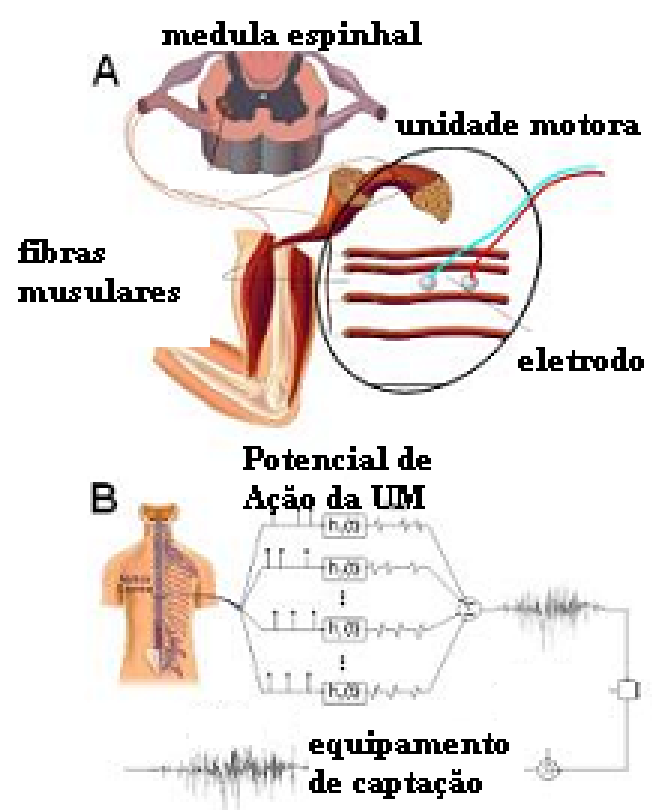

Figura 10. Representação esquemática da geração do sinal mioelétrico. A) Aspecto anatômico. B) Modelo fisiológico e instrumentação (Adaptado de De Luca (1979)).

$\mathrm{Na}$ aquisição de sinais com amplitudes tão baixas, a existência de ruídos da mesma intensidade do sinal é um problema inerente à medida. Para minimizar os ruídos recomenda-se a utilização de eletrodos ativos. Estes são confeccionados com um amplificador diferencial muito próximo dos eletrodos de captação (HERMENS, et al., 2000). Um diagrama típico do amplificador diferencial pode ser visto na figura 11.

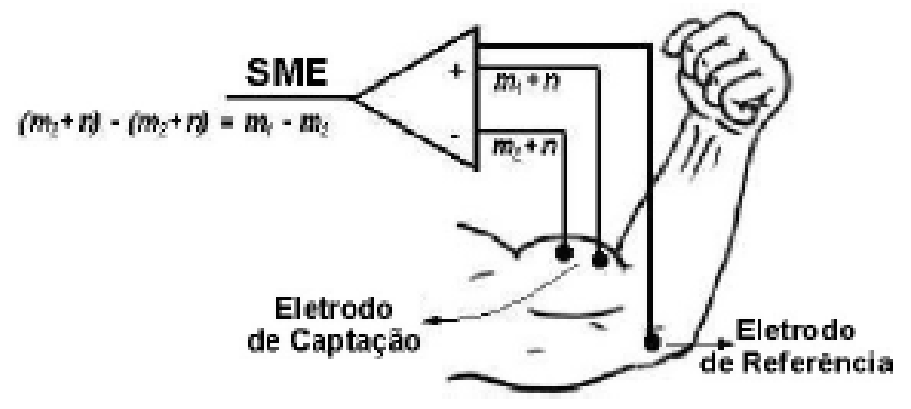

Figura 11. Amplificação diferencial, onde $\mathrm{n}$ representa o ruído do sistema e do ambiente e m1 $-\mathrm{m} 2$ o SME resultante. 
Em relação aos procedimentos para o posicionamento dos eletrodos, recomenda-se que estes não sejam acoplados perto dos pontos motores ou dos tendões musculares e que as superfícies de captação sejam separadas por no máximo 40mm. Dessa forma, sugere-se posicionar os eletrodos em uma região intermediária a estas estruturas, evitando também a proximidade a outros músculos ativos (HERMENS et al., 2000).

Após a captação do sinal de EMG, este precisa ser tratado a fim de se interpretar as alterações fisiológicas decorrentes das contrações. Existem dois tipos básicos de análises, os quais o sinal de EMG pode ser submetido: (a) análise no domínio do tempo e (b) análise no domínio da freqüência.

A análise no domínio do tempo do sinal de EMG permite, principalmente, a visualização do padrão de ativação muscular durante uma contração, podendo servir como referência para comparações entre diferentes tipos de contrações, exercícios e sobrecargas. Este método permite, ainda, que as relações entre força e atividade elétrica muscular possam ser observadas, apesar de ser uma vertente ainda controversa na literatura (ONISHI et al., 1999; MOHAMED; PERRY; HISLOP, 2002).

\subsection{O grupo muscular isquiotibial}

A grande massa muscular localizada na face posterior da coxa é constituída pelos músculos semitendinoso, semimembranoso e bíceps femoral, os quais são chamados coletivamente de isquiotibiais ou hamstrings ${ }^{4} \mathrm{e}$ possuem uma inserção proximal comum na tuberosidade isquiática. Este grupo muscular possui um importante papel da flexão do joelho, mas também estão envolvidos na extensão do quadril e na rotação do joelho, quando este está fletido (ONISHI et al., 2002).

Os músculos semimembranoso e semitendinoso, além de agirem na extensão do quadril e na flexão do joelho, eles também podem rodar medialmente a tíbia sobre o fêmur, particularmente quando o joelho está semifletido (MOHAMED; PERRY; HISLOP, 2003). O semitendinoso é um

\footnotetext{
${ }^{4}$ Hamstrings é a nomenclatura atribuída para este grupo muscular na língua inglesa; este termo também é utilizado no português por alguns autores.
} 
músculo que possui um longo tendão semelhante a um cordão arredondado, o qual se inicia no terço inferior da coxa. Sua inserção distal está na face medial na parte posterior da tíbia (figura 12). O músculo semimembranoso é um músculo profundo e se insere distalmente na parte posterior do côndilo medial da tíbia (figura 12 e 13) (MOORE, 1994).

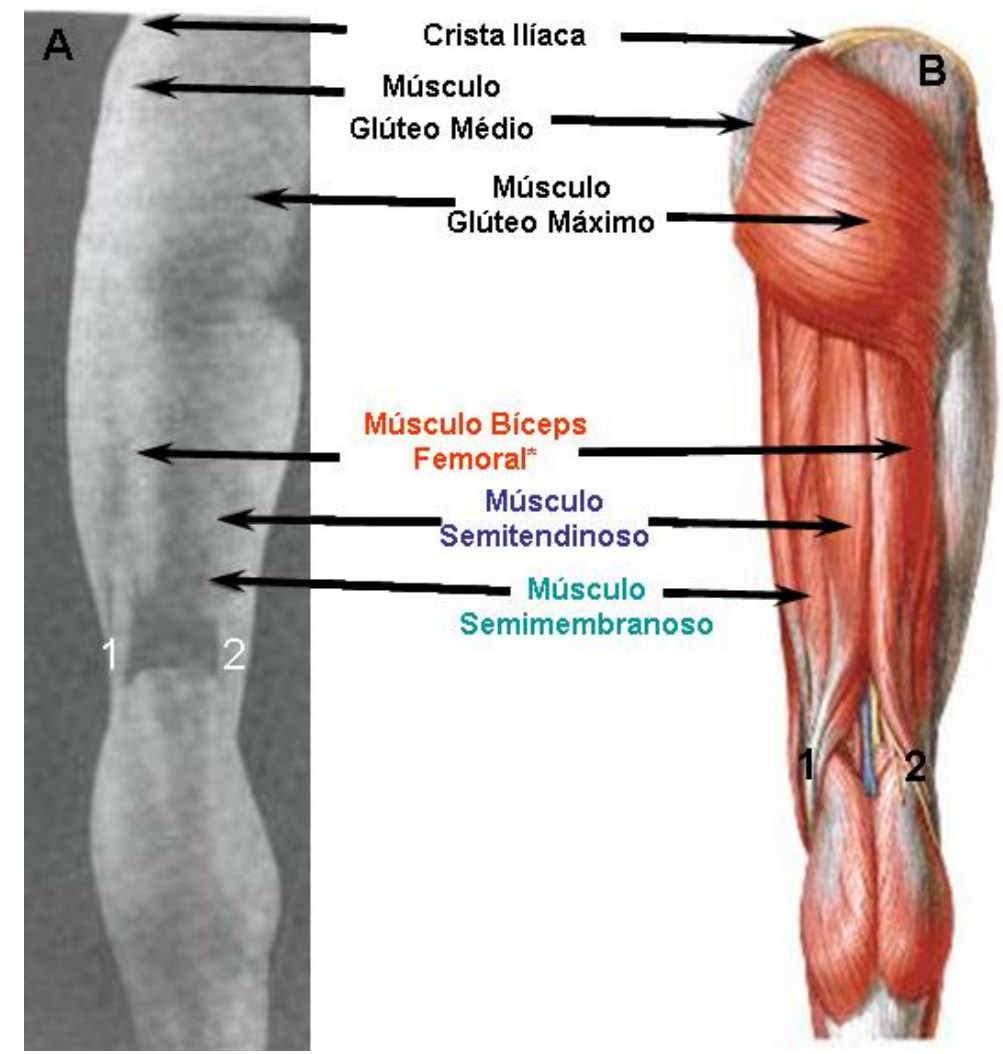

Figura 12. A) Anatomia de superfície das regiões do glúteo, da coxa e do joelho (vista posterior). B) Dissecção superficial da face posterior destas regiões, destacando a localização dos Músculos Isquiotibiais e dos tendões do bíceps femoral (1) e do semimembranoso e semitendinoso (2). $\left(^{*}\right)$ Neste caso está representada apenas a cabeça longa do bíceps femoral (Adaptado de Netter (1999) e MOORE (1994)).

O músculo bíceps femoral está situado na face póstero-lateral da coxa, originando-se de duas cabeças, separadas por uma distância considerável: a cabeça longa e a cabeça curta. A cabeça longa fixa-se na tuberosidade isquiática, juntamente com os músculos semimembranoso e o semitendinoso. A cabeça curta tem sua origem proximal a partir da metade inferior do fêmur. No terço inferior da coxa, a cabeça longa começa a se estreitar, juntando-se na sua face profunda à cabeça curta do bíceps (figura 12, 13 e 14) (MOORE, 1994; ONISHI et al., 2002). 


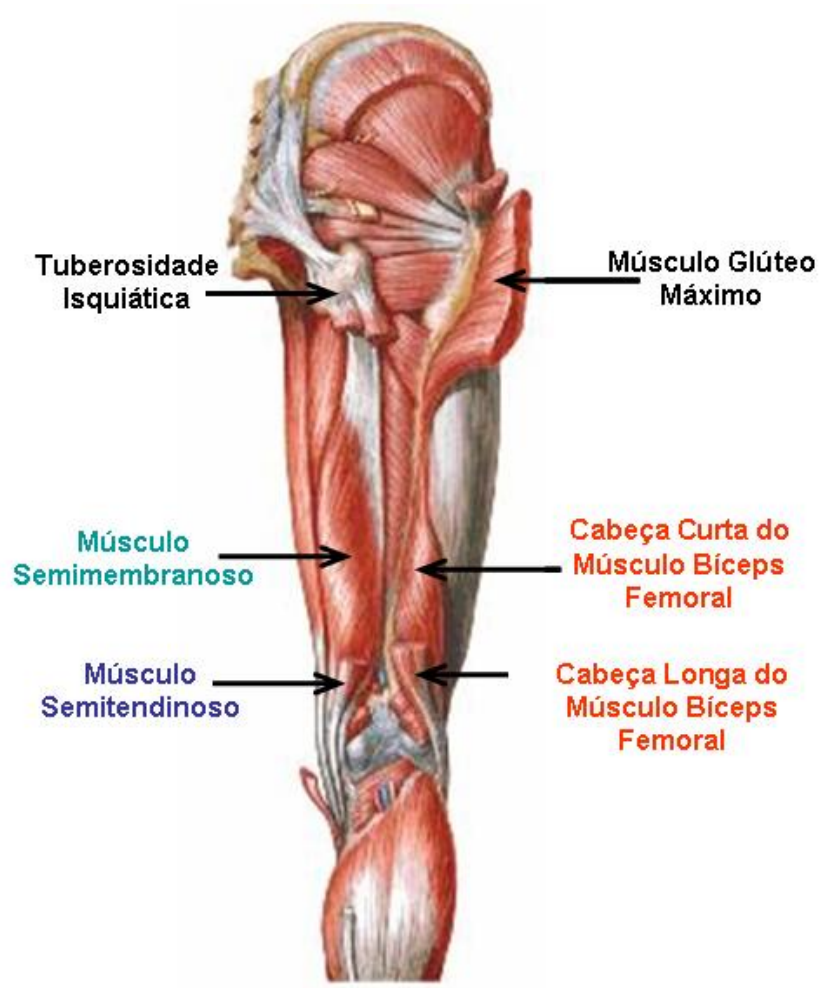

Figura 13. Dissecção profunda da face posterior das regiões do glúteo, da coxa e do joelho. Desta-se a localização da tuberosidade isquiática e dos músculos semimembranoso e da cabeça curta do bíceps femoral (Adaptado de Netter (1999) e MOORE (1994)).

O bíceps femoral, juntamente com os demais músculos da coxa, garante a estabilidade dinâmica da articulação do joelho e também possui a função de rotador lateral do joelho. Daí a preocupação presente nos programas de reabilitação em realizar trabalhos de fortalecimento muscular e alongamento nestes músculos (MOHAMED; PERRY; HISLOP, 2003). O bíceps, em particular, desempenha um papel importante na flexão do joelho e na substituição das funções do ligamento cruzado anterior, evitando a translação anterior da tíbia em relação ao fêmur, quando este sofre rupturas(LI et al., 1999; LIU; MAITLAND, 2000; YANAGAWA et al., 2002). 


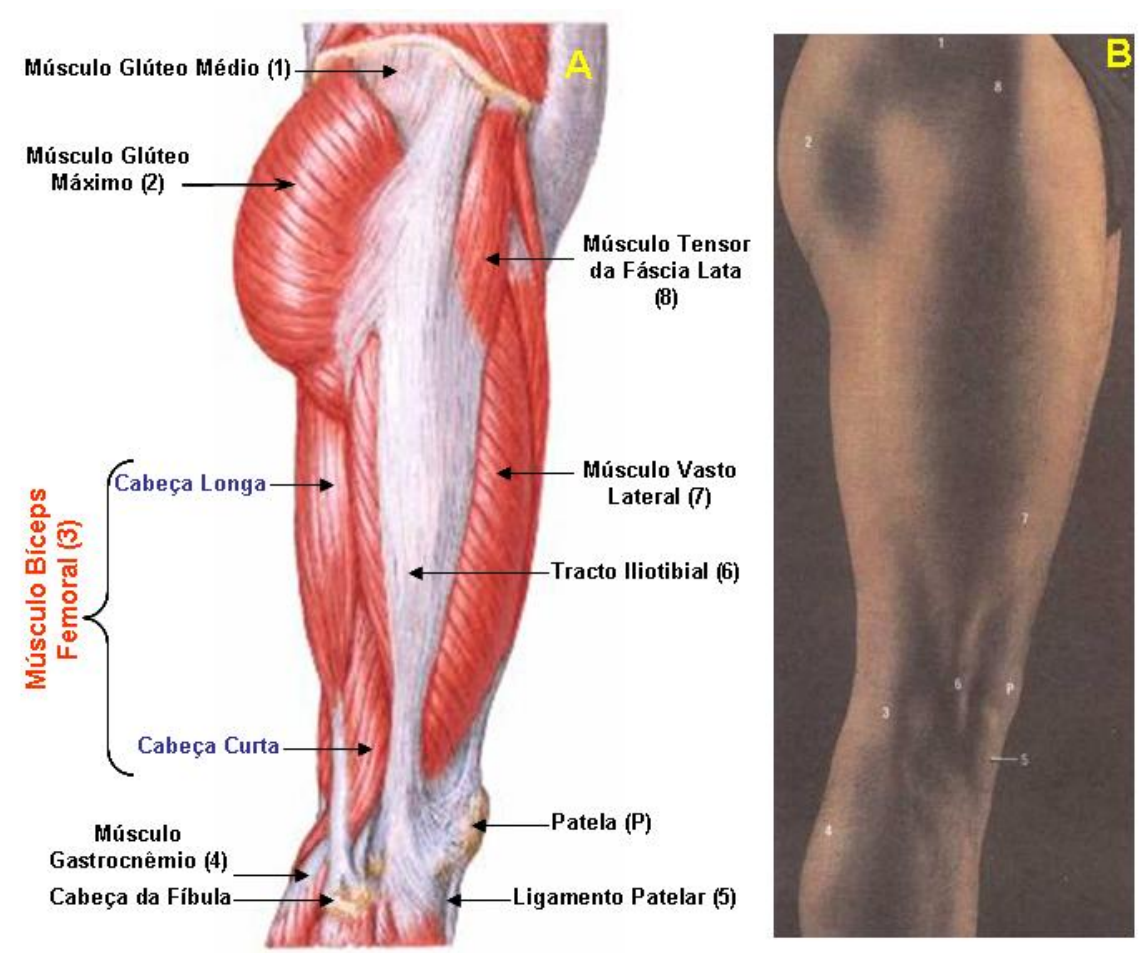

Figura 14. A) Dissecção superficial da face lateral das regiões do glúteo, da coxa e do joelho, destacando a localização do músculo bíceps femoral (vista lateral). B) Anatomia de superfície correspondente destas regiões (Adaptado de Netter (1999) e MOORE (1994)).

Quando se trata de estudos de EMG de superfície, o músculo semitendinoso e a cabeça longa do bíceps possuem uma importante propriedade, que é a sua localização superficial. Isto facilita a captação dos sinais elétricos. Assim, trabalhos que possuem como objetivos estudar a atividade elétrica dos isquiotibiais utilizam a cabeça longa do bíceps como representante deste grupo muscular (KELLIS; BALTZOPOULOS, 1998). No caso da análise eletromiográfica, é importante conhecer a morfologia que caracteriza o músculo envolvido, como por exemplo, a massa, o volume, o comprimento das fibras, o tipo de fibras e a área de secção transversal. A cabeça longa do bíceps femoral consiste num músculo, conforme descrito anteriormente, que possui ação biarticular e é um rotador lateral da articulação do joelho. Além disso, é inervado pelo nervo tibial e possui uma massa de 128 , $4 \mathrm{~g}$; um volume de $241,4 \mathrm{~cm}^{3}$, sua fibras musculares possuem por volta de 80,2 $\mathrm{mm}$ e a área de secção transversal de $29,8 \mathrm{~cm}^{2}$. Em relação ao tipo de fibra muscular esse músculo possui um maior percentual de fibras do tipo I, 
correspondendo a 66.9\%, o que pode definir a característica de ter capacidade para contrações mais sustentadas ou repetidas, que requerem tensão relativamente baixa (ONISHI et al., 2002).

\subsection{Modelo biomecânico do joelho}

A articulação do joelho é a mais complexa em termos mecânicos e uma das mais simples em termos funcionais. As estruturas ósseas que compõem esta articulação são os côndilos do fêmur, a patela, o platô tibial e a cabeça proximal da fíbula (figura 15) (KAPANDJI, 2000).

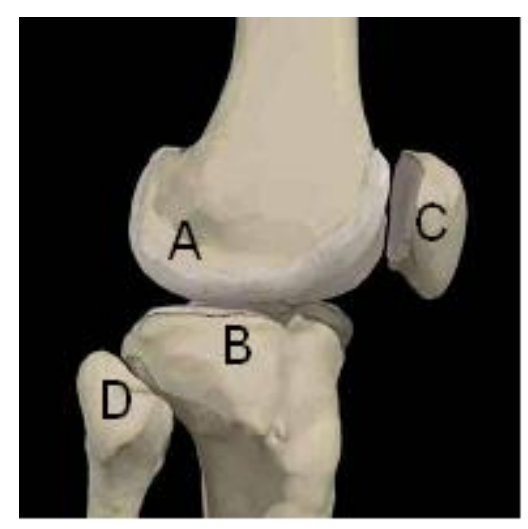

Figura 15. Vista sagital das estruturas ósseas que compõem a articulação do joelho. A) Côndilos femurais; B) Platô tibial; C) Patela; D) Cabeça proximal da fíbula (Adaptado de Primal

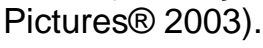

O movimento humano pode ser descrito e modelado matematicamente com o objetivo de se compreender os mecanismos internos reguladores e executores do movimento. As descrições matemáticas de um determinado movimento devem ser precedidas por um modelo biomecânico do sistema osteomioarticular estudado. Este deve contemplar as estruturas anatômicas envolvidas no movimento, assim como a distribuição das forças e momentos articulares, levando em conta uma referência bi ou tridimensional (BAUMANN, 1995; AMADIO, 1996).

A precisão do modelo biomecânico de um segmento corporal está diretamente ligada à forma como o mesmo é obtido. Alguns anos atrás, para se obter um modelo fidedigno ao segmento estudado o mesmo deveria ser 
proveniente da observação de cadáveres. No entanto, com o avanço das tecnologias na área de instrumentação médica, os modelos biomecânicos dos segmentos do corpo humano estão cada vez mais precisos, permitindo até análises tridimensionais da estrutura anatômica (YAMAGHUCHI; ZAJAC, 1989; GLITCH; BAUMANN, 1997).

O modelo tridimensional, apesar de fornecer informações mais detalhadas sobre as forças de ação muscular em um determinado sistema biológico, é muito complexo. Sua principal aplicação nas articulações é a determinação das forças estáticas e dinâmicas de estruturas como os ligamentos e para a definição da topografia das superfícies articulares (YAMAGHUCHI; ZAJAC, 1989; GLITCH; BAUMANN, 1997).

Para descrever a articulação do joelho e a linha de força do grupo muscular isquiotibial, um modelo biomecânico bidimensional simples é suficiente. No entanto, o modelo biomecânico da articulação do joelho deve considerar que esta articulação é policêntrica, ou seja, para cada grau de flexão da articulação existe um eixo de rotação instantâneo diferente. Esse fator dificulta a modelagem influenciando na qualidade dos resultados obtidos por meio das equações dinâmicas desenvolvidas (YAMAGHUCHI; ZAJAC, 1989).

Para a execução deste estudo adotou-se como base para 0 desenvolvimento do modelo biomecânico do joelho, o modelo proposto por Smidt (1973). Neste modelo os músculos isquiotibiais são considerados como um único grupo muscular. A identificação das contribuições independentes de cada músculo é uma tarefa praticamente impossível, visto que os componentes anatômicos de transmissão das forças (tendões) geradas pelas fibras musculares até a inserção, são fisicamente entrelaçados (DVIR, 2002).

A linha de ação de força deste grupo muscular é definida como uma linha que se origina na parte posterior da fíbula e é paralela ao fêmur (figura 16) (SMIDT, 1973). O braço de momento do tendão dos isquiotibiais ao redor do joelho foi mensurado in vitro (HERZOG, 1993) e in vivo usando roentgenografia (SMIDT, 1973; NISELL, 1985), videofluoroscopia (BALTZOPOULOS, 1995) ou imagem por ressonância magnética (WRETENBERG et al., 1996). 
Em geral os braços de momento do tendão dos isquiotibiais variam de 2 a $3 \mathrm{~cm}$. Ellis (1979) indicou que o braço de momento deste grupo muscular é aproximadamente 50 a $80 \%$ do braço de momento do tendão patelar. Isto indica que para o mesmo braço de força, os isquiotibiais têm que exercer uma força maior que o quadríceps.

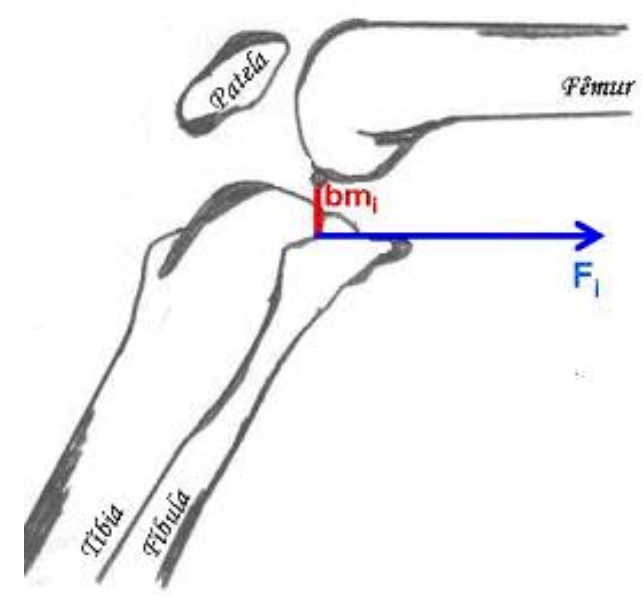

Figura 16. Representação simplificada da linha de força dos isquiotibiais $\left(F_{i}\right)$ e seu respectivo braço de momento $\left(\mathrm{bm}_{\mathrm{i}}\right)$, considerando o centro da articulação tibiofemoral como o eixo de rotação (Adaptado de Kellis (1998)).

Considerando o braço de momento como a distância perpendicular da linha de força dos isquiotibiais até o ponto de contato tibiofemoral (figura 16), Kellis e Baltzopoulos (1999) determinaram valores do braço de momento através de imagem por videofluoroscopia da flexão do joelho em intervalos variando de 0 a 90 graus. Esses valores variaram de 29,9 $\pm 2.6 \mathrm{~mm}$, em intervalos de 0 a 10 graus, para 20,5 4,8 mm, em intervalos de 80 a 90 graus. Os valores dos demais intervalos podem ser visualizados na tabela 1. 
Tabela 1. Valores do braço de momento dos isquiotibiais descritos por Kellis e Baltzopoulos (1999) para intervalos de ângulos de flexão do joelho de $0^{\circ}$ a $90^{\circ}$ ( $\theta$ : ângulo de flexão do joelho em graus; bm: braço de momento em milímetros, sendo os valores entre parênteses o desvio padrão de cada valor).

\begin{tabular}{cc}
\hline \hline$\theta\left(^{\circ}\right)$ & bm $(\mathbf{m m})$ \\
\hline $1-10$ & $29.9(2.6)$ \\
$11-20$ & $25.4(2.3)$ \\
$21-30$ & $26.6(2.3)$ \\
$31-40$ & $28.2(3.1)$ \\
$41-50$ & $27.9(2.9)$ \\
$51-60$ & $28.3(3.3)$ \\
$61-70$ & $27.8(5.7)$ \\
$71-80$ & $24.3(5.5)$ \\
$81-90$ & $20.5(4.8)$ \\
\hline \hline
\end{tabular}

Em resumo, todo movimento com variação de velocidade ocorre sob a ação de forças. No movimento humano as forças internas produzidas pelos músculos respondem pela ação ativa do movimento. A geração destas forças é controlada diretamente pelo sistema nervoso central, segundo mecanismos específicos. A contração muscular, devido a despolarização dos diferentes tipos de fibras, é decorrente de um estímulo nervoso. A massa muscular atua no sistema de alavanca musculoesquelética que, por sua vez, responde pela interação com o meio ambiente. Para a compreensão do movimento humano, os modelos biomecânicos devem levar em conta todas estas questões conjuntamente. Neste capítulo de revisão, procurou apresentar uma breve descrição de todos estes aspectos, os quais geram o movimento humano. Os próximos capítulos serão dedicados ao estudo das propriedades mecânicas da corda elástica e ao estudo da ação do grupo muscular isquiotibial durante exercícios resistidos com diferentes tipos de resistência, bem como a relação entre a força e o sinal de eletromiográfico. 


\section{MATERIAIS E MÉTODOS}

O presente trabalho foi desenvolvido em quatro etapas: A primeira foi o (1) "estudo das propriedades da corda elástica", em seguida, dedicou-se a elaboração do (2) "modelo biomecânico da atuação dos isquiotibiais. A partir das equações da força deste grupo muscular, desenvolvidas a partir do modelo, seguiu-se para a terceira etapa, na qual foram realizadas as (3) "simulações da força dos isquiotibiais" em diferentes tipos de exercícios resistidos e, finalmente, a quarta etapa foi a realização dos (4) "ensaios experimentais". A seguir estão descritos os materiais e a metodologia empregada em cada etapa.

\section{Estudo das propriedades da corda elástica}

A fim de se obter informações para a otimização do uso dos tubos de látex utilizados em nossos trabalhos, foi realizado um estudo das propriedades mecânicas desses tubos da marca Lengruber ${ }^{5}$ fabricados no Brasil e da Theraband $\circledast$, de fabricação americana.

Utilizou-se 3 amostras de tubos novos da Lengruber, sendo cada uma identificada por sua referência (200, 202 e 204), a qual está relacionada com os valores dos seus diâmetros internos e externos. Da mesma forma, utilizou-se 2 amostras dos tubos Thera-band $\AA$, uma da classificação vermelha e uma da azul. Cada amostra foi compreendida de 5 corpos de prova, cada um com 70 mm de comprimento útil.

As medidas diretas das dimensões dos corpos de prova foram efetuadas por meio de um paquímetro da marca Stainless Hardened 60920, com escala graduada metálica de $10 \mathrm{~cm}$ e nônio $0,05 \mathrm{~mm}$. A caracterização mecânica dos

\footnotetext{
${ }^{5}$ Lengruber Comércio de Látex Ltda. São Paulo - SP -Brasil.
} 
tubos de látex foi realizada na máquina de ensaios mecânicos $\mathrm{EMIC}^{6}$, de capacidade máxima de 500 Kgf, do Laboratório de Polímeros do Departamento de Física, Química e Biologia da FCT/UNESP de Presidente Prudente.

A caracterização mecânica seguiu os parâmetros estabelecidos no método definido pela EMIC para os ensaios com tubos de látex. Os corpos de prova passaram por um ensaio de tração axial compreendido por 10 ciclos de estiramento, atingindo uma deformação de 300\% do comprimento inicial, numa velocidade de $500 \mathrm{~mm} / \mathrm{min}$ (figura 17). A partir desses ensaios mecânicos, foram observadas as médias de tensão máxima atingida e o comportamento de histerese. O próprio sistema possui um software específico denominado TESC para o tratamento dos dados, o qual calcula os valores de força máxima, tensão e histerese de cada corpo de prova, bem como suas respectivas médias e gráficos.
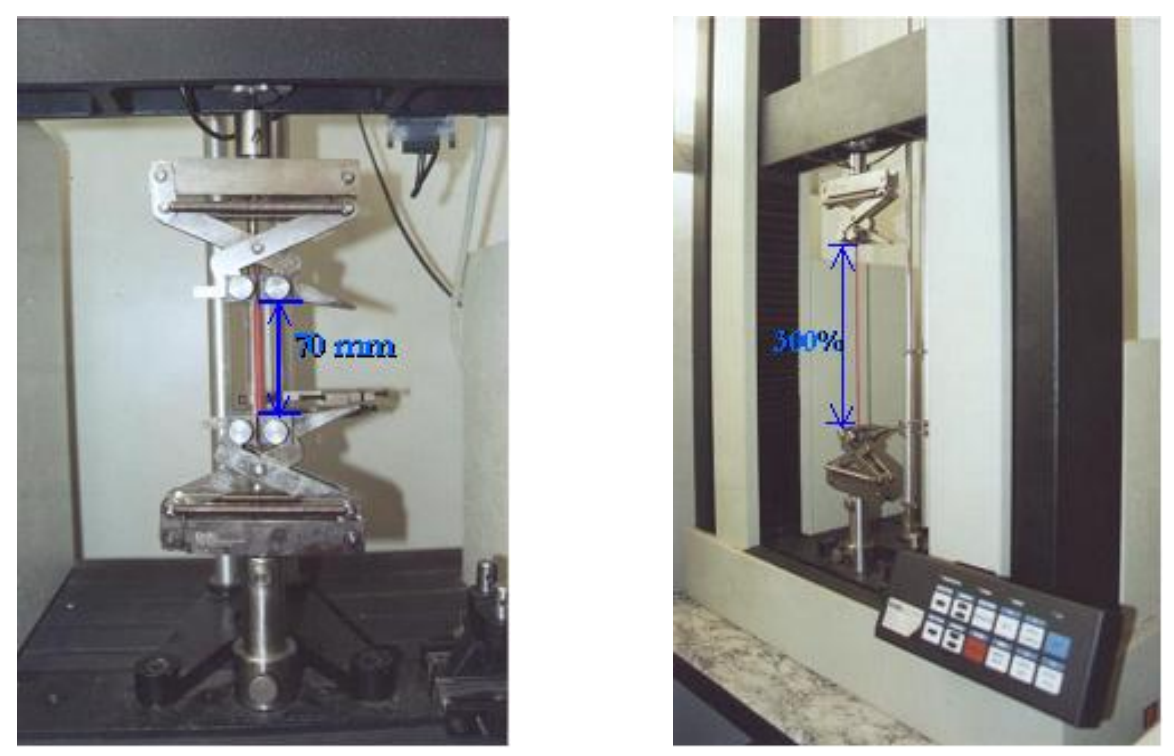

Figura 17. Caracterização mecânica das cordas elásticas no EMIC.

\footnotetext{
${ }^{6}$ EMIC - equipamentos e sistemas de ensaio Ltda.
} 


\subsection{Modelo biomecânico da atuação dos isquiotibiais}

Foi considerado para a elaboração das equações o modelo bidimensional que considera a direção da linha de força dos isquiotibiais como paralela ao fêmur (SMIDT, 1973). A força do grupo muscular em estudo foi determinada a partir da construção do diagrama de corpo livre da perna para cada posição do indivíduo de interesse, ou seja, decúbito dorsal, decúbito ventral, decúbito lateral, sentado e em pé.

Para o equacionamento, fez-se necessário a adoção de alguns valores de medidas antropométricas, que foram obtida pelas aproximações clássicas da literatura (De LEVA, 1996). Os principais parâmetros inerciais do segmento da perna utilizados foram o comprimento, a posição do centro de massa e o peso. O comprimento da perna é considerado igual a $25 \%$ da altura do indivíduo, considerando como ponto proximal o centro da articulação do joelho e o ponto distal o maléolo lateral. O centro de massa se localiza a 44,59\% do comprimento da perna, partindo do centro da articulação do joelho. E, finalmente, o peso da perna que corresponde a $4,33 \%$ do peso corporal total (De Leva, 1996).

Outro parâmetro importante usado no modelo, foi o braço de momento dos isquiotibiais, o qual varia com a posição angular da perna. Neste trabalho, adotou-se um ajuste aos valores médios descrito por Kellis e Baltzopoulos (1999). Na figura 18, apresenta-se o ajuste realizado por uma função polinomial de $4^{\circ}$ grau para descrever os valores médios do braço de momento em função do ângulo de flexão.

A tabela2, por sua vez, apresenta os valores dos parâmetros do polinômio do braço de momento dos isquiotibiais (bmi), o qual pode ser visualizado em seguida:

$$
B m_{i}=A+B_{1} \cdot x+B_{2} \cdot x^{2}+B_{3} \cdot x^{3}+B_{4} \cdot x^{4}
$$


Tabela 2. Parâmetros da função polinomial do $4^{\circ}$ grau utilizada para o ajuste dos valores dos braços de momento dos isquiotibiais.

\begin{tabular}{ccc}
\hline \hline Parâmetros & Valores & Erro \\
\hline $\mathbf{A}$ & 33,7565 & 1,48294 \\
$\mathbf{B}_{\mathbf{1}}$ & $-1,01571$ & 0,24353 \\
$\mathbf{B}_{\mathbf{2}}$ & 0,04197 & 0,01185 \\
$\mathbf{B}_{\mathbf{3}}$ & $-6,13586 \mathrm{E}-4$ & $2,12921 \mathrm{E}-4$ \\
$\mathbf{B}_{\mathbf{4}}$ & $2,81418 \mathrm{E}-6$ & $1,247 \mathrm{E}-6$ \\
\hline \hline
\end{tabular}

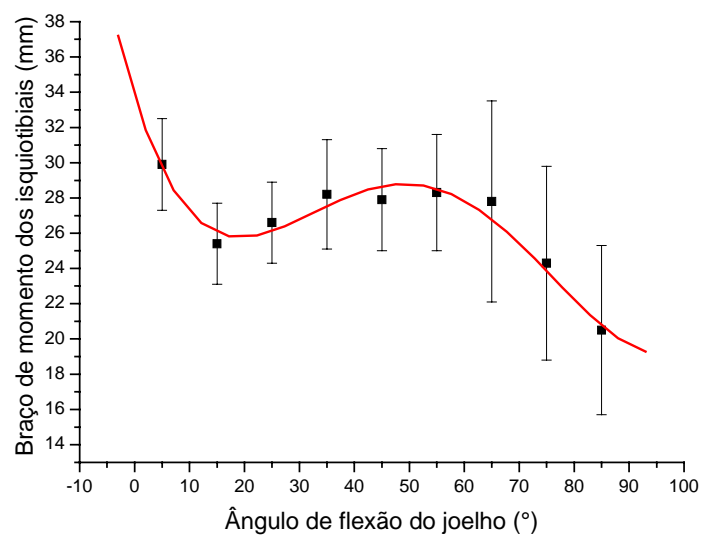

Figura 18. Gráfico representativo da distribuição dos valores de braço de momento dos isquiotibiais, durante flexão do joelho, numa amplitude de movimento de 0 a $90^{\circ}$ (Adaptado de Kellis e Baltzopoulos, 1999).

\subsection{Simulações da força dos isquiotibiais}

Foi considerado para as simulações, a situação de exercícios resistidos utilizando-se a resistência elástica e o peso fixo, ambos aplicados pelo sistema mecânico de exercício proposto por Azevedo et al. (2003). A força da ação dos isquiotibiais foi simulada para cada modelo por meio de rotinas matemáticas desenvolvidas no software MatLab 6.5, sendo que, alguns dados foram tratados também no Origin 7.0. Com estas simulações, construiu-se gráficos da força muscular em função da posição em diferentes exercícios. Ressalta-se que, para a realização de todas as simulações, considerou-se a velocidade de 
rotação do membro constante, ou seja, que a aceleração angular é igual a zero $(\alpha=0)$.

Nas equações dinâmicas, utilizadas neste trabalho, desprezou-se 0 momento de inércia da polia do sistema de exercício. Foi considerada apenas à equação da força de resistência proporcionada pela corda elástica ou pelo peso fixo, através do sistema mecânico de exercício.

\subsection{Ensaios experimentais}

Na fase experimental, registrou-se a posição do membro (goniometria), a força aplicada ao movimento (dinametria) e o sinal mioelétrico da cabeça longa do músculo bíceps femoral (eletromiografia), durante os exercícios. Os dados obtidos foram tratados para modelar a força interna dos isquiotibiais e correlacioná-la com a atividade elétrica da cabeça longa do bíceps femoral. A determinação da força interna do grupo muscular em estudo foi baseada no modelo biomecânico do joelho proposto por Smidt (1973), conforme descrito anteriormente e no modelo antropométrico proposto por Zatsiorsky-Seluynov e modificado por De LEVA (1996). Os ensaios experimentais consistiram de movimentos de flexo-extensão do joelho, com os voluntários posicionados em decúbito dorsal, utilizando-se resistência elástica e fixa, ambas no sistema mecânico de exercício.

\subsubsection{Voluntários e o modelo antropométrico}

Para o desenvolvimento da fase experimental foram selecionados 10 indivíduos do sexo masculino, sem antecedentes de lesões musculoesqueléticas nos joelhos e com características antropométricas distintas, concentradas nos limites do modelo antropométrico proposto por Zatsiorsky-Seluynov e modificado por De LEVA (1996). Segundo este modelo, indivíduos do sexo masculino que possuem massa de $73 \pm 9,0 \mathrm{Kg}$ e estatura de $174,1 \pm 6,2 \mathrm{~cm}$, os parâmetros inerciais do segmento da perna como o seu 
comprimento, posição do centro de massa deste segmento e peso da perna, possuem, respectivamente, os seguintes valores percentuais: $25 \%$ da altura do indivíduo, considerando como ponto proximal o centro da articulação do joelho e o ponto distal o maléolo lateral, $44,59 \%$ do comprimento da perna, partindo do centro da articulação do joelho, e 4,33\% do peso corporal total.

Os indivíduos que participaram deste estudo possuíam idade média de $22,5 \pm 2,68$ anos, massa média de 71,8 \pm 10,61 $\mathrm{Kg}$ e altura média de 175,6 \pm $6,98 \mathrm{~cm}$. Baseado nestes parâmetros foram calculados o comprimento do segmento da perna, posição do centro de massa e peso da perna, de cada voluntário, os quais apresentaram os seguintes valores médios, respectivamente, $43,9 \pm 1,74 \mathrm{~cm}, 19,57 \pm 0,78 \mathrm{~cm}$ e $30,48 \pm 4,5 \mathrm{~N}$. Os valores individuais podem ser visualizados na tabela 3 .

Tabela 3. Características antropométricas dos voluntários submetidos aos ensaios experimentais (Lp: comprimento da perna; $\mathrm{Cm}$ : centro de massa; $\mathrm{Pp}$ : peso da perna; I:momento de inércia).

\begin{tabular}{cccccccc}
\hline Sujeitos & Idade & $\begin{array}{c}\text { Massa } \\
(\mathbf{K g})\end{array}$ & Altura $(\mathbf{c m})$ & $\mathbf{L p}(\mathbf{c m})$ & $\mathbf{C m}(\mathbf{c m})$ & $P p(\mathbf{N})$ & $I$ \\
\hline \hline $\mathbf{1}$ & 27 & 77 & 181 & 45,25 & 20,17 & 32,67 & 0,23 \\
$\mathbf{2}$ & 20 & 75 & 172 & 43 & 19,17 & 31,82 & 0,20 \\
$\mathbf{3}$ & 19 & 67 & 178 & 44,5 & 19,84 & 28,43 & 0,19 \\
$\mathbf{4}$ & 21 & 58 & 175 & 43,75 & 19,51 & 24,61 & 0,16 \\
$\mathbf{5}$ & 23 & 65 & 170 & 42,5 & 18,95 & 27,58 & 0,17 \\
$\mathbf{6}$ & 22 & 83 & 184 & 46 & 20,51 & 35,22 & 0,25 \\
$\mathbf{7}$ & 27 & 84 & 172 & 43 & 19,17 & 35,64 & 0,22 \\
$\mathbf{8}$ & 21 & 83 & 177 & 44,25 & 19,73 & 35,22 & 0,23 \\
$\mathbf{9}$ & 23 & 72 & 185 & 46,25 & 20,62 & 30,55 & 0,22 \\
$\mathbf{1 0}$ & 22 & 55 & 162 & 40,5 & 18,06 & 22,91 & 0,13 \\
\hline Média & $22,5 \pm 2,68$ & $71,8 \pm 10,61$ & $175,6 \pm 6,98$ & $43,9 \pm 1,74$ & $19,57 \pm 0,78$ & $30,48 \pm 4,5$ & $0,20 \pm 0,04$ \\
\hline
\end{tabular}


Todos os voluntários foram esclarecidos sobre os procedimentos dos experimentos e assinaram um termo de consentimento (APÊNDICE A). Todos os ensaios experimentais foram realizados no Laboratório de Fisioterapia Aplicada ao Movimento Humano da Faculdade de Ciências e Tecnologia/ FCTUNESP de Presidente Prudente, São Paulo.

\subsubsection{Instrumentação}

\subsubsection{Sistema mecânico de exercício, corda elástica e peso fixo}

O sistema mecânico de exercício utilizado nas simulações e nos experimentos foi proposto a fim de se padronizar a execução de exercícios que utilizem a resistência elástica ou fixa. Tal sistema foi desenvolvido em parceria com a escola técnica SENAI -Pascoal Crepaldi, unidade de Presidente Prudente. Trata-se de uma roda com raio de $350 \mathrm{~mm}$ com um sulco de $15 \mathrm{~mm}$ em todo o seu perímetro, sustentada por base fixada no chão. No eixo de rotação da roda existe um rolamento, através do qual a roda está fixa ao pilar de sustentação (figura 19). O membro é acoplado ao sistema através de uma alavanca radial com comprimento ajustável, na qual localiza uma manopla, também ajustável, para o apoio do tornozelo, nos casos de exercício com membro inferior.

A tensão gerada pela corda se mantém perpendicular ao eixo axial da perna do sujeito durante todo o arco de movimento, sendo este o aspecto principal do sistema. Tal fato não ocorre em uma situação de aplicação clínica, pois a corda elástica é frequentemente amarrada diretamente ao tornozelo do paciente. 


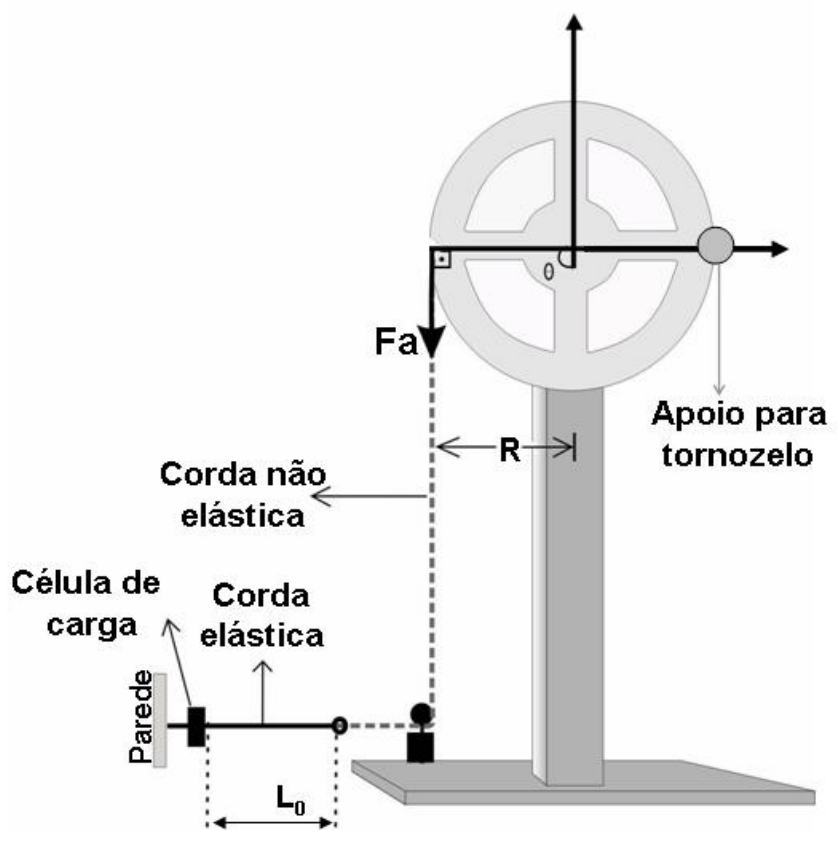

Figura 19. Sistema mecânico de exercício para uso da resistência elástica como tipo de sobrecarga ( $L_{0}$ : comprimento inicial da corda; R: raio da roda; $F_{a}$ : força aplicada ao movimento).

Pode-se observar na figura 19 que a corda elástica não é presa diretamente no sistema de exercício. Uma das extremidades da corda elástica está fixa à célula de carga, e a outra extremidade à corda não elástica. Justifica-se, tal procedimento, para se evitar o atrito do material elástico com a superfície da caneleta da roda do sistema.

A roda funciona como um sistema de alavanca. A figura 20 mostra as forças aplicadas à roda. Do lado esquerdo, tem-se a ação da força de resistência externa $\left(F_{R}\right)$, que pode ser produzida pela corda ou por um peso fixo, e do lado direito a força de interação entre a roda e a perna, chamada força aplicada $\left(F_{a}\right)$. Assim, o torque resultante na roda será: 
$F_{R} R_{R}-F_{a} L_{c}=I_{R} \alpha$

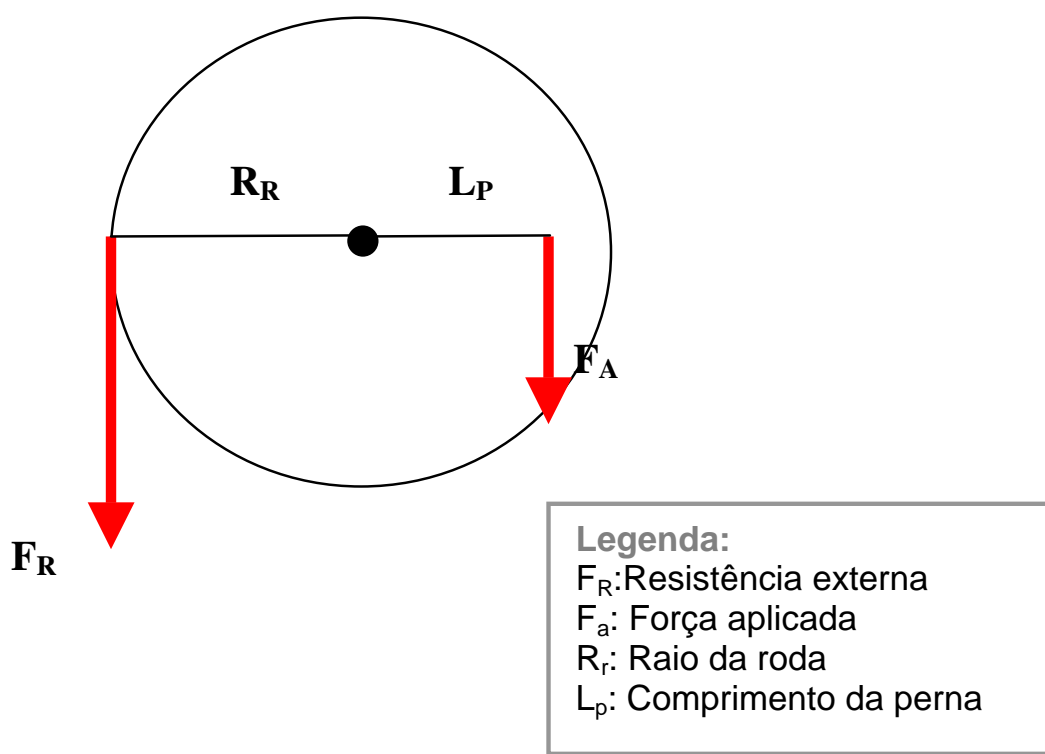

Figura 20. Relação entre a força de resistência e a força aplicada pelo membro na roda.

Considerando uma situação de equilíbrio dinâmico, onde a aceleração angular é zero, obtém-se a seguinte relação entre a força de resistência $\left(F_{a}\right)$ produzida pela corda, ou pelo peso fixo, e a força aplicada à perna $F_{a}$ :

$$
F_{\mathrm{a}}=F_{\mathrm{R}}\left(R_{\mathrm{R}} / L_{\mathrm{P}}\right)
$$

Nos exercícios com a resistência elástica foram utilizadas cordas elásticas da marca nacional Lengruber, referência 204, com 60 cm de comprimento (figura 21). Para cada voluntário foram utilizadas cordas novas, as quais foram conservadas em local seco, bem arejado e protegidas da ação da luz.

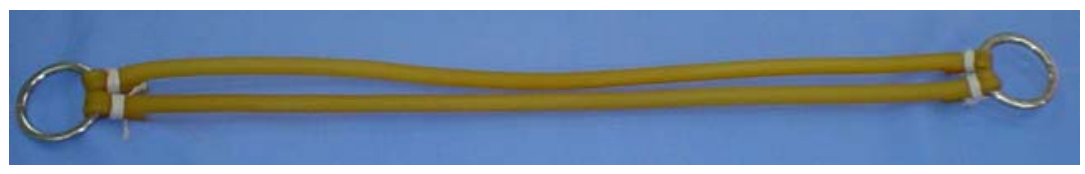

Figura 21. Corda elástica utilizada nos ensaios experimentais. 
Para os exercícios com resistência fixa as cordas elásticas foram substituídas por anilhas (figura 22 A). Para realizar as contrações isométricas, a roda ficava fixa no ângulo de $90^{\circ}$ através de um cabo de aço preso a roda e a célula de carga. (figura 22 B).
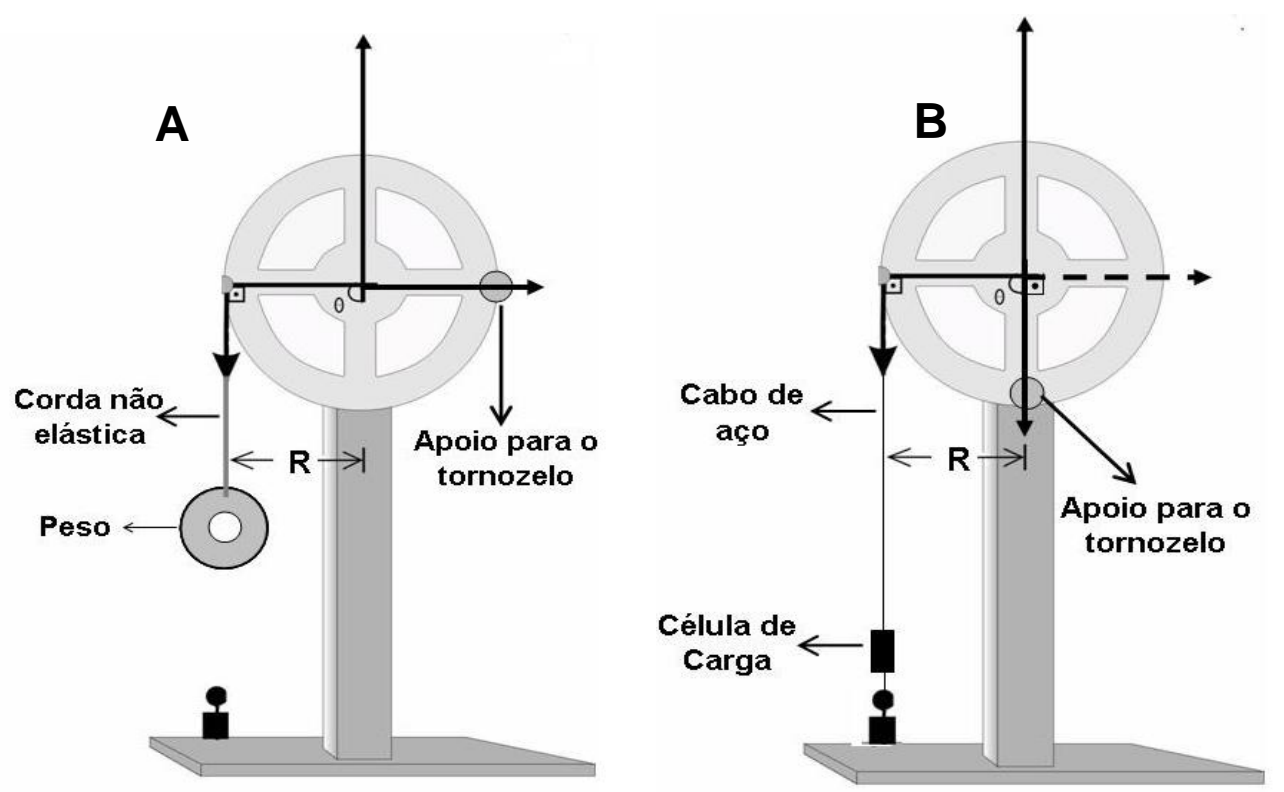

Figura 22. A) Sistema adaptado para o uso da resistência fixa. B) Sistema adaptado para a realização de contrações isométricas.

\subsubsection{Instrumentos de medição}

Para a captação dos sinais de dinametria, goniometria e eletromiografia foi utilizado um módulo condicionador de sinais da marca Lynx ${ }^{7}$, modelo BioEMG 1000, o qual possui 8 canais biopotenciais, dos quais um foi configurado para a aquisição do sinal eletromiográfico do bíceps femoral, e 4 canais de instrumentação. Destes canais de instrumentação, um foi configurado para receber os sinais da goniometria e outro para os sinais de dinametria (figura 23 e 24 A). Todos os canais apresentam ganho final de 1000 vezes e freqüência de amostragem de $2000 \mathrm{~Hz}$. Os canais configurados para receber os sinais de EMG apresentam um filtro digital, tipo ButterWorth, sendo um passa baixa com freqüência de corte de $500 \mathrm{~Hz}$ e um passa-alta com

\footnotetext{
${ }^{7}$ Lynx Tecnologia Eletrônica Ltda. Rua Sales Junior, 476 - São Paulo - Brasil.
} 
freqüência de corte de $20 \mathrm{~Hz}$. A aquisição e armazenamento dos sinais em arquivos de dados foram feitos pelo software Bioinspector 1.8, também da Lynx.

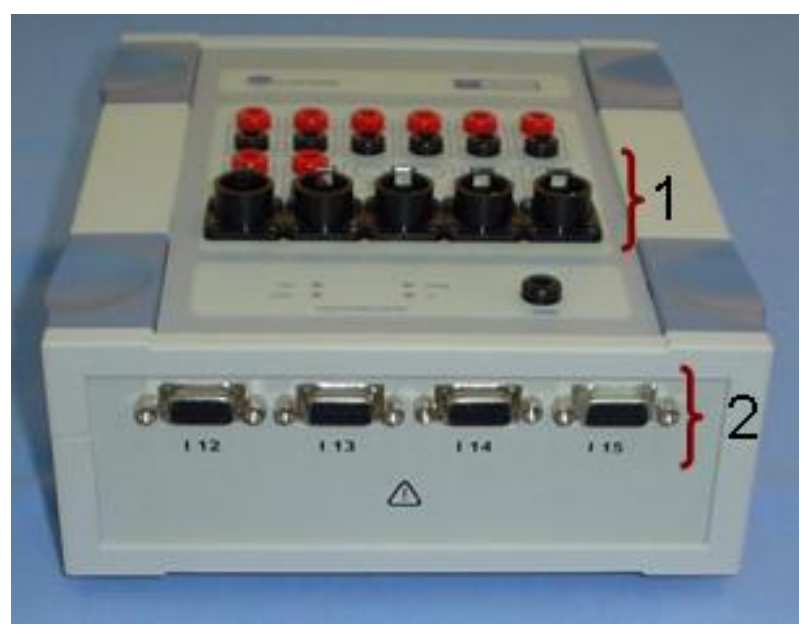

Figura 23. Módulo condicionador de sinais da marca Lynx, modelo BioEMG 1000. (1) Canais biopotenciais para eletrodos bipolar ativo; (2) Canais de instrumentação.

Para a aquisição do sinal eletromiográfico foi utilizado um par de eletrodos de superfície, modelo Meditrace da marca 3M, com superfícies de captação de $\mathrm{AgCl}$ com $10 \mathrm{~mm}$ de diâmetro, que foram posicionados separados entre si por $20 \mathrm{~mm}$ (figura $24 \mathrm{~B}$ ). O cabo do eletrodo possui um circuito préamplificador com ganho de 20 vezes, CMRR (Common Mode Rejection Ratio) maior que $80 \mathrm{~dB}$ e impedância de $1012 \Omega$. 

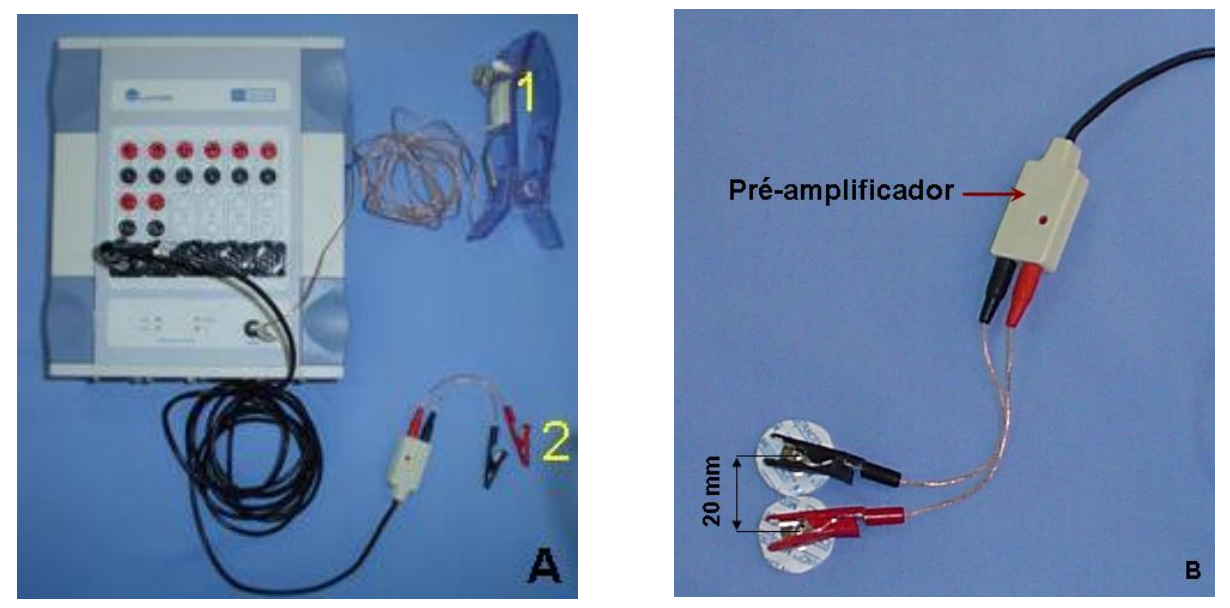

Figura 24. A) Módulo condicionador de sinais (1. Eletrodo de referência; 2. Eletrodo ativo). B) Par de eletrodos ativos utilizados para a captação do sinal eletromiográfico. Destaca-se o circuito pré-amplificador e a distância de $20 \mathrm{~mm}$ dos centros de cada eletrodo.

A aquisição da intensidade da força aplicada ao movimento de flexoextensão foi realizada por uma célula de carga, com capacidade para 980N, modelo MM da marca Kratos Dinamômetros ${ }^{8}$ (figura 25).

Para as medidas da posição angular do membro inferior do voluntário, durante os ciclos de flexão e extensão da articulação do joelho, utilizou-se um eletrogoniômetro. Este sensor é constituído por um potenciômetro linear de precisão multivoltas de $10 \mathrm{~K} \Omega$, montado na forma de um divisor de tensão. $\mathrm{O}$ potenciômetro está acoplado ao eixo da roda conforme mostra a figura 26 , associando a resistência elétrica à posição da mesma. A tensão lida pelo módulo condicionador de sinais é convertida em ângulo via software. Antes do início da coleta de dados, o eletrogoniômetro era calibrado para cada voluntário, para evitar maiores flutuações (figura 26).

\footnotetext{
${ }^{8}$ Kratos Dinamômetros Ltda. Rua Dr. João Marques Maurício, 360, Embu, SP - Brasil.
} 


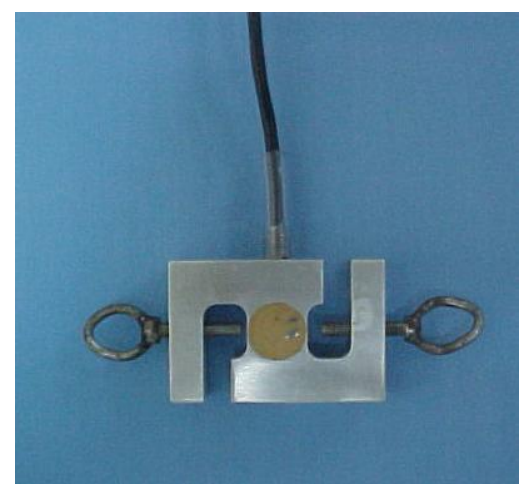

Figura 25. Célula de carga.

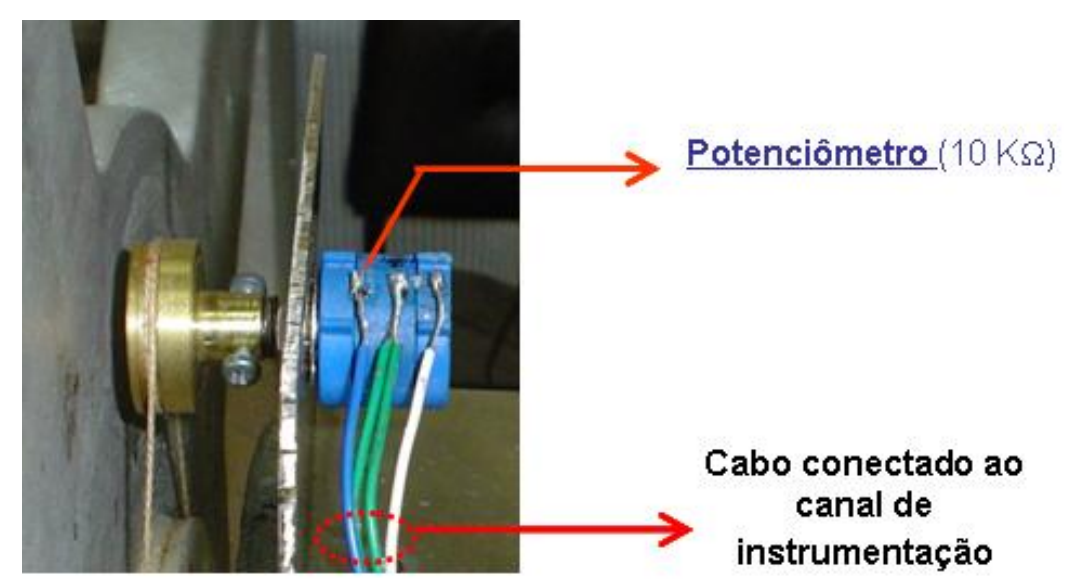

Figura 26. Eletrogoniômetro.

Durante o desenvolvimento do protocolo experimental os voluntários foram orientados a executar movimentos de flexão e extensão da articulação do joelho numa freqüência de $2 \mathrm{~Hz}$, tentando manter a velocidade angular constante. Esse ritmo foi controlado com o auxílio de um metrônomo.

Além dos materiais acima relacionados, foram também utilizados os seguintes materiais acessórios: divã, cadeira com ajuste do encosto e travesseiro para posicionamento dos voluntários; faixas de velcro para estabilização do quadril, da coxa e do tornozelo na manopla de apoio da roda; lâmina, álcool e algodão para tricotomia e limpeza da pele e dos eletrodos. 


\subsubsection{Protocolo experimental}

\subsubsection{Fixação dos eletrodos para captação dos sinais de EMG}

Para o posicionamento dos eletrodos, seguiram-se os procedimentos recomendados pela SENIAM (Surface Electromyography for the Non-invasive Assessment of Muscles) (HERMENS et al., 2000; 2002). Inicialmente, cada voluntário foi posicionado em decúbito ventral sobre o divã para a localização do ventre da cabeça longa do músculo bíceps femoral. Para isso, o joelho foi fletido num ângulo menor que $90^{\circ}$ e uma pressão manual na direção da extensão foi aplicada ao nível do tornozelo, solicitando-se a realização da flexão por parte do voluntário (HERMENS, 2000; 2002; KENDALL et al., 1995). Após a localização do ventre muscular, o eletrodo foi fixado no local descrito na tabela 4. O local de fixação dos eletrodos está ilustrado na figura 27 e o eletrodo de referência foi colocado no punho. Todos os sujeitos foram submetidos a tricotomia, abrasão e limpeza dos locais de acoplamento antes da fixação dos eletrodos.

Tabela 4. Regras para posicionamento e orientação dos eletrodos na cabeça longa do bíceps femoral, segundo padronização proposta pela SENIAM (HERMENS et al., 2002).

\begin{tabular}{|c|c|c|}
\hline Músculo & Posição do Eletrodo & $\begin{array}{c}\text { Orientação do } \\
\text { Eletrodo }\end{array}$ \\
\hline $\begin{array}{l}\text { Bíceps Femoral } \\
\text { (cabeça longa) }\end{array}$ & $\begin{array}{l}\text { Os eletrodos devem ser } \\
\text { colocados a } 50 \% \text { da linha entre } \\
\text { a tuberosidade isquiática e o } \\
\text { epicôndilo lateral da tíbia. }\end{array}$ & $\begin{array}{l}\text { Na direção da linha } \\
\text { entre a tuberosidade } \\
\text { isquiática e o epicôndilo } \\
\text { da tíbia. }\end{array}$ \\
\hline
\end{tabular}




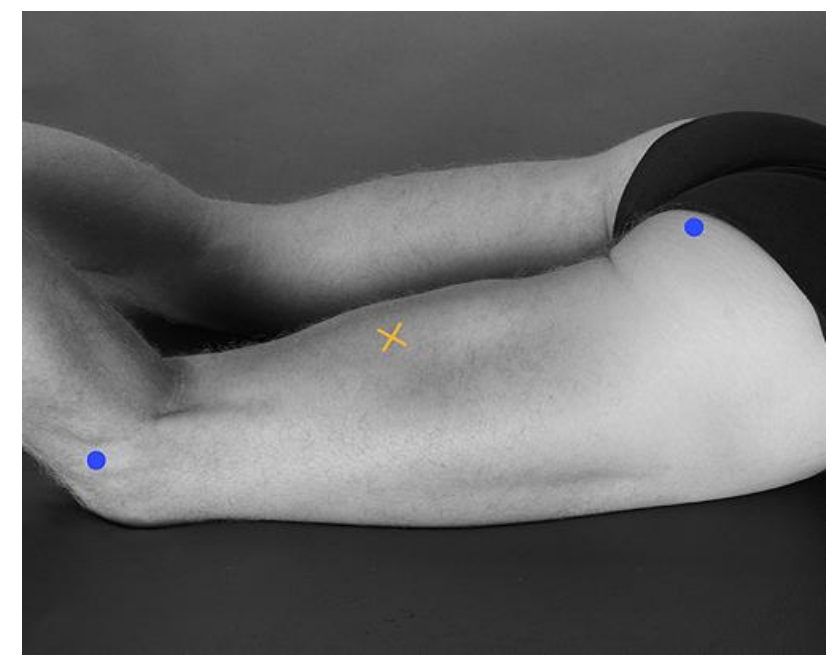

Figura 27. Esquema representativo do local de colocação dos eletrodos $(x)$ sobre o músculo bíceps femoral (HERMENS et al., 2002).

\subsubsection{Posicionamento no sistema mecânico de exercício}

Após a colocação dos eletrodos, os voluntários foram posicionados em decúbito dorsal numa cadeira com o encosto ajustável, o qual foi mantido numa elevação de $10^{\circ}$. A altura da cadeira foi ajustada de modo que a articulação do joelho ficasse alinhada ao eixo de rotação do sistema. Além disso, foram utilizadas faixas de velcro para estabilizar o quadril e os joelhos, a fim de se evitar movimentos compensatórios. Um rolo almofadado foi colocado entre a cadeira e a coluna lombar do voluntário para apoio e maior conforto durante a coleta de dados. O tornozelo do indivíduo foi posicionado sobre a manopla da roda e fixado com uma faixa de velcro, para evitar o deslocamento durante dos movimentos de flexo-extensão (figura 28). 

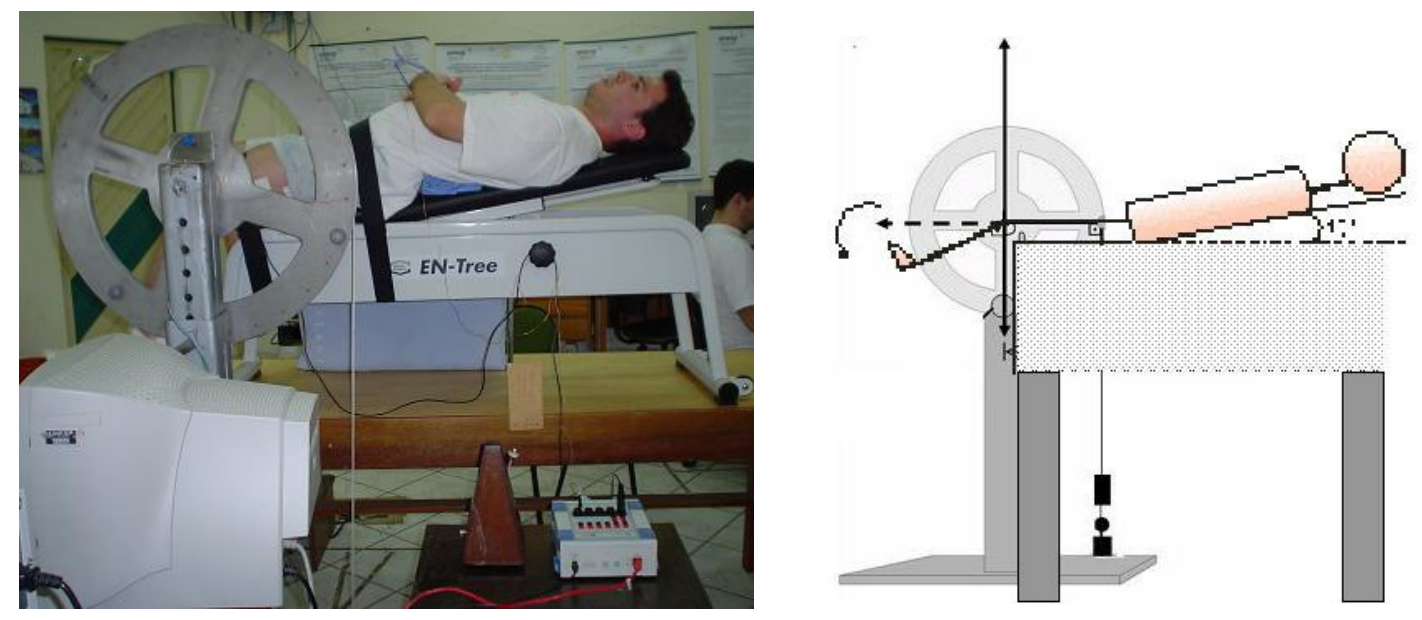

Figura 28. Posicionamento do voluntário no sistema mecânico de exercício.

\subsubsection{Coleta de dados}

O protocolo para coleta de dados foi iniciado com o registro de duas contrações voluntárias isométricas máximas no ângulo articular de $90^{\circ}$, sendo que, foi selecionado o melhor sinal para as análises. Para isso a manopla do sistema foi travada no ângulo de 90 graus e o indivíduo foi orientado a aplicar força máxima durante 6 segundos. Nesse período, registrou-se o sinal eletromiográfico e a força exercida através da célula de carga.

Para cada indivíduo foi calculado o valor RMS do sinal de EMG e a força média durante a contração isométrica máxima. Para este cálculo, desprezou-se o primeiro e o último segundo do sinal, aproveitando os 4 segundos intermediários. A partir da força máxima registrada, definiu-se o número de cordas elásticas para a realização do experimento com resistência variável e também o valor do peso livre para o experimento com resistência constante. $O$ número de cordas utilizado foi escolhido de forma que, no sistema mecânico de exercícios e em $90^{\circ}$, a força aplicada pela corda fosse aproximadamente $50 \%$ da força isométrica máxima neste mesmo ângulo de acordo com gráfico da figura 29. A figura 21, mostrada anteriormente, ilustra uma resistência com duas cordas. 


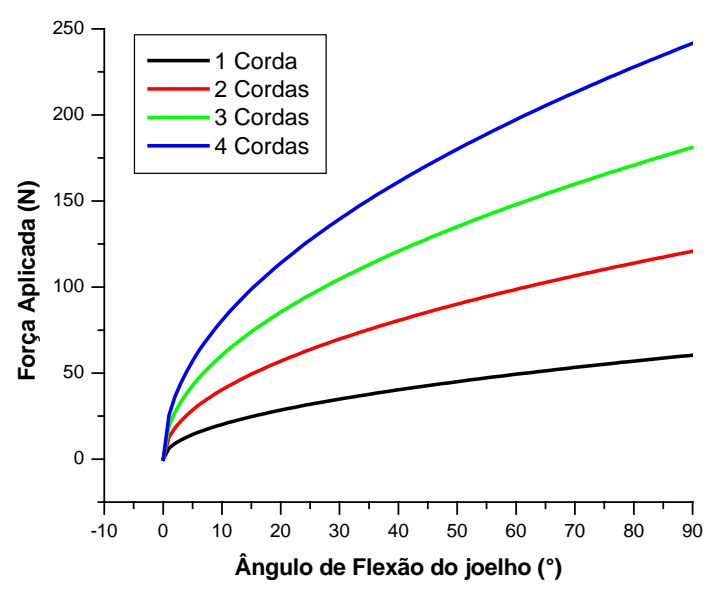

Figura 29. Valores de tensão oferecidos por diferentes números de cordas elástica de acordo com ângulo de flexão do joelho.

Uma vez definido o valor das resistências fixa e elástica a partir da contração isométrica máxima, primeiramente foi realizado o exercício com peso fixo e a seguir com a corda elástica. Com o peso fixo, o indivíduo foi orientado a realizar 20 ciclos de flexo-extensão num ritmo constante. Após 10 minutos de repouso, foram realizados os ciclos de flexo-extensão utilizando as cordas elásticas.

Os dados de eletromiografia, tensão da corda e goniometria, coletados nesta etapa do trabalho, foram tratados para posterior análise em rotinas específicas para esta avaliação, construídas no software Matlab 6.5.

\subsubsection{Tratamento dos dados}

O sistema de medida registra os sinais de eletromiografia, posição angular da perna e a força medida pela célula de carga em função do tempo de aquisição. Numa matriz única são armazenados os dados constituintes de todos os sinais captados durante os numerosos ciclos de exercícios de flexoextensão. A figura 30-1 exemplifica estes sinais brutos em função do tempo para três ciclos subseqüentes. 
(1)
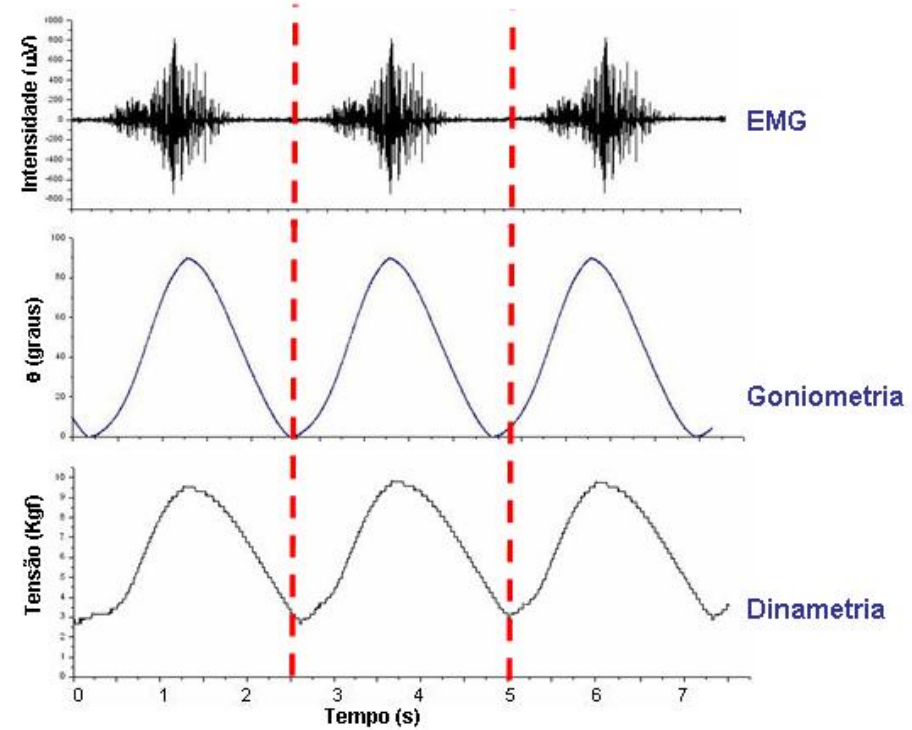

(2)
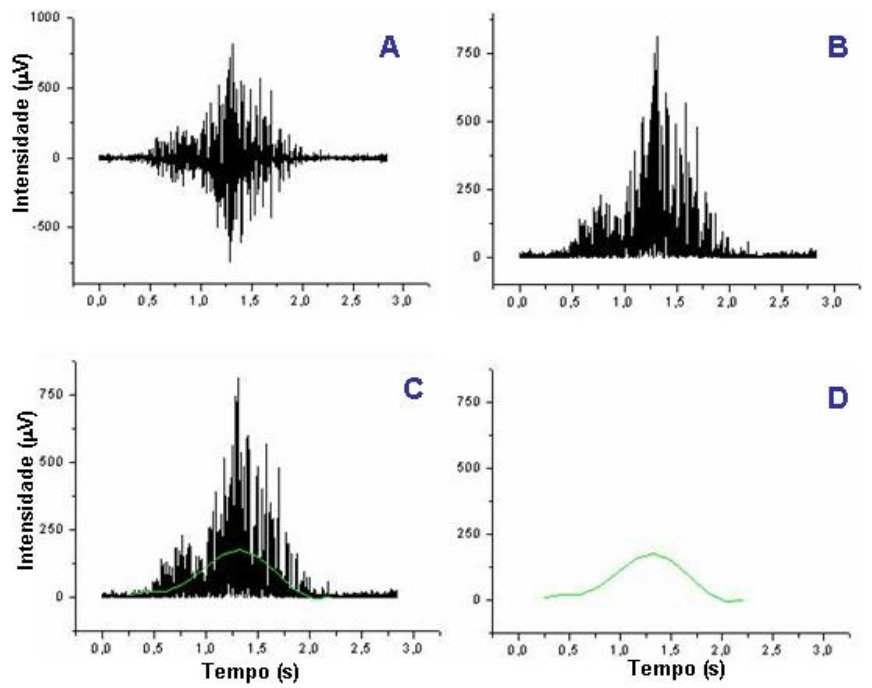

Figura 30. (1) Ciclos de sinais sem nenhum tratamento da intensidade eletromiográfica, da posição angular da perna e da força registrada na célula de carga. (2) Exemplo de seqüência de tratamento de EMG no domínio do tempo. A) sinal de EMG bruto durante um ciclo de flexoextensão; B) RMS do sinal (sinal retificado); C) Envoltória do sinal retificado sobreposta ao sinal e; C) Envoltória do sinal.

Para correlacionar as grandezas envolvidas nas medidas, os cálculos devem ser efetuados a partir dos valores médios de vários ciclos. Como os sinais apresentam grandes flutuações, foi feita uma análise visual prévia para selecionar, manualmente, 10 ciclos, que não apresentassem grandes ruídos e ou distorções. Os valores médios de EMG, posição e força, destes 10 ciclos foram calculados por interpolação por meio das rotinas, considerando o tempo do ciclo normalizado de 0 a 100\%, como a base de tempo. 
O sinal pré-selecionado manualmente passa por uma seleção automática de seu fim e início. Esta seleção foi feita através dos dados da posição angular da perna utilizando-se um algoritmo que detecta um limiar de referência, o qual foi definido como $5^{\circ}$. O sistema procura o valor da posição que mais se aproxima de $5^{\circ} \mathrm{e}$, este é tomado como início, se a derivada média neste ponto é positiva e, é tomado como final se a derivada média é negativa.

Durante este tratamento de sinal para o cálculo de um ciclo médio, o sinal de EMG recebe um tratamento específico. Pela rotina o sinal eletromiográfico bruto (figura 30-2/A) foi retificado em onda completa (figura 302/B), em seguida, foi determinado o envoltório linear usando um filtro passa baixa tipo Butterworth de $4^{\mathrm{a}}$ ordem e com freqüência de corte de $5 \mathrm{~Hz}$ (figura 30-2/C). Este envoltório passa, então, a constituir o sinal de EMG (figura 302/D). A figura 30 mostra o conjunto destas etapas do tratamento do sinal eletromiográfico e a figura 31, mostra os sinais de EMG, da goniometria e da força aplicada, resultante de uma média dos 10 ciclos, na base de tempo normalizada.
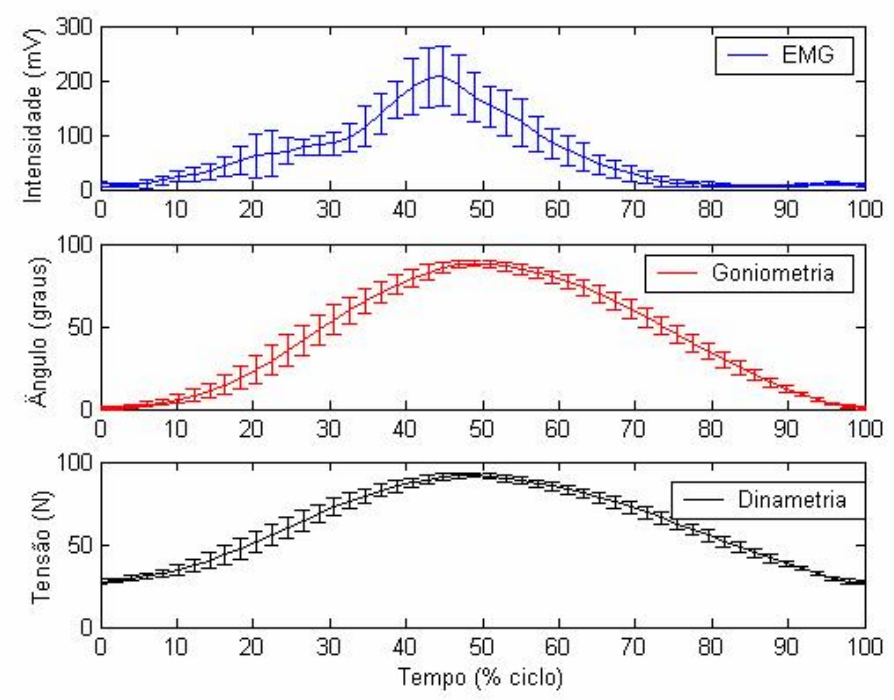

Figura 31. Esquema ilustrando o sinal de eletromiografia, a posição angular da perna e a força registrada na célula de carga na base de tempo normalizada. 
Neste item, fez-se uma descrição, de uma forma geral, sobre o tratamento dos sinais. Nas análises específicas, que serão apresentadas no item de resultados e discussão, outros tratamentos complementares serão abordados. No entanto todos os sinais passaram pelo processamento básico aqui descrito. 


\section{RESULTADOS}

\section{1. Estudo das propriedades da corda elástica}

Os valores médios de tensão máxima e da histerese produzida durante os ensaios de caracterização mecânica das cordas elásticas Lengruber e Thera-band $®$, estão apresentadas na tabela 5 .

Tabela 5: Áreas de secção transversal das cordas estudadas e seus respectivos valores de histerese e tensão máxima a 300\% de deformação.

\begin{tabular}{l|ccccc}
\hline \hline & $\begin{array}{c}\text { Lengruber } \\
\mathbf{2 0 0}\end{array}$ & $\begin{array}{c}\text { Lengruber } \\
\mathbf{2 0 2}\end{array}$ & $\begin{array}{c}\text { Lengruber } \\
\mathbf{2 0 4}\end{array}$ & $\begin{array}{c}\text { Thera-band } \\
\text { vermelha }\end{array}$ & $\begin{array}{c}\text { Thera-band } \\
\text { azul }\end{array}$ \\
\hline Área $\left(\mathbf{m m}^{2}\right)$ & 12,57 & 47,71 & 84,83 & 17,28 & 35,34 \\
\hline Histerese (J) & $0,084 \pm 0,005$ & $0,20 \pm 0,20$ & $0,6 \pm 0,1$ & $0,168 \pm 0,004$ & $\begin{array}{c}0,302 \pm \\
0,006\end{array}$ \\
\hline $\begin{array}{l}\text { Tensão máxima } \\
(\mathbf{N})\end{array}$ & $17,15 \pm 0,39$ & $46,94 \pm 0,68$ & $62,72 \pm 2,94$ & $32,34 \pm 1,96$ & $55,47 \pm 0,68$ \\
\hline \hline
\end{tabular}

A medida de histerese está associada à área compreendida, pelo gráfico de tensão versus deformação, em cada ciclo de expansão seguido de uma retração. Se não houvesse perda de energia neste ciclo a curva de expansão deveria ser igual à retração, sobrepondo-a. A área da curva em um ciclo fechado representa a energia perdida neste ciclo.

Os valores de tensão máxima em 300\% de deformação mostram que não há uma correlação entre as cordas Lengruber 200, 202 e 204 e as TheraBand $®$ azul e vermelha. A Thera-Band $®$ vermelha oferece uma resistência intermediária entre as cordas 200 e 202 e, a Thera- Band® azul apresenta valores próximos à 204 (tabela 5).

A figura 32 mostra as curvas de tensão-deformação durante os ensaios das amostras de Thera-Band® vermelha e azul e Lengruber 200, 202 e 204. Todas as medidas apresentam uma diferença entre o primeiro e os demais ciclos, e todas apresentam curvas similares com o mesmo formato. Ou seja, 
todas as amostras, independente da fabricação, possuem o mesmo comportamento.

$\mathrm{Na}$ figura 33, pode-se observar um ensaio complementar com uma corda elástica Lengruber 204, realizado no próprio sistema mecânico de exercício, com o objetivo de verificar se existe alterações das características básicas da corda quando usada nas condições experimentais, ou seja, com velocidade de extensão muito menor que a adotada no ensaio. Assim, na figura 33 tem-se a tensão versus a deformação numa situação estática, em que as medidas são realizadas em repouso, pode-se observar que nos quatro ciclos realizados os resultados foram similares entre si, mantendo o mesmo comportamento dos corpos de prova mostrados na figura 32. 

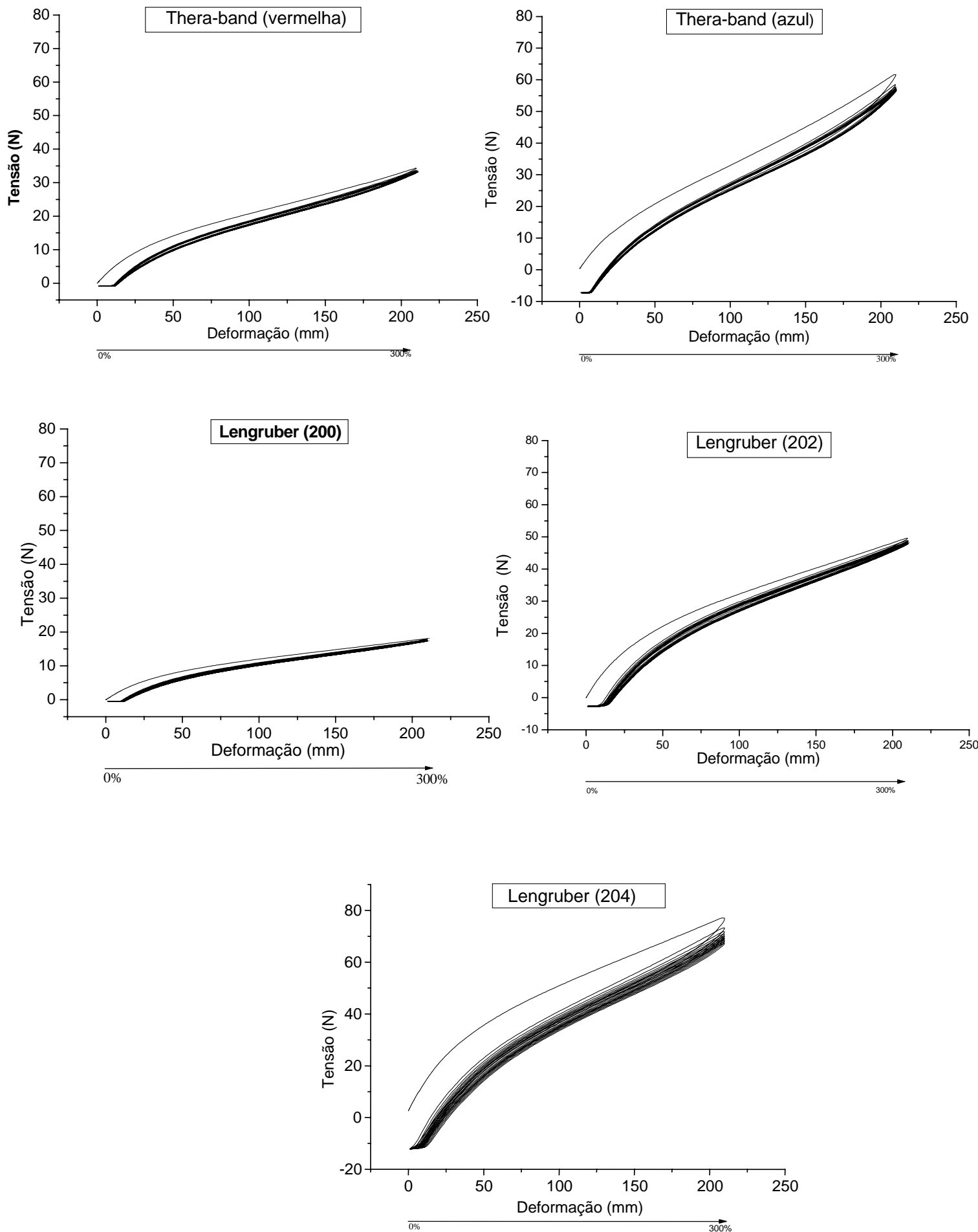

Figura 32. Curvas de tensão-deformação durante ensaios com amostras das cordas elástica Lengruber e Thera-Band ${ }^{\circledR}$. 


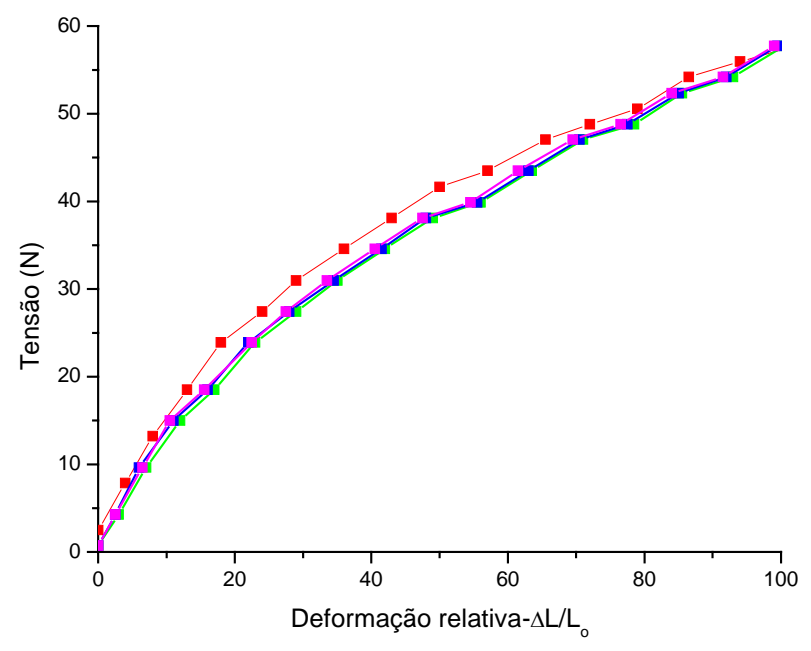

Figura 33. Ensaio com a corda elástica (204) Lengruber no sistema de tração (condição estática).

A partir da figura 33 foi determinada a relação entre a tensão da corda $\left(F_{c}\right)$ e a deformação porcentual da mesma $\left(\Delta L / L_{0}\right)$.

Assim, fazendo-se um ajuste logarítmico na figura 33, obteve-se a figura 34, por meio da qual foi determinado que a força da corda possui uma relação do tipo:

$$
\mathrm{F}_{\mathrm{C}}=\lambda \mathrm{A}\left(\frac{\Delta \mathrm{L}}{\mathrm{L}_{\mathrm{o}}}\right)^{\mathrm{n}}
$$

Através da figura 34 foram determinados, também, os valores de $\mathbf{n}$ e $\lambda \mathbf{A}$, ou seja, 0,5 e 44,7, respectivamente. 


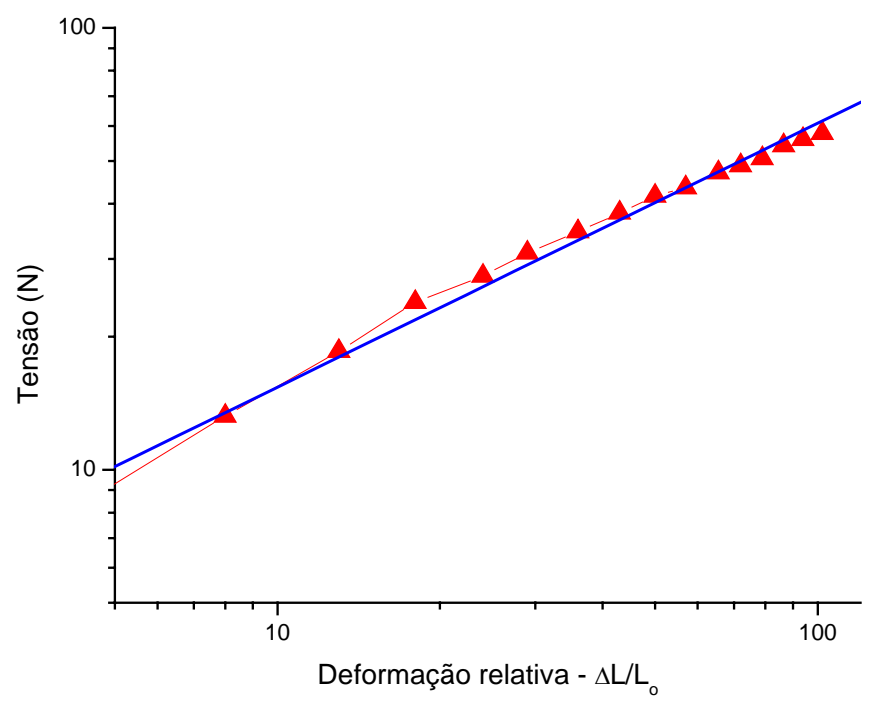

Figura 34. Gráfico logarítmico da tensão da corda e a deformação relativa.

Portanto, a tensão gerada pela corda elástica Lengruber 204, no sistema mecânico de exercício, pode ser simulada pela equação 5 , mostrando que este material não obedece a Lei de Hooke. Essa Lei ocorreria se na equação 4, n fosse igual a 1.

$$
\mathrm{F}_{\mathrm{C}}=44,7\left(\frac{\Delta \mathrm{L}}{\mathrm{L}_{\mathrm{o}}}\right)^{0,5}
$$

\subsection{Modelo biomecânico da atuação dos isquiotibiais}

Com o objetivo de verificar como o grupo muscular isquiotibial age em cada exercício em particular, procurou-se descrever equações que forneçam a força de ação deste músculo. Determinou-se a dependência da força muscular em função da posição angular para exercícios de flexão do joelho com diferentes tipos de resistência, ou seja, diferentes forças aplicadas externamente $\left(F_{a}\right)$ e em diferentes posições: decúbito dorsal, decúbito ventral, decúbito lateral, em pé e sentado. As equações foram determinadas a partir do diagrama de corpo livre de uma perna em movimento de flexo-extensão. 
Adotou-se a aproximação de se considerar a perna como um cilindro homogêneo que rotaciona em torno de um eixo localizado em uma de suas extremidades. O peso do pé foi desprezado e o peso da perna $\left(W_{p}\right)$ foi aplicado no centro de massa e calculado como uma porcentagem do peso corporal. Considera-se que o eixo de rotação passa pelo ponto de contato entre o côndilo femoral e a tíbia, perpendicular ao plano sagital, onde a força de contato entre a tíbia e o fêmur $\left(F_{c}\right)$ atua.

Em seguida, estão apresentados os diagramas de corpo livre e suas respectivas equações para cada posicionamento do indivíduo para a realização do movimento de flexo-extensão do joelho.

\subsubsection{Voluntário em decúbito dorsal}

A figura 35 apresenta o diagrama de corpo livre da perna do indivíduo em decúbito dorsal. Neste diagrama $F_{\mathbf{a}}$ é a força aplicada contra o movimento de flexão; $\mathbf{W}_{\mathbf{p}}$ é o peso da perna; $\mathbf{c m}$ é o centro de massa da perna; $\mathbf{F}_{\mathbf{b}}$ é a força interna dos isquiotibiais; $F_{c}$ é a força de contato articular entre o fêmur e a tíbia; $\alpha$ é o ângulo entre $F_{c}$ e o eixo da tíbia; $\theta$ é o ângulo de flexão do joelho; $L_{p}$ é o comprimento da perna; $\mathbf{L}_{c m}$ é a posição longitudinal do centro de massa; $\mathrm{e}$ bm é o braço de momento.

Conforme descrito na metodologia, o vetor da força dos isquiotibiais $\left(\mathbf{F}_{\mathbf{b}}\right)$ foi definido como a linha que se origina da face posterior da fíbula e é paralela ao fêmur (SMIDT, 1973). A força aplicada $\left(\mathbf{F}_{\mathbf{a}}\right)$ na altura posterior do tornozelo pela resistência utilizada, pode ser elástica ou fixa e, o sistema mecânico garante que ela se mantenha sempre orientada perpendicularmente ao eixo da tíbia. No diagrama de corpo livre aparecem, ainda, as forças de contato $\left(\mathbf{F}_{\mathbf{c}}\right)$ e a força peso da perna $\left(\mathbf{W}_{\mathbf{p}}\right)$. 

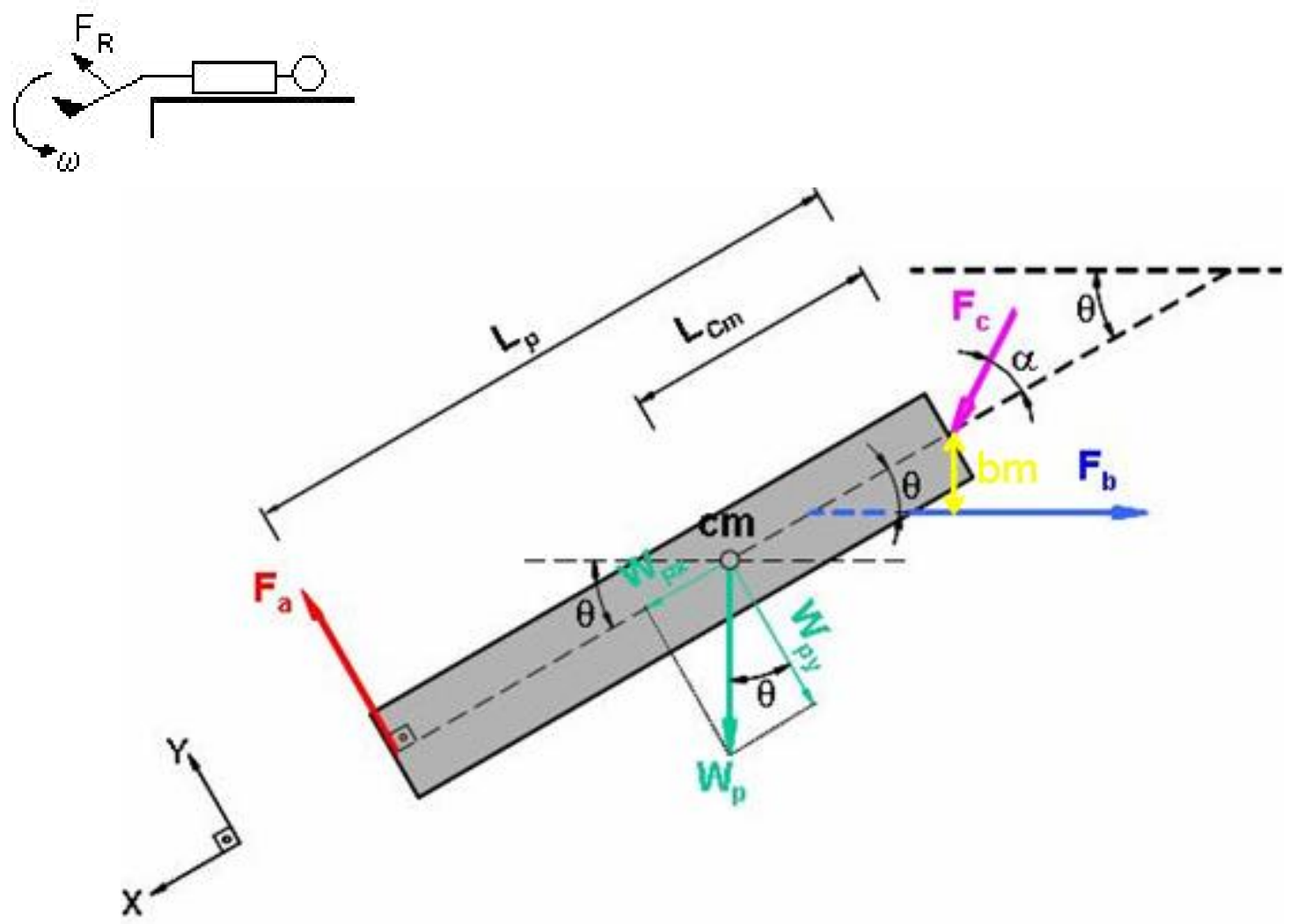

Figura 35. Diagrama de corpo livre representando a perna de um indivíduo em decúbito dorsal.

Considerando que a perna se movimenta com uma aceleração angular $\alpha$, a somatória do torque é dada por:

$$
\sum \tau=\mathrm{I} \alpha
$$

Então, a partir da elaboração do diagrama de corpo livre, pode-se escrever que:

$$
\mathrm{F}_{\mathrm{a}} \cdot \mathrm{L}_{\mathrm{p}}-\mathrm{W}_{\mathrm{p}} \cdot \cos \theta \cdot \mathrm{L}_{\mathrm{cm}}-\mathrm{F}_{\mathrm{b}} \cdot \mathrm{b}_{\mathrm{m}} \cdot=\mathrm{I} \alpha
$$

Conseqüentemente, a força dos isquiotibiais, neste caso, é dada por:

$$
\mathrm{F}_{\mathrm{b}}=\frac{\mathrm{F}_{\mathrm{a}} \cdot \mathrm{L}_{\mathrm{p}}-\mathrm{W}_{\mathrm{p}} \cdot \operatorname{Cos} \theta \cdot \mathrm{L}_{\mathrm{Cm}}-\mathrm{I} \alpha}{\mathrm{b}_{\mathrm{m}}}
$$

Ressalta-se que a força de contato, $\mathbf{F}_{\mathbf{c}}$, não gera torque, pois está 
aplicada justamente sobre o ponto de contato, onde se considera estar situado o eixo de rotação.

Para determinar a força dos isquiotibiais em função da posição angular é necessário, primeiramente, determinar a força externa $\left(\mathbf{F}_{\mathrm{a}}\right)$. Assim, $\mathbf{F}_{\mathbf{a}}$ será constante quando se tratar de peso fixo ou será variável quando se tratar de corda elástica.

Os parâmetros, peso da perna $\left(\mathbf{W}_{\mathbf{p}}\right)$, comprimento da perna $\left(\mathbf{L}_{\mathbf{p}}\right)$ e posição do centro de massa $\left(\mathbf{L}_{\mathbf{c m}}\right)$ estão apresentados na tabela 3. A aceleração angular é a segunda derivada da posição angular em relação ao tempo.

$$
\alpha=\frac{\mathrm{d}^{2} \theta}{\mathrm{dt}^{2}}
$$

\subsubsection{Voluntário em decúbito ventral}

A ação das forças na perna na situação de exercício de flexão do joelho, quando o indivíduo está posicionado em decúbito ventral, pode ser visualizada através do diagrama de corpo livre representado na figura 36.

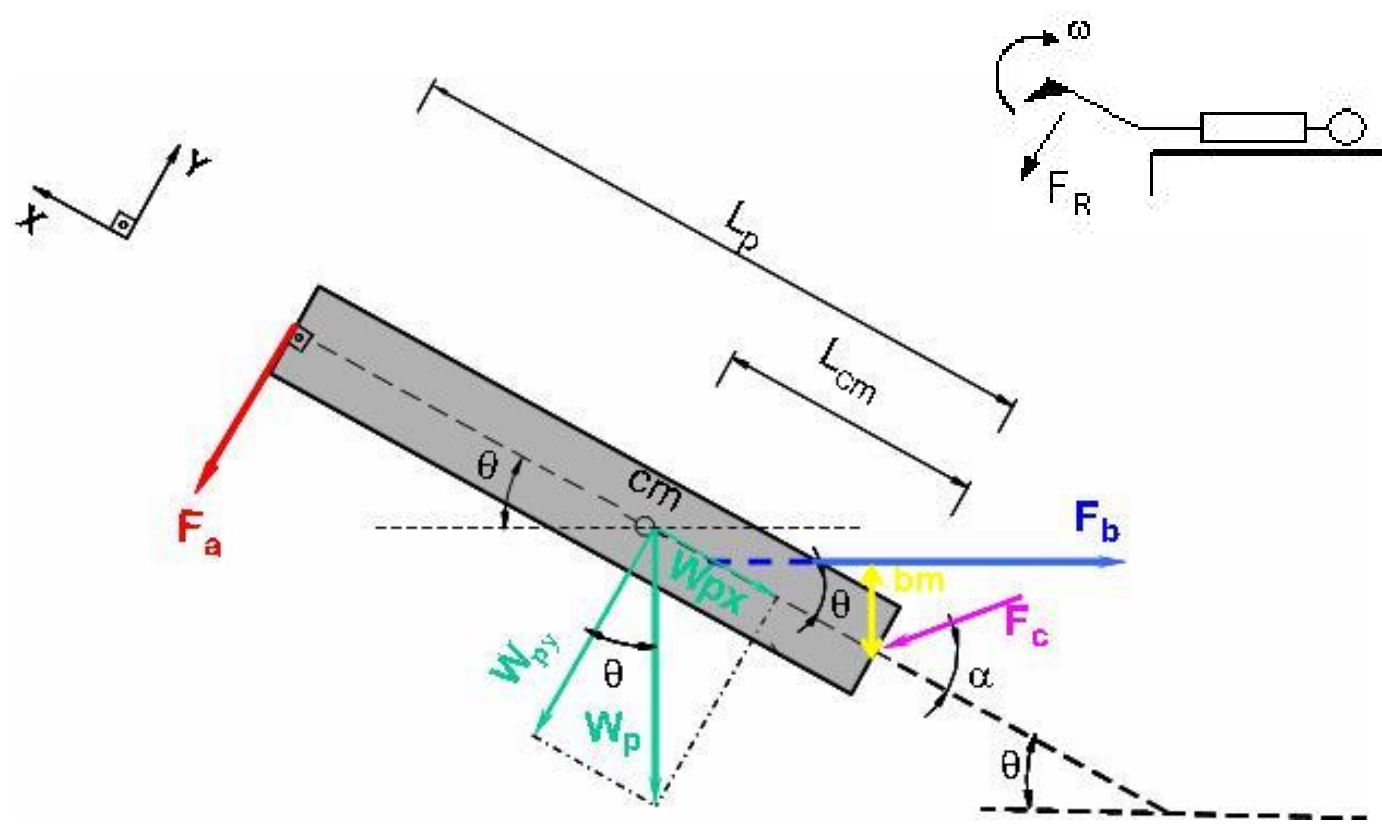

Figura 36. Diagrama de corpo livre representando a perna de um indivíduo em decúbito ventral. 
A partir do diagrama e considerando que $\sum \tau=\mathrm{I} \alpha$, temos que:

$$
-\mathrm{F}_{\mathrm{a}} \cdot \mathrm{L}_{\mathrm{p}}-\mathrm{W}_{\mathrm{p}} \cdot \cos \theta \cdot \mathrm{L}_{\mathrm{cm}}+\mathrm{F}_{\mathrm{b}} \cdot \mathrm{bm}=\mathrm{I} \alpha
$$

De onde pode determinar-se que a força dos isquiotibiais em decúbito ventral é dada por:

$$
\mathrm{F}_{\mathrm{b}}=\frac{\mathrm{F}_{\mathrm{a}} \cdot \mathrm{L}_{\mathrm{P}}+\mathrm{W}_{\mathrm{p}} \cdot \operatorname{Cos} \theta \cdot \mathrm{L}_{\mathrm{Cm}}+\mathrm{I} \alpha}{\mathrm{b}_{\mathrm{m}}}
$$

\subsubsection{Voluntário em pé}

As forças que agem sobre a perna quando realiza exercício de flexão do joelho com o indivíduo em pé pode ser visualizada através do diagrama de corpo livre mostrado na figura 37.
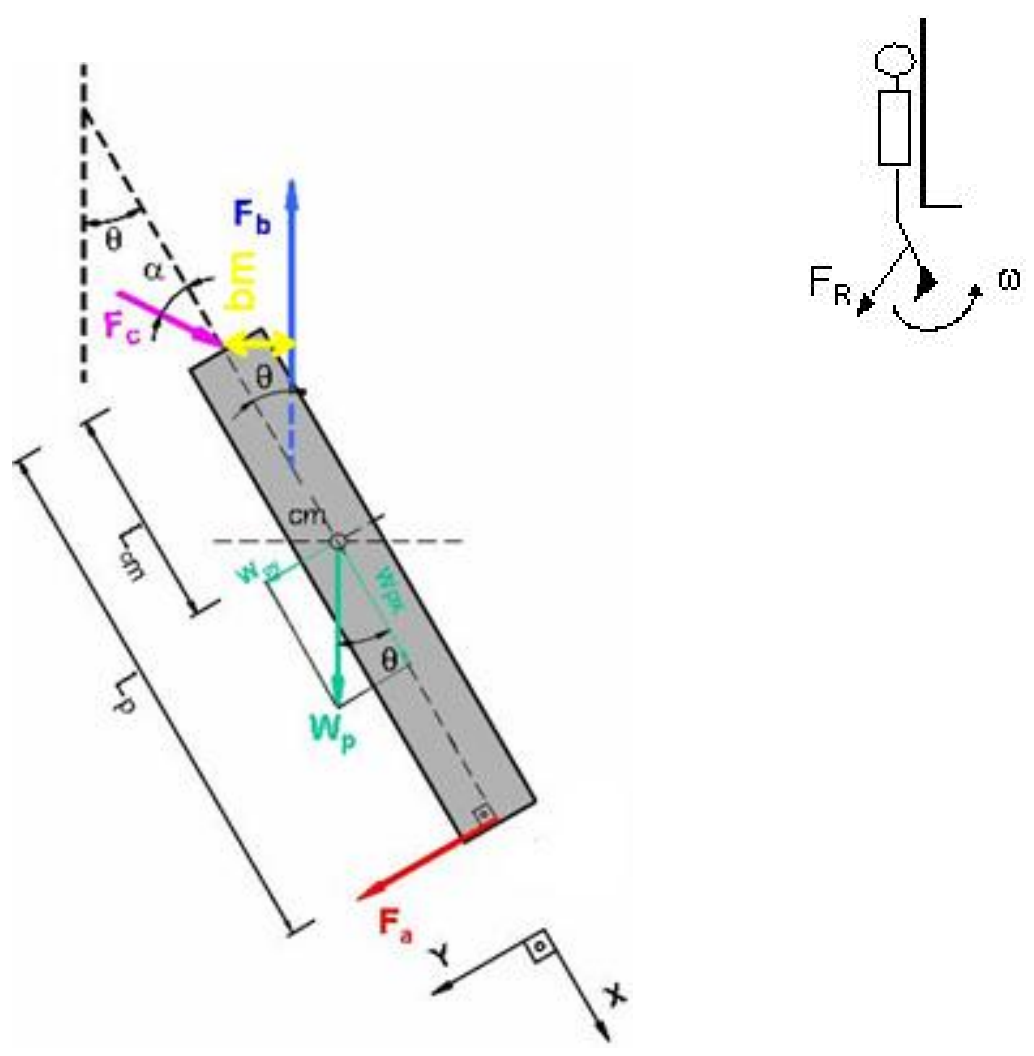

Figura 37. Diagrama de corpo livre representando a perna de um indivíduo em pé. 
A partir do diagrama da figura 37 e considerando que $\sum \tau=\mathrm{I} \alpha$, tem-se que:

$$
-\mathrm{F}_{\mathrm{a}} \cdot \mathrm{L}_{\mathrm{p}}-\mathrm{W}_{\mathrm{p}} \cdot \operatorname{sen} \theta \cdot \mathrm{L}_{\mathrm{cm}}+\mathrm{F}_{\mathrm{b}} \cdot \mathrm{bm}=\mathrm{I} \alpha
$$

A partir desta equação, pode-se determinar que a força do grupo muscular isquiotibial, quando o indivíduo está em pé, é dada por:

$$
\mathrm{F}_{\mathrm{b}}=\frac{\mathrm{F}_{\mathrm{a}} \cdot \mathrm{L}_{\mathrm{P}}+\mathrm{W}_{\mathrm{P}} \cdot \operatorname{sen} \theta \cdot \mathrm{L}_{\mathrm{Cm}}+\mathrm{I} \alpha}{\mathrm{b}_{\mathrm{m}}}
$$

\subsubsection{Voluntário sentado}

O diagrama de corpo livre quando um indivíduo realiza exercício de flexão do joelho na posição sentada pode ser visualizado na figura 38.

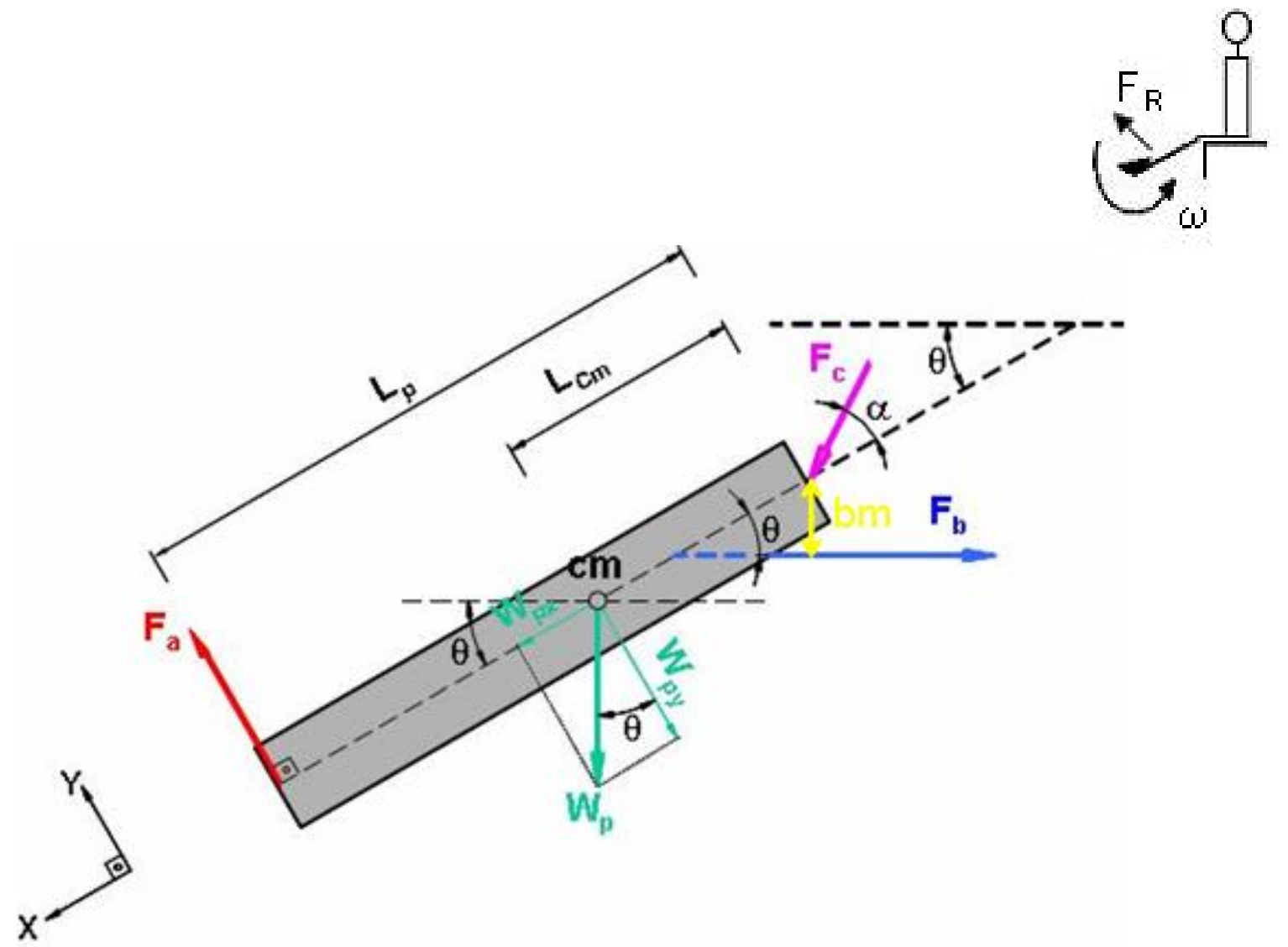

Figura 38. Diagrama de corpo livre representando a perna de um indivíduo sentado. 
A partir do diagrama da figura 38 e considerando que $\sum \tau=\mathrm{I} \alpha$ temos que:

$$
-\mathrm{F}_{\mathrm{a}} \cdot \mathrm{L}_{\mathrm{p}}-\mathrm{W}_{\mathrm{p}} \cdot \cos \theta \cdot \mathrm{L}_{\mathrm{cm}}+\mathrm{F}_{\mathrm{b}} \cdot \mathrm{bm}=\mathrm{I} \alpha
$$

De onde se pode determinar que a força dos isquiotibiais, considerando o indivíduo sentado, é dada por:

$$
\mathrm{F}_{\mathrm{b}}=\frac{\mathrm{F}_{\mathrm{a}} \cdot \mathrm{L}_{\mathrm{P}}+\mathrm{W}_{\mathrm{P}} \cdot \operatorname{sen} \theta \cdot \mathrm{L}_{\mathrm{Cm}}+\mathrm{I} \alpha}{\mathrm{b}_{\mathrm{m}}}
$$

\subsubsection{Voluntário em decúbito lateral}

A figura 39 mostra o diagrama de corpo livre para o indivíduo em decúbito lateral. Nesta posição, a força peso não possui componentes atuando na direção do movimento, portanto, não aparece no diagrama. Assim, considerando que $\sum \tau=\mathrm{I} \alpha$, podemos determinar a força do grupo muscular:

$$
-\mathrm{F}_{\mathrm{a}} \cdot \mathrm{L}_{\mathrm{p}}+\mathrm{F}_{\mathrm{b}} \cdot \mathrm{bm}=\mathrm{I} \alpha
$$

Logo:

$$
F_{b}=\frac{I \cdot \alpha+F_{a} \cdot L_{p}}{b_{m}}
$$




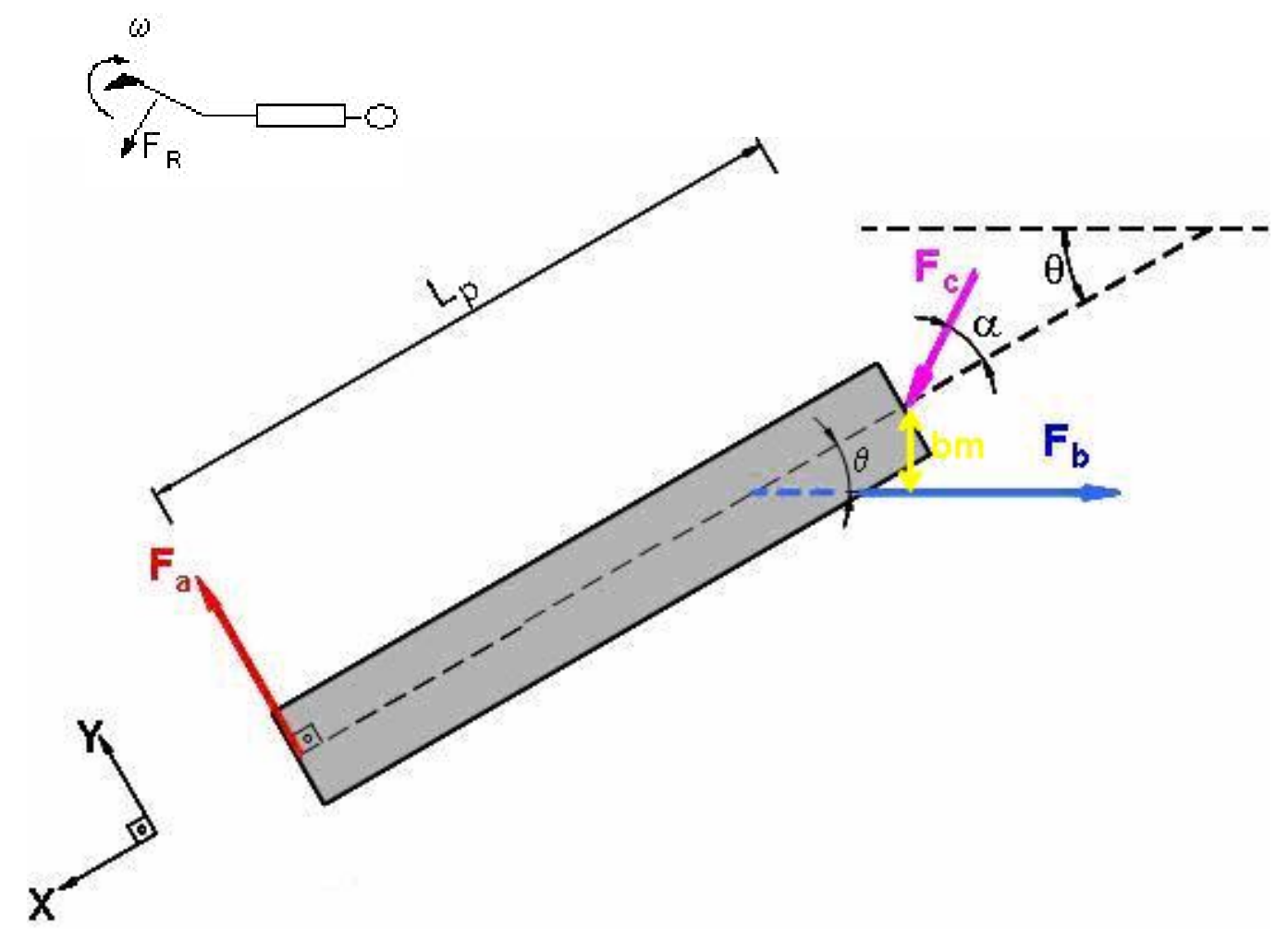

Figura 39. Diagrama de corpo livre representando a perna de um indivíduo em decúbito lateral.

A seguir, apresenta-se a tabela 6, que reúne as equações para a força do grupo muscular isquiotibial nas diferentes posições, conforme foram apresentadas acima. A diferença entre todas as posições reside na atuação da força peso da perna. Em todas as equações aparece o termo I $\alpha$, que representa o torque resultante $\left(\sum \tau=\mathrm{I} \alpha\right)$. No entanto, quando se tem o caso particular de movimento com velocidade constante (w=cte) a aceleração angular é zero e este termo se anula. 
Tabela 6. Equações da força do grupo muscular isquiotibial para diferentes posições do indivíduo na realização da flexo-extensão do joelho.

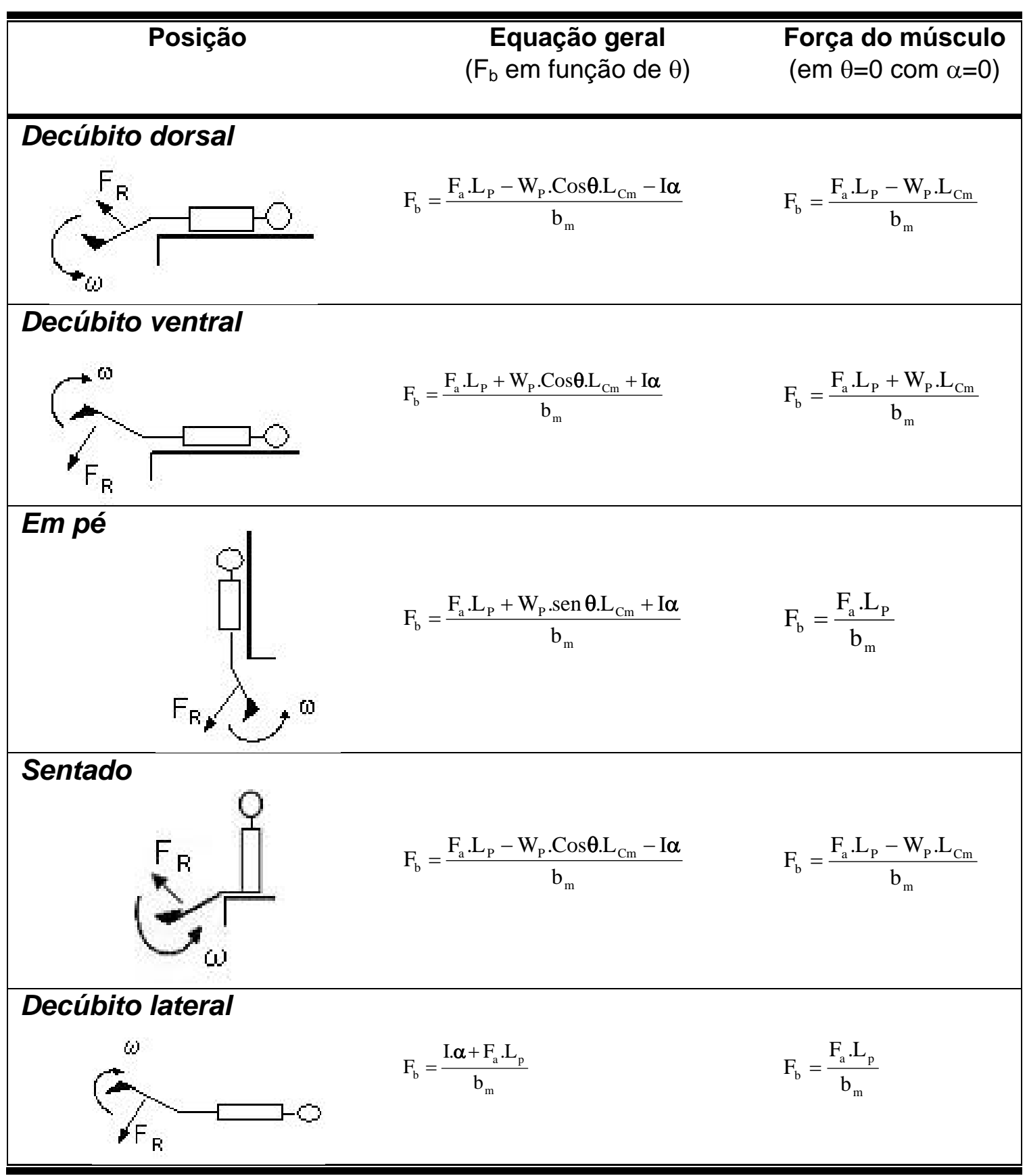


Na coluna da direita da tabela 6, apresenta-se a expressão da força dos isquiotibiais considerando a aproximação de que $\mathbf{l} \alpha=0$, na posição inicial, ou seja, quando $\theta=0$. Em todas as expressões, na posição inicial aparece 0 termo $F_{a} L_{p}$ que representa o torque gerado pela força de resistência aplicada. Em decúbito lateral e em pé, para iniciar o movimento, os isquiotibiais devem vencer apenas o torque aplicado pela força externa, pois a contribuição do peso da perna é nula quando o ângulo $\theta$ é igual a zero. Já, em decúbito dorsal ou sentado e decúbito ventral, a contribuição do torque deve ser considerado, devido ao peso $\left(\mathbf{W}_{\mathbf{p}} \mathbf{L}_{\mathbf{c m}}\right)$ no início do movimento.

\subsection{Simulação da força dos isquiotibiais}

Foi realizada uma série de simulações da força exercida pelo grupo muscular isquiotibial, durante exercícios de flexão do joelho, em diversas posições, utilizando-se como força de resistência externa a corda elástica e o peso fixo. Para as simulações, considerou-se que a força da corda elástica é dada pela equação 5, e que o sistema de alavanca multiplica a força conforme descrito pela equação 3. Considerou-se, ainda, que quando a perna está acoplada à roda e a ação muscular faz a roda girar um ângulo $\theta$, a variação de comprimento da corda é igual ao arco descrito pelo movimento da roda. Isto significa que, se a roda de raio $R_{R}$ sofre um deslocamento angular $\theta$, a corda sofrerá uma variação no seu comprimento dada por $\Delta L=\theta R_{R}$, sendo $\theta$ em radianos. Com estas considerações, a força elástica aplicada ao membro pela roda pode ser simulada pela seguinte equação:

$$
\mathbf{F}_{\mathrm{A}}=\gamma \mathrm{A}\left(\mathbf{R}_{\mathbf{R}} \theta / \mathbf{L}_{\mathrm{o}}\right)^{\mathrm{n}}\left(\mathbf{R}_{\mathbf{R}} / \mathbf{L}_{\mathrm{P}}\right)
$$

Onde $\gamma \mathrm{A}=44,7 \mathrm{~N}$ é um parâmetro que está relacionado com a espessura da corda, obtido pelo ajuste experimental de uma corda Lengruber 204; $R_{R}=35 \mathrm{~cm}$ é o raio da roda; $\theta$ é a posição angular da perna; $L_{0}=60 \mathrm{~cm}$ é o comprimento inicial da corda; $\mathbf{n}=0,5$ é o fator exponencial da expressão, 0 qual relaciona tensão com a deformação na corda e, finalmente, $L_{P}=43,4 \mathrm{~cm}$ é 
o comprimento da perna. Estes valores são aqueles descritos no capítulo de materiais e métodos, sendo que, o comprimento da perna foi definido considerando um indivíduo de 1,73 m de altura.

Para simular a força muscular, quando se coloca na roda um peso fixo para oferecer a resistência, deve-se considerar apenas que a roda faz o papel de uma alavanca, conforme mostra a equação 3, resultando em:

$$
F_{A}=W\left(R_{R} / L_{P}\right)
$$

Onde $W$ é o peso das anilhas colocadas no sistema, $R_{R}$ é o Raio da roda e $L_{P} 0$ comprimento da perna.

Assim, considerando as equações acima, para a corda elástica ou para o peso fixo, e cada equação da força do grupo muscular isquiotibial, para cada posição do indivíduo que seja de interesse, obtém-se a força muscular em função da posição angular da perna.

A figura 40 apresenta a simulação da força do grupo muscular isquiotibial no exercício de flexão do joelho, considerando o indivíduo em decúbito dorsal e diferentes números de cordas colocadas no sistema mecânico para a realização do exercício. A figura 41, por sua vez, simula a mesma situação, mas utilizando diferentes pesos no sistema mecânico de exercício.

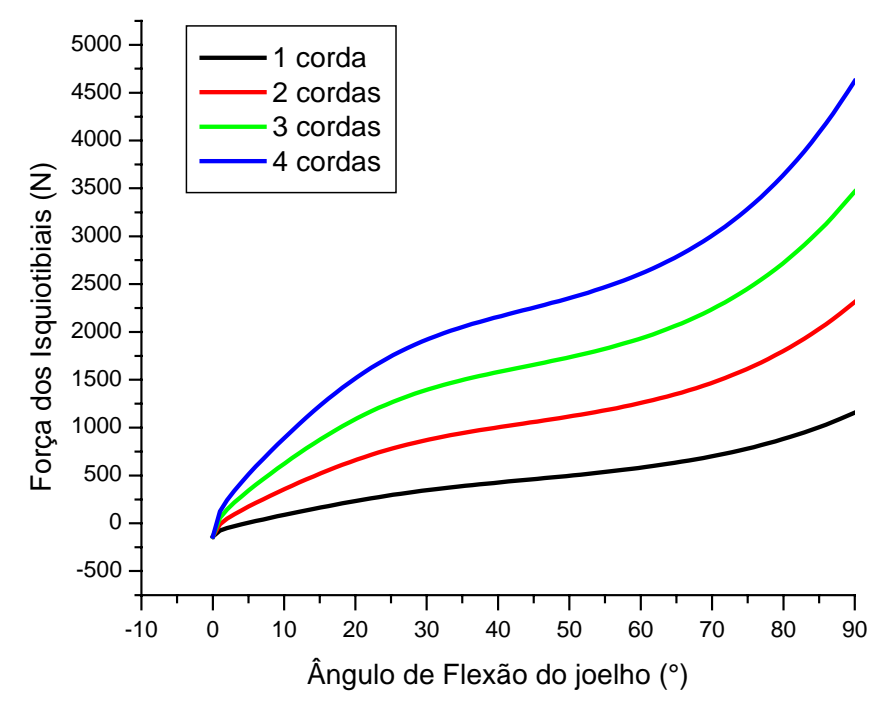

Figura 40. Simulação da força dos isquiotibiais em exercícios de flexão do joelho, considerando o indivíduo em decúbito dorsal, utilizando-se diferentes números de corda elástica. 


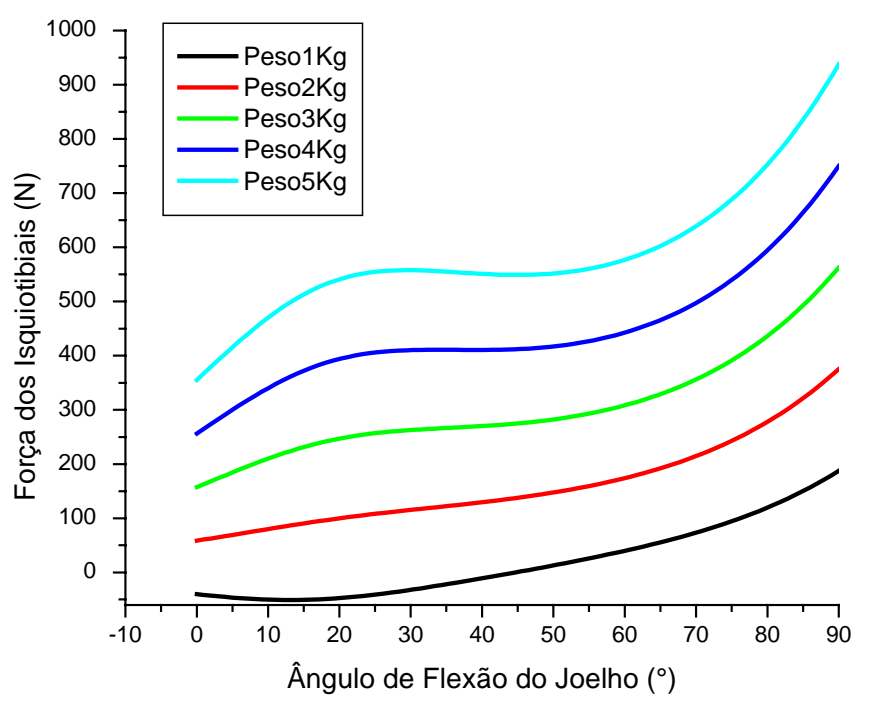

Figura 41. Simulação da força dos isquiotibiais em exercícios de flexão do joelho, considerando o indivíduo em decúbito dorsal, utilizando-se diferentes pesos.

$\mathrm{Na}$ figura 42, observa-se a força dos músculos isquiotibiais no movimento de flexão do joelho, considerando o indivíduo em decúbito dorsal e utilizando situações de exercício com corda elástica, peso fixo e sem nenhuma resistência, ou seja, $F_{a}=0$. Esse comportamento das curvas de força também é observada nos exercícios realizados com o indivíduo sentado, pois os modelos utilizados não levam em consideração a posição do quadril. Quando a corda elástica é aplicada como resistência ao movimento, a força muscular se inicia em zero e aumenta progressivamente. Quando o peso fixo é utilizado, o início do movimento requer uma força muscular de valores mais altos, neste caso próximo de $200 \mathrm{~N}$. 


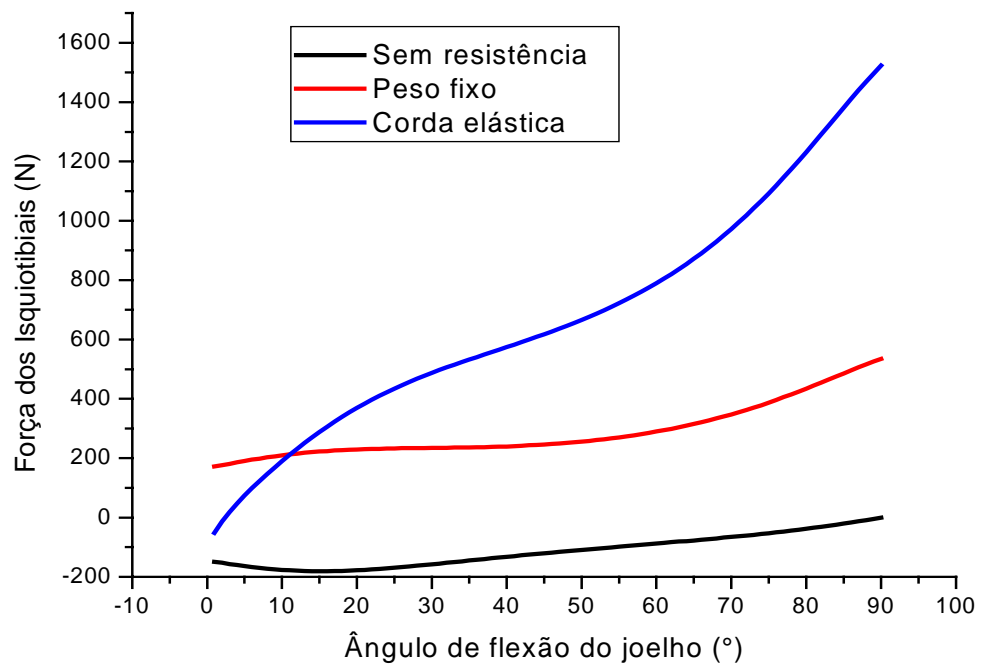

Figura 42. Simulação da força dos isquiotibiais em exercícios de flexão do joelho, considerando o indivíduo em decúbito dorsal, utilizando-se diferentes tipos de resistências.

A figura 43 mostra a força do grupo muscular isquiotibial na posição de decúbito lateral em duas situações: uma quando se utiliza a corda elástica como recurso para oferecer resistência ao exercício e outra, quando a resistência é obtida com o uso do peso fixo.

$\mathrm{Na}$ figura 44 estão simuladas as curvas da força muscular obtidas quando se considera um indivíduo realizando o movimento de flexão do joelho em pé e utilizando a corda elástica e o peso fixo como resistência e também sem resistência, ou seja, considerando apenas o peso da própria perna, o qual não é desprezível.

A figura 45 apresenta as simulações da força dos isquiotibiais quando a flexão do joelho é realizada sem resistência, com a corda elástica e com o peso fixo, e com o indivíduo em decúbito ventral. Neste caso, tem-se novamente diferença nos valores iniciais da força do grupo muscular quando se compara a utilização da corda e do peso. 


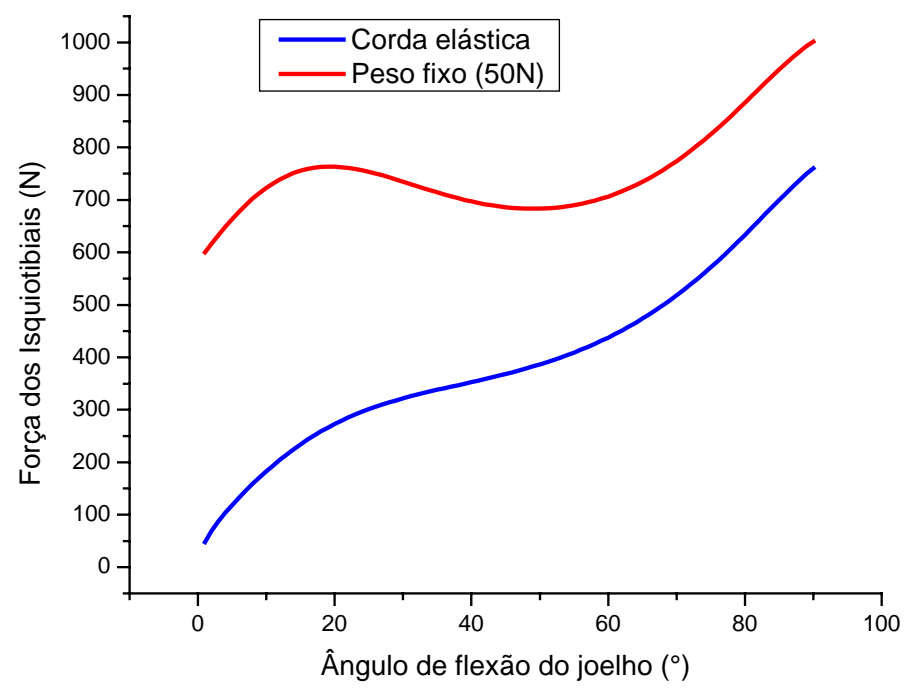

Figura 43. Simulação da força dos isquiotibiais em exercícios de flexão do joelho, considerando o indivíduo em decúbito lateral, utilizando-se diferentes tipos de resistências.

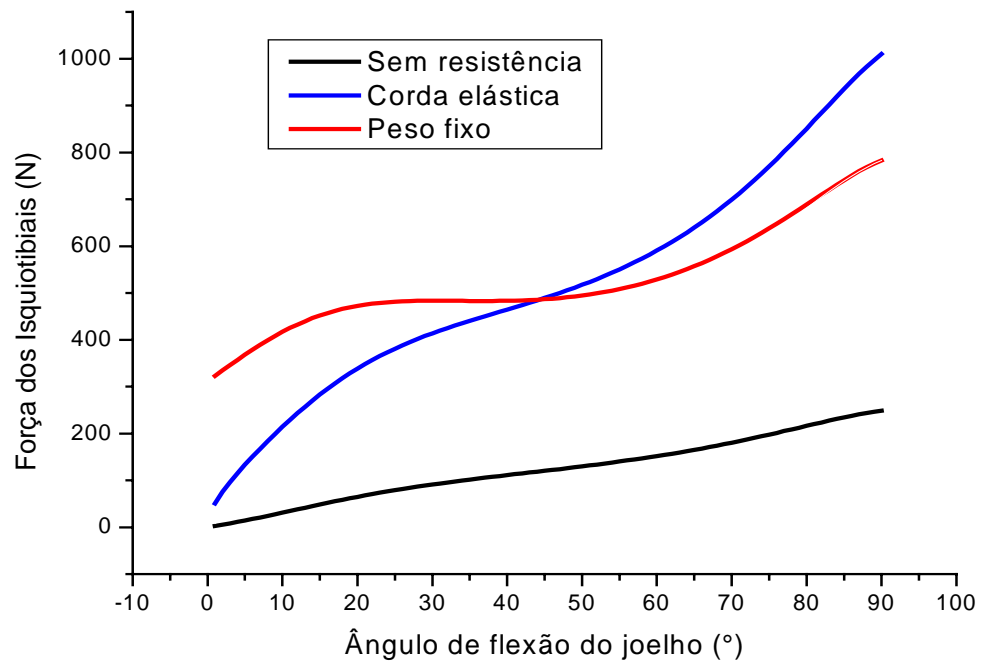

Figura 44. Simulação da força dos isquiotibiais em exercícios de flexão do joelho, considerando o indivíduo em pé, utilizando-se diferentes tipos de resistências. 


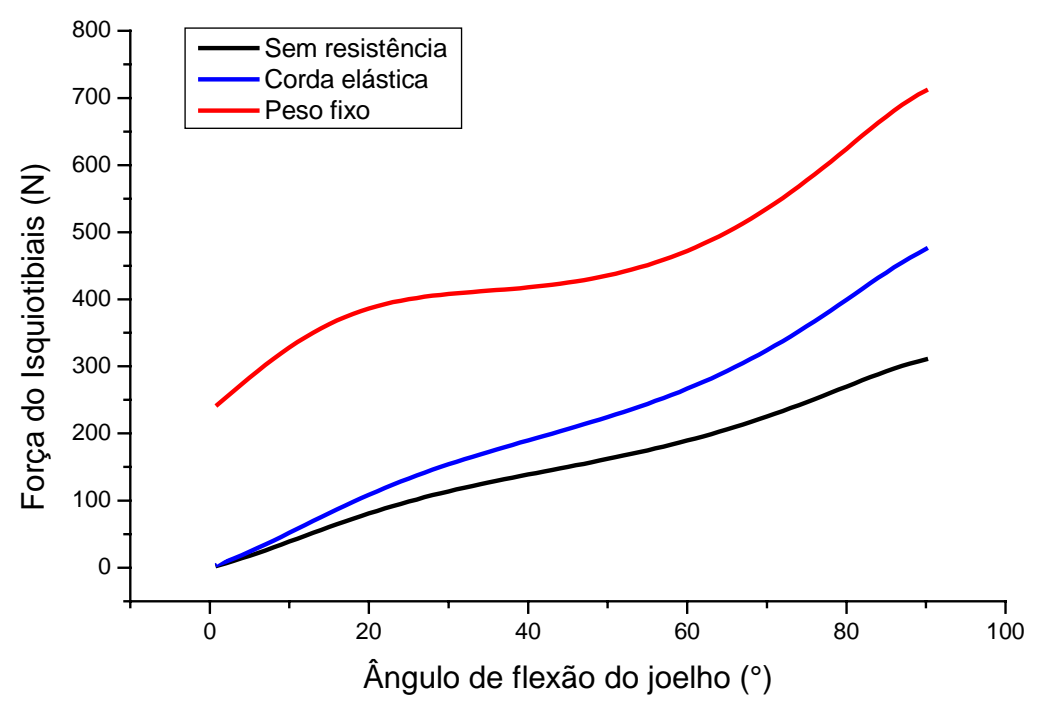

Figura 45. Simulação da força dos isquiotibiais em exercícios de flexão do joelho, considerando o indivíduo em decúbito ventral, utilizando-se diferentes tipos de resistências.

Para uma melhor visualização das diferenças que existem no comportamento da força muscular em diferentes situações, foram elaboradas as figuras 46 e 47. Estas figuras apresentam gráficos que contém as curvas de força dos isquiotibiais quando um indivíduo realiza exercício de flexão do joelho com a corda elástica como resistência (figura 46) e quando faz o mesmo movimento, no entanto, com uma resistência fixa (figura 47). Em ambos os casos, foi considerado o indivíduo nas posições descritas acima, ou seja, decúbito dorsal, cujo comportamento da força é igual ao sentado, decúbito ventral, decúbito lateral e em pé. 


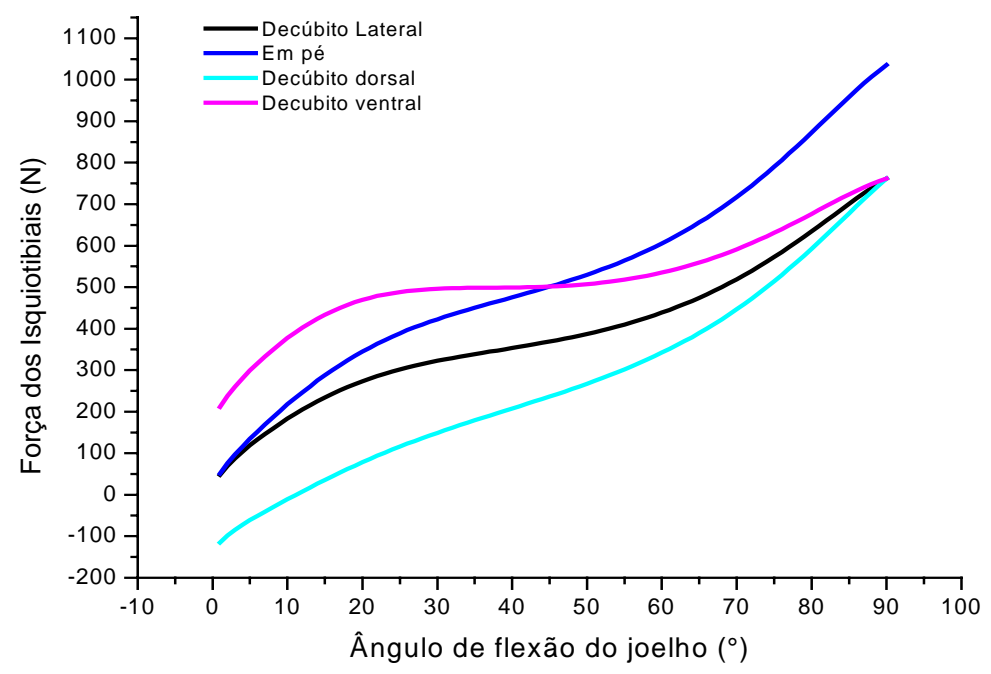

Figura 46. Simulação da força dos isquiotibiais em exercícios de flexão do joelho, considerando o indivíduo em diferentes posições e a corda elástica como resistência.

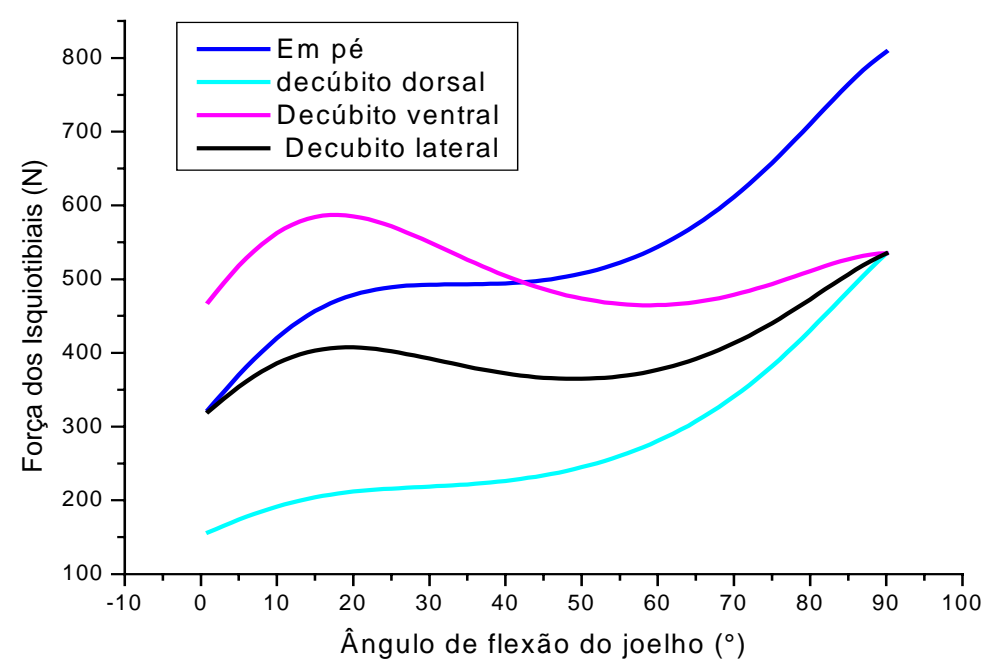

Figura 47. Simulação da força dos isquiotibiais em exercícios de flexão do joelho, considerando o indivíduo em diferentes posições e o peso fixo como resistência.

Baseando-se na visualização dos resultados apresentados, adotou-se o decúbito dorsal como posicionamento dos voluntários para a realização dos ensaios experimentais. Pode-se observar que, neste caso, tem-se a melhor diferenciação entre a força gerada pelo grupo muscular isquiotibial quando se usa a corda elástica e àquela gerada quando se utiliza o peso fixo. Houve o interesse de que as forças tivessem perfis distintos para facilitar a correlação 
com o sinal eletromiográfico captado. Além disso, foi levado em consideração, também, a questão da praticidade do sistema mecânico de exercício para a adoção desta posição.

\subsection{Ensaios experimentais}

O protocolo experimental foi aplicado em dez voluntários para se observar o comportamento da força dos isquiotibiais. No entanto, foram selecionados os dados de um voluntário para a visualização geral desse comportamento. Os resultados dos demais voluntários podem ser visualizados nos apêndices B (coletas realizadas com a corda elástica) e C (coletas realizadas com o peso fixo).

Com o objetivo de correlacionar a força interna dos isquiotibiais com a atividade elétrica da cabeça longa do bíceps femoral, registrou-se os dados da posição do membro; da força aplicada e do sinal de eletromiográfico. Esses dados foram tratados por meio de rotinas matemáticas desenvolvidas conforme feita anteriormente.

Antes de se iniciar a coleta de dados propriamente dita solicitou-se que o voluntário realizasse uma contração voluntária muscular isométrica máxima com o joelho em $90^{\circ}$, registrando a força isométrica máxima bem como o sinal de EMG. A partir desses dados, determinou-se os valores das sobrecargas tanto para o peso fixo quanto para a corda. Os valores de força máxima e o RMS do sinal de EMG atingidos nessas condições, por cada voluntário, e as resistências preconizadas para o desenvolvimento do protocolo experimental podem ser visualizados na tabela 7 . 
Tabela 7. Valores médios de força da contração voluntária isométrica máxima (CVIM), da resistência fixa, da resistência elástica e do RMS do sinal de EMG em $90^{\circ}$.

\begin{tabular}{ccccc}
\hline \hline Voluntários & CVIM (Kgf) & RMS_Bíceps & $\mathbf{N}^{\circ}$ de cordas & Peso (Kg) \\
\hline $\mathbf{1}$ & $21,52 \pm 1,11$ & $159,07 \pm 25,77$ & 3 & 10 \\
$\mathbf{2}$ & $21,33 \pm 2,9$ & $190,72 \pm 36,90$ & 2 & 12 \\
$\mathbf{3}$ & $12,00 \pm 0,93$ & $70,87 \pm 12,02$ & 2 & 6 \\
$\mathbf{4}$ & $20,40 \pm 2,12$ & $323,00 \pm 72,23$ & 2 & 8 \\
$\mathbf{5}$ & $26,00 \pm 1,45$ & $321,05 \pm 59,60$ & 2 & 11 \\
$\mathbf{6}$ & $22,36 \pm 1,28$ & $160,50 \pm 25,98$ & 3 & 11 \\
$\mathbf{7}$ & $21,07 \pm 1,32$ & $157,00 \pm 28,11$ & 3 & 11 \\
$\mathbf{8}$ & $27,25 \pm 0,65$ & $223,27 \pm 38,00$ & 3 & 11 \\
$\mathbf{9}$ & $18,47 \pm 1,48$ & $147,46 \pm 36,26$ & 2 & 9 \\
$\mathbf{1 0}$ & $11,86 \pm 1,13$ & $65,80 \pm 11,32$ & 2 & 6 \\
\hline \hline
\end{tabular}

Inicialmente, estão apresentados os dados referentes aos exercícios usando a corda elástica como resistência externa. A figura 48 mostra os dados da força gerada pelo grupo muscular isquiotibial, calculada segundo o modelo biomecânico para as condições experimentais adotadas, os dados do sinal eletromiográfico captados da cabeça longa do bíceps femoral; da posição angular da perna durante o arco de flexo-extensão e a tensão na célula de carga. Observa-se que, todos esses sinais foram normalizados na base do tempo. Além disso, o pico do sinal de EMG ocorre antes de 50\% do ciclo. 

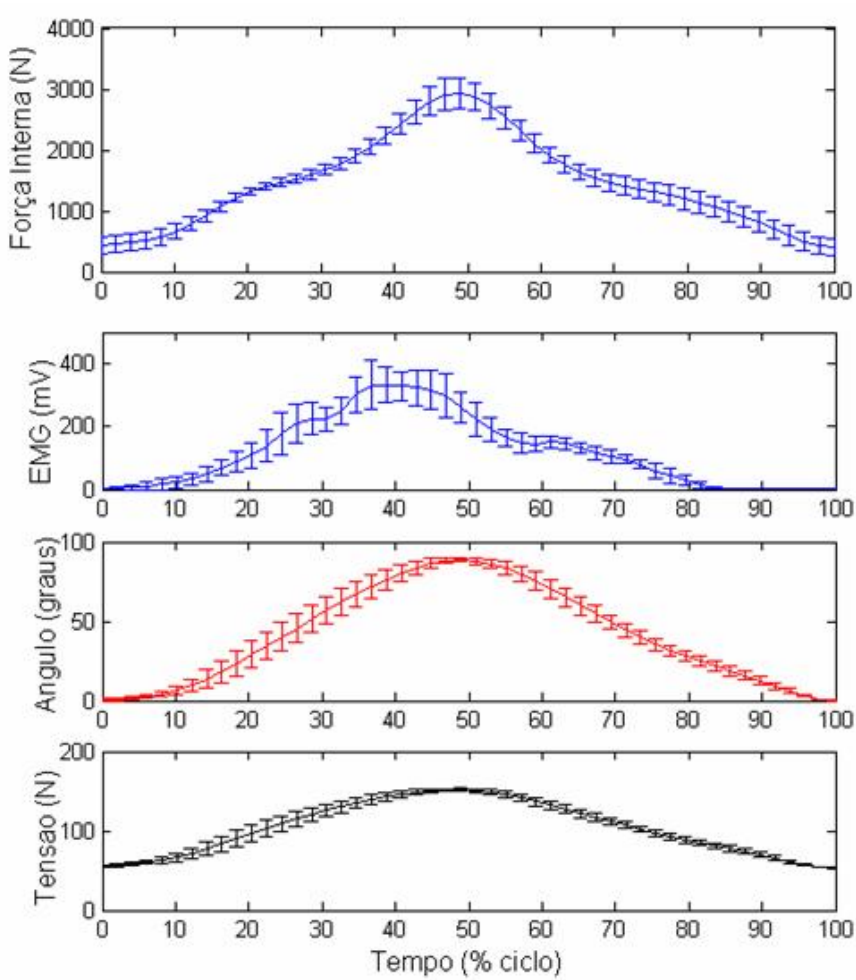

Figura 48. Força interna dos isquiotibiais, intensidade do sinal EMG, posição angular da perna e tensão da corda elástica normalizados na base do tempo.

A velocidade e a aceleração angular, durante os movimentos de flexoextensão do joelho, foram obtidas pela derivação da curva da posição angular da perna e podem ser visualizadas na figura 49, em função do tempo (normalizado). Além disso, pode-se observar que a velocidade e a aceleração angular são menores na fase excêntrica do movimento, ou seja, durante a extensão do joelho. 

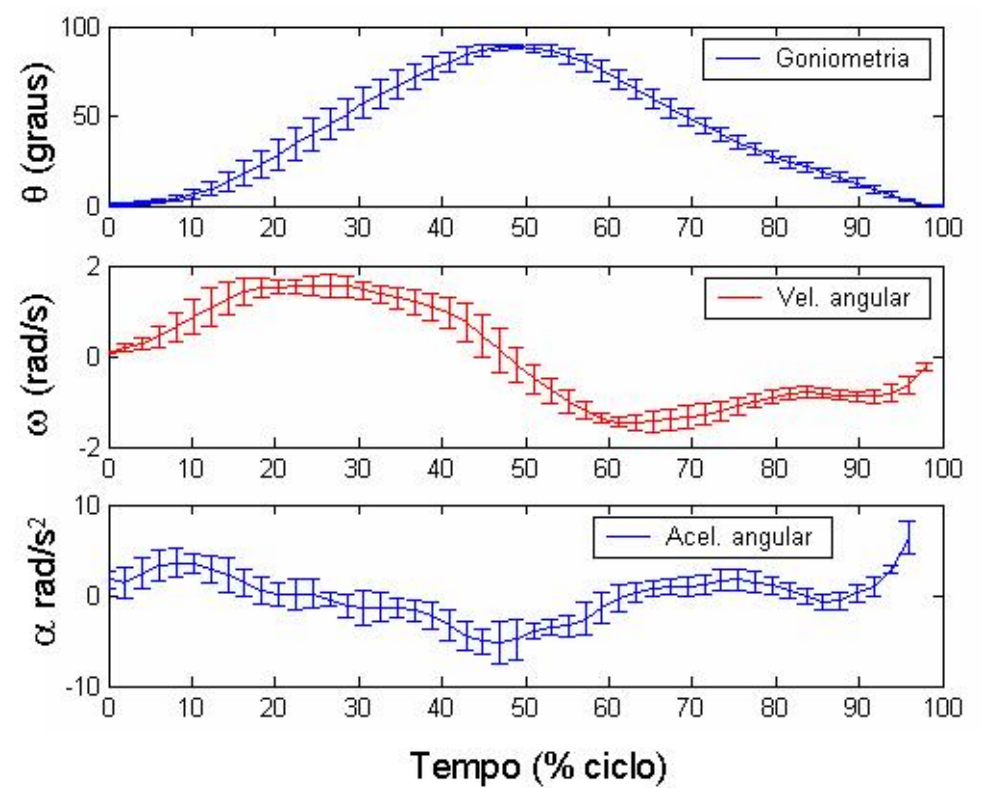

Figura 49. Velocidade e aceleração angular, durante o movimento de flexo-extensão do joelho com a corda elástica como resistência.

Para uma melhor visualização e possíveis comparações entre a força e o sinal eletromiográfico, os dados foram normalizados em função da força máxima do grupo muscular alcançada pelo voluntário na condição isométrica e do sinal eletromiográfico correspondente. O valor médio da força isométrica máxima e do sinal eletromiográfico constitui, assim, uma referência individual em cada exercício.

$\mathrm{Na}$ figura 50 estão apresentadas as curvas de força, torque e eletromiografia durante o movimento de flexo-extensão, normalizados pela força, torque e EMG da contração isométrica máxima, respectivamente. Podese observar que o pico da força ocorre ligeiramente antes de $50 \%$ do ciclo e nunca atinge o valor 1 . Isso ocorre porque esse valor representa a força máxima alcançada em 90 graus pelo voluntário durante contração isométrica. 

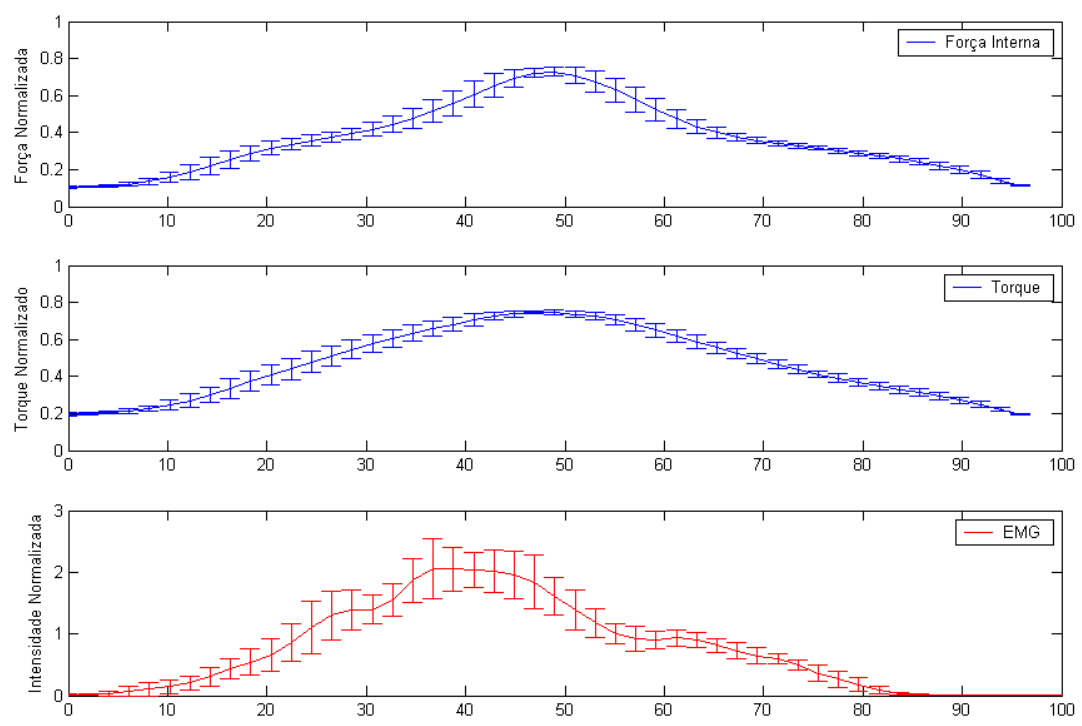

Figura 50. - Curvas de força dos isquiotibiais, de torque e de sinal EMG, normalizadas pela contração voluntária isométrica máxima em 90 graus, de movimentos de flexo-extensão do joelho com a corda elástica como resistência.

A figura 51 apresenta a força calculada para o grupo muscular isquiotibial e seu respectivo sinal eletromiográfico, ambos em função do ângulo de movimento $(\theta)$ e separados em fase excêntrica e concêntrica dos movimentos de flexo-extensão.
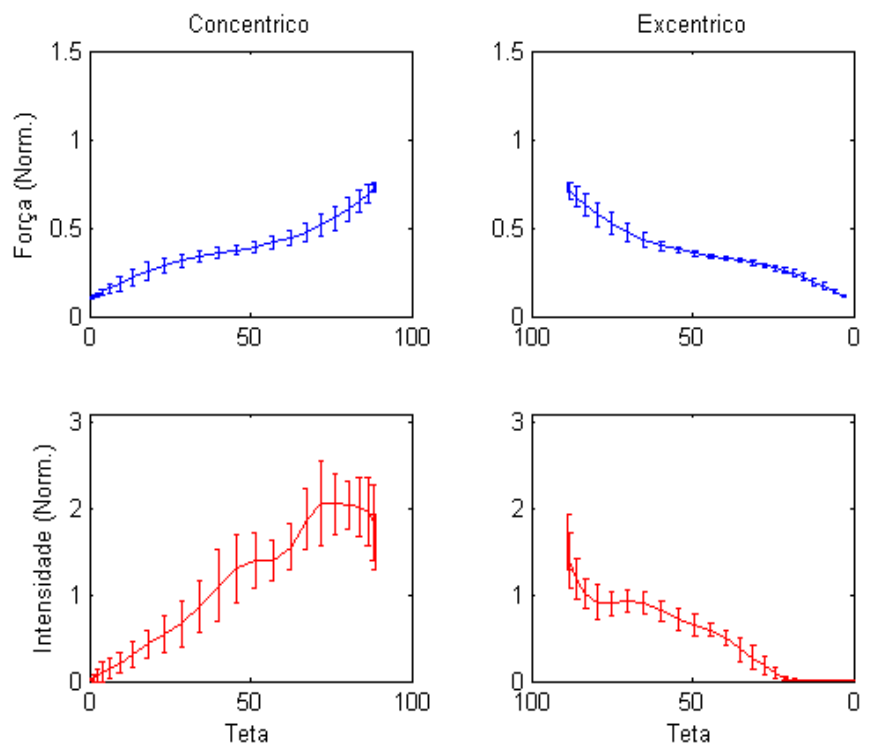

Figura 51. Relação da força dos isquiotibiais e da intensidade do sinal EMG com o ângulo de flexão do joelho $(\theta)$, nas fases concêntrica e excêntrica de exercícios com corda elástica como resistência. 
$\mathrm{Na}$ seqüência, pode-se visualizar a correlação feita entre a força muscular e o sinal EMG obtidos, também separados em fase concêntrica e excêntrica (figura 52).
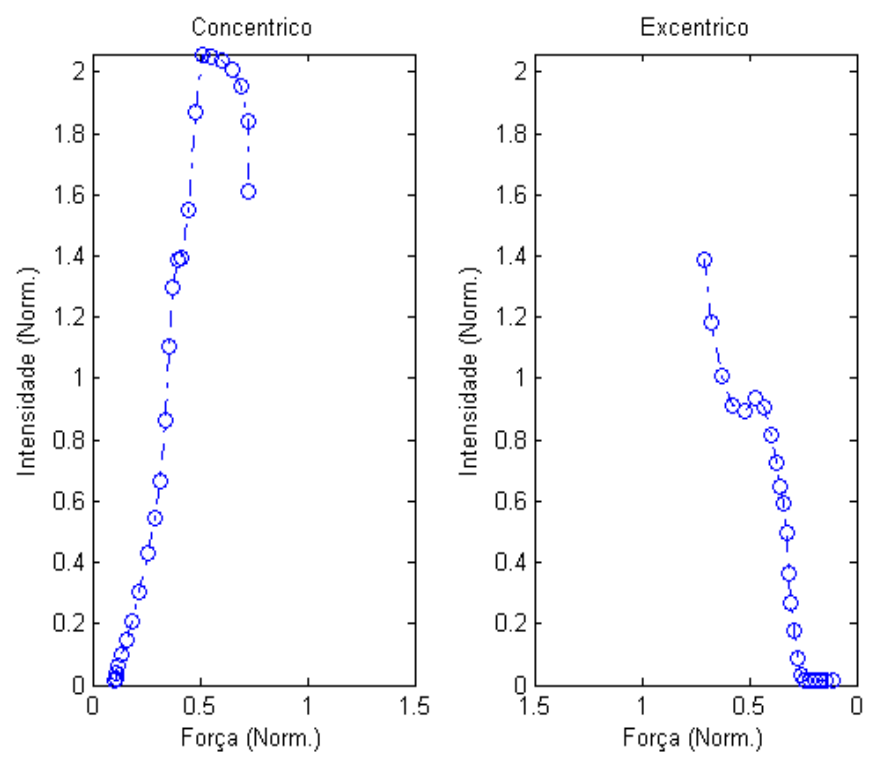

Figura 52. Relação entre a intensidade do sinal EMG normalizado e a força dos isquiotibiais normalizada nas fases concêntrica e excêntrica de exercício realizado com corda elástica como resistência.

A relação entre força e sinal eletromiográfico é aproximadamente linear para a maioria dos indivíduos. No entanto, o sinal eletromiográfico começa a diminuir antes da força atingir seu valor máximo.

Além da relação entre força muscular e sinal eletromiográfico, foi calculado a relação entre sinal eletromiográfico e torque. Inicialmente, na figura 53, apresenta-se o torque e a eletromiografia em função da posição angular da perna e divididos em fase concêntrica e excêntrica do movimento. 

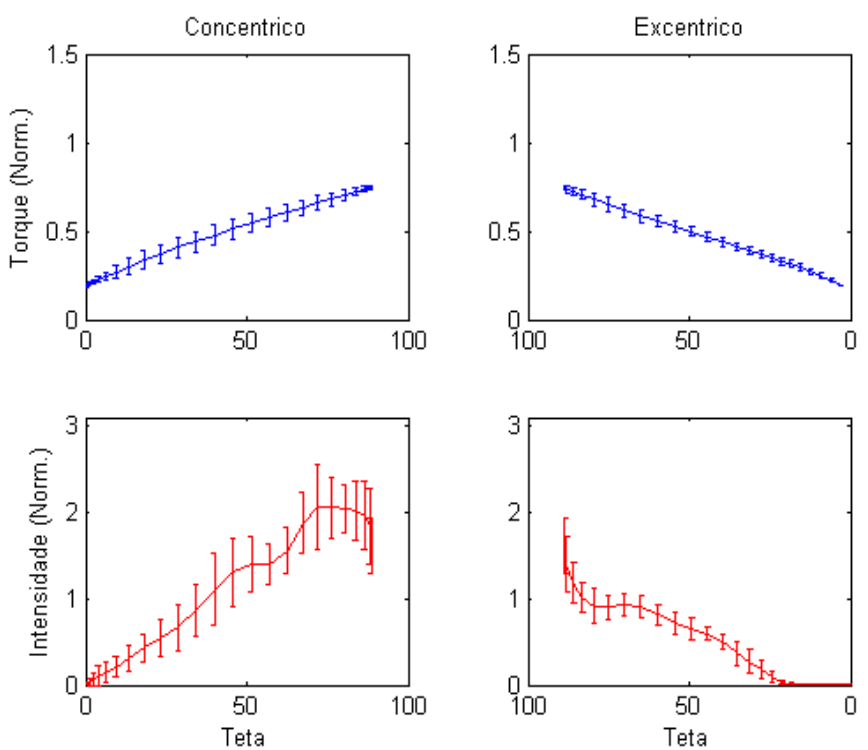

Figura 53. Relação do torque e da intensidade do sinal EMG com o ângulo de flexão do joelho $(\theta)$, nas fases concêntrica e excêntrica de exercícios realizados com corda elástica como resistência.

A figura 54, por sua vez, apresenta a relação obtida entre a intensidade do sinal eletromiográfico e torque gerado pelo sistema musculoesquelético, sendo que tal relação está dividida em fase concêntrica e excêntrica.
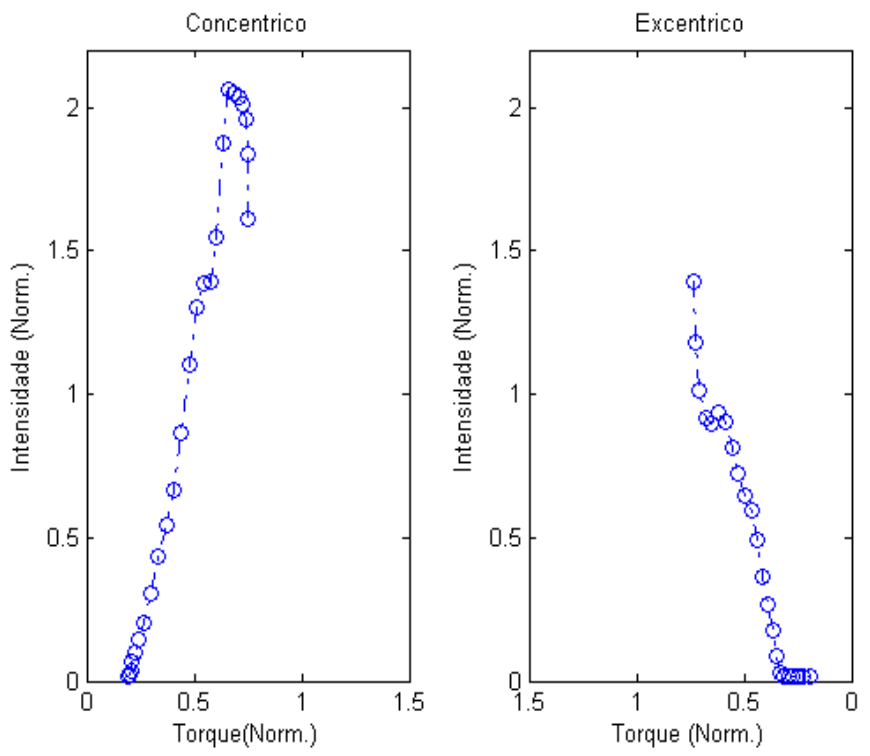

Figura 54. Relação entre a intensidade do sinal EMG normalizado e o torque normalizado, nas fases concêntrica e excêntrica de exercício realizado com corda elástica como resistência. 
Na seqüência, estão apresentados os dados tratados, obtidos da fase do protocolo experimental em que se realizou a flexo-extensão do joelho com resistência fixa no sistema mecânico de exercício. Os gráficos e as relações feitas para os dados obtidos nos exercícios feitos com a utilização da corda elástica foram repetidos àqueles obtidos para os dados dos exercícios feitos com peso fixo.

As figuras de número 55 a 61 representam os resultados dos dados tratados em rotina específica no MatLab. Pode-se observar que existe uma linearidade menor nas relações com o peso fixo e o sinal eletromiográfico atinge valores maiores que 1 (figuras 57-61).
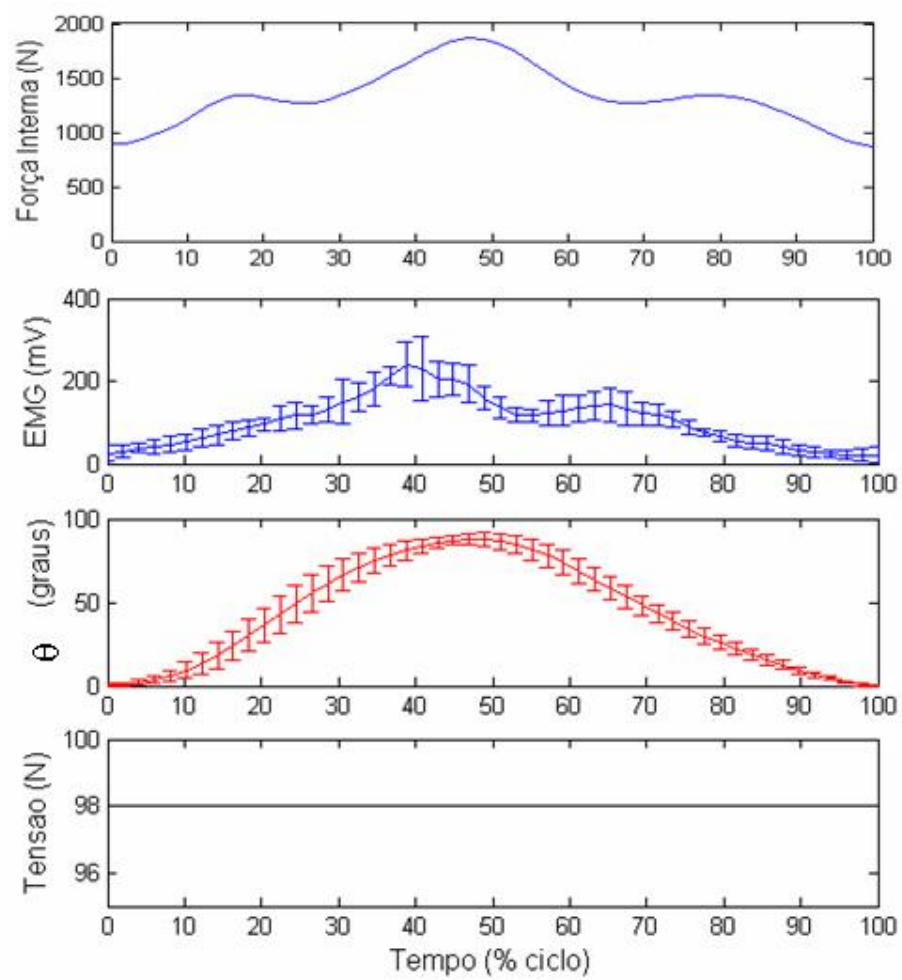

Figura 55. Força interna dos isquiotibiais, intensidade do sinal EMG, posição angular da perna e peso fixo normalizados na base do tempo. 

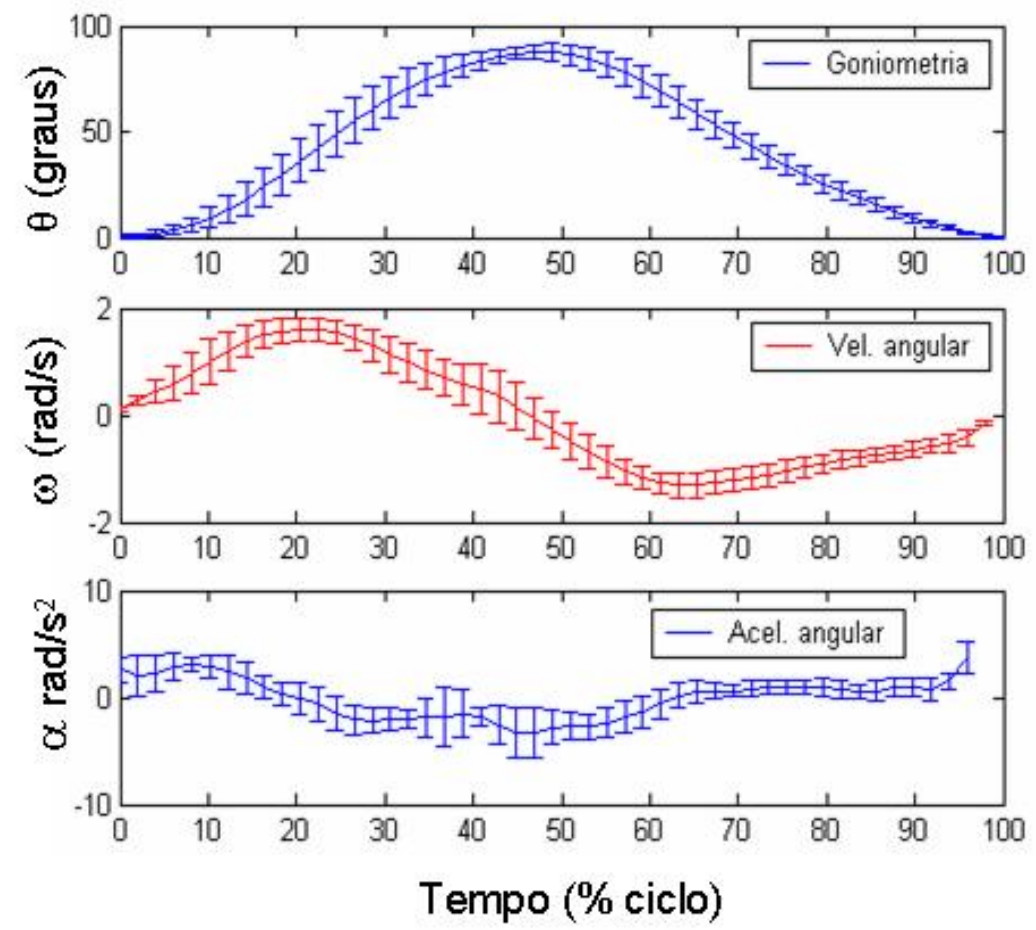

Figura 56. Velocidade e aceleração angular obtidas pela derivação da curva da posição angular da perna, durante o movimento de flexo-extensão do joelho com o peso fixo como resistência.
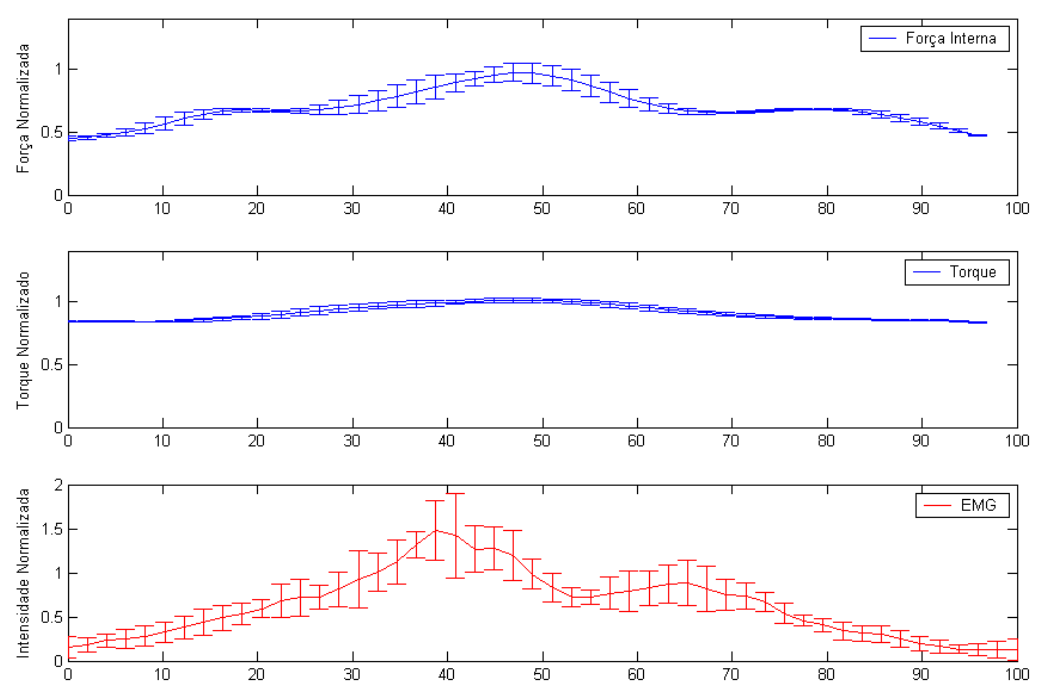

Figura 57. Curvas de força dos isquiotibiais, torque e sinal EMG, normalizados pela contração voluntária isométrica máxima em 90 graus, obtidas durante a flexo-extensão do joelho com o peso fixo como resistência. 

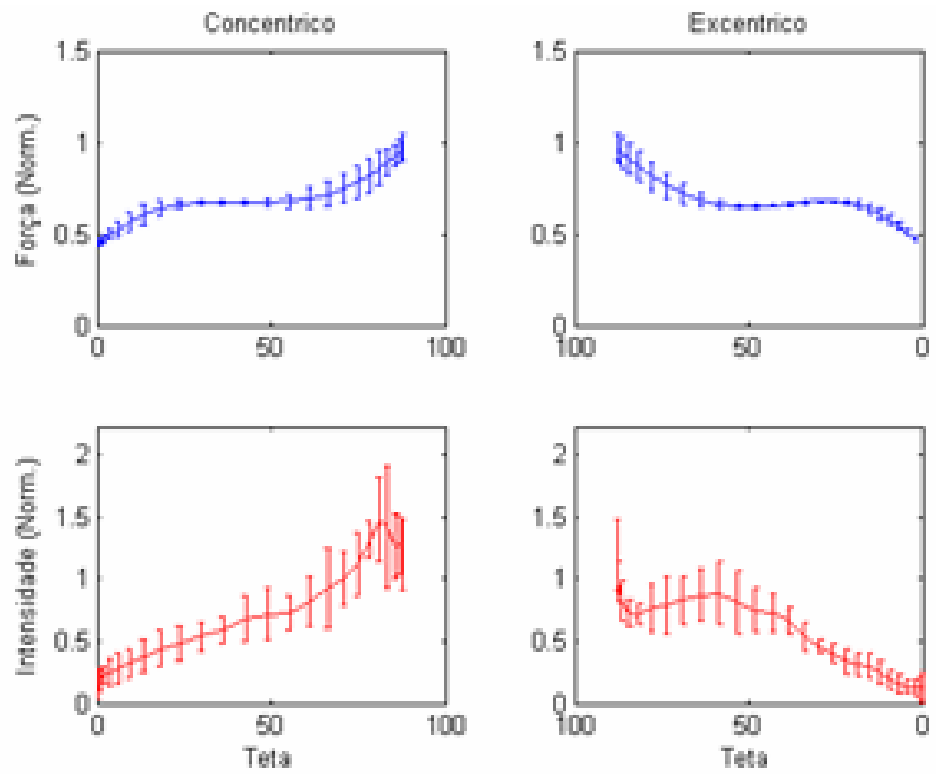

Figura 58. Relação da força dos isquiotibiais e da intensidade do sinal EMG com o ângulo de flexão do joelho $(\theta)$, nas fases concêntrica e excêntrica de exercício com peso fixo como resistência.
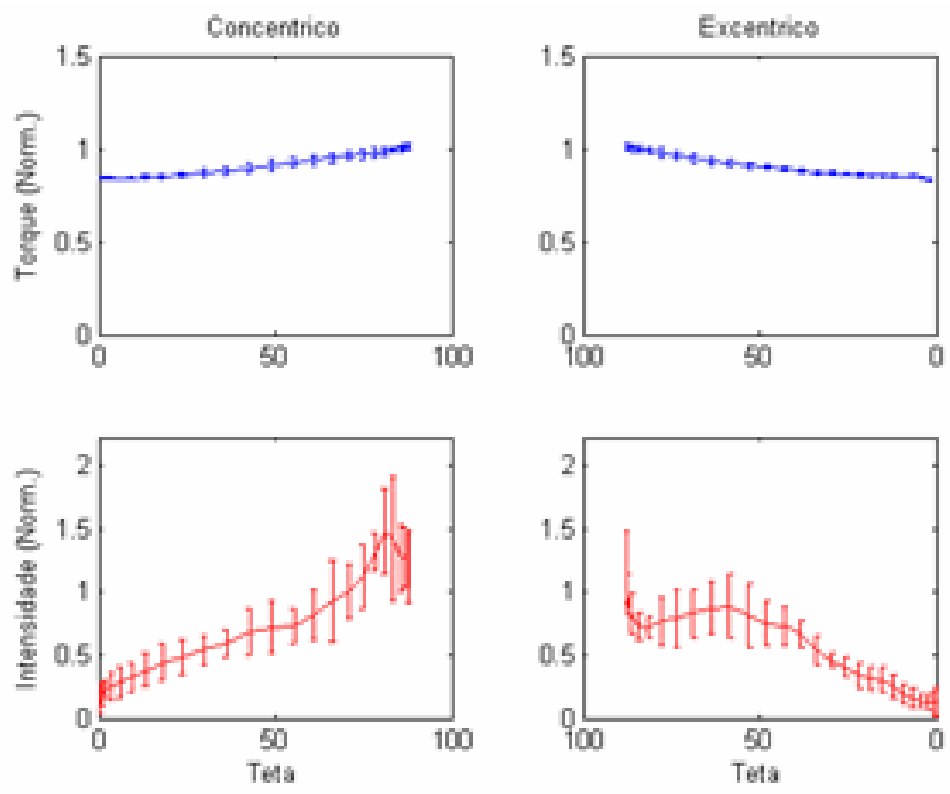

Figura 59. Relação entre a intensidade do sinal EMG normalizado e a força dos isquiotibiais normalizada, nas fases concêntrica e excêntrica de exercício realizado com peso fixo como resistência. 

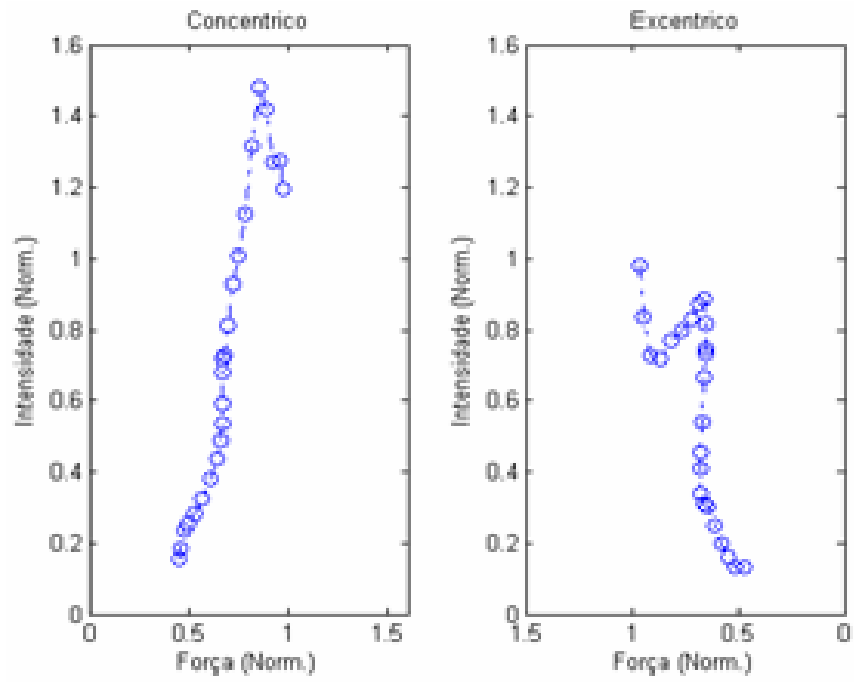

Figura 60. Relação do torque e da intensidade do sinal EMG com o ângulo de flexão do joelho $(\theta)$, nas fases concêntrica e excêntrica de exercício realizado com peso fixo como resistência.
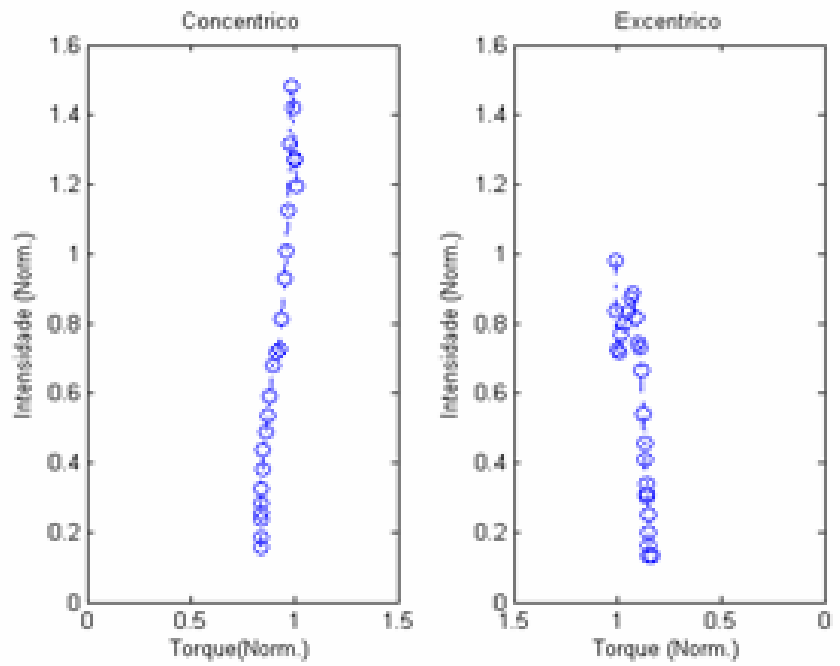

Figura 61. Relação entre a intensidade do sinal EMG normalizado e o torque normalizado, nas fases concêntrica e excêntrica de exercício realizado com peso fixo como resistência. 


\section{DISCUSSÃO}

O fortalecimento muscular consiste numa importante fase dos protocolos de reabilitação e, também, dos protocolos de treinamento. As modalidades de exercícios que envolvem o ganho de força muscular, além de serem as mais difundidas, consistem em um importante objeto de estudo (KISNER; COLBY, 1998; FRONTERA; DAWSON; SLOVIK; 2001; BARBANTI, 2002; YANAGAWA et al., 2002).

O aumento da força muscular é alcançado pela realização de exercícios, utilizando-se sobrecargas externas ao movimento, as quais são oferecidas através de resistências constantes ou variáveis. Para produzir uma resistência constante são aplicados os pesos fixos ao segmento exercitado, e uma resistência variável pode ser produzida pelo uso de materiais elásticos (resistência elástica) durante o arco de movimento (KISNER; COLBY, 1998; HINTERMEISTER et al., 1998; FRONTERA; DAWSON; SLOVIK; 2001; PATTERSON et al., 2001; BENATTI et al., 2003). Ao contrário dos pesos fixos, os materiais elásticos não vêm acompanhados de suas informações quantitativas, ou seja, os valores das suas resistências. Com isso, a seleção e a progressão dos níveis de resistência é subjetivo e, freqüentemente, dependente da percepção de esforço do indivíduo e do conhecimento do terapeuta. Apenas alguns fabricantes fornecem aos usuários informações sobre as características físicas dos seus materiais (SIMONEAU et al., 2001).

A resistência elástica é, atualmente, uma ferramenta amplamente utilizada nos processos de reabilitação para o fortalecimento muscular e é aplicada por meio de tubos elásticos, conhecidos por corda elástica, ou faixas elásticas de diversas fabricações e que oferecem diferentes tipos de resistências, distinguidas por cor. A aceitação para o uso destes materiais vem aumentando devido a sua versatilidade, viabilidade econômica e pelos resultados apresentados pelos usuários durante a reabilitação (HINTERMEISTER et al., 1998; PATTERSON et al., 2001; SIMONEAU et al., 2001; AZEVEDO et al., 2003; BENATTI et al., 2003). No Brasil, como 
alternativa aos materiais elásticos importados fabricados especificamente para uso em programas de reabilitação, são usados os tubos de borracha sintética, butadieno-estireno, fabricados para uso geral em medicina (AZEVEDO et al., 2003; AZEVEDO; 2003; BENATTI et al., 2003). Estes, por sua vez, não possuem estudos visando sua caracterização para o uso na reabilitação.

No entanto, é importante para o treinamento de força muscular que os profissionais envolvidos com a reabilitação ou com o treinamento esportivo conheçam as características das ferramentas utilizadas para a aplicação de seus protocolos, sejam os materiais elásticos ou os pesos fixos, e, ainda, as diferença de aplicação entre eles e as respostas dos músculos exercitados em cada situação.

A otimização do uso dos materiais elásticos para exercícios resistidos requer um entendimento das características físicas do material, principalmente a sua relação tensão-deformação e como ocorre a degradação do material em função das suas condições de uso. Pois, no processo de reabilitação, a corda elástica é utilizada de maneira intensa, conseqüentemente, pode perder sua eficiência no que se diz respeito à geração de tensão relacionada ao tempo de uso (HINTERMEISTER et al., 1998; PATTERSON et al., 2001; SIMONEAU et al., 2001). Além disso, deve-se considerar a possibilidade de diferenças no ganho de força muscular relacionadas com a posição adotada pelo indivíduo para a realização do exercício.

Neste trabalho, foram realizados ensaios para a caracterização mecânica de diferentes amostras de cordas elásticas. A tabela 5 mostrou os valores de histerese e tensão máxima para uma deformação de 300\% obtidos nos ensaios para quatro amostras de corda. As amostras da corda elástica

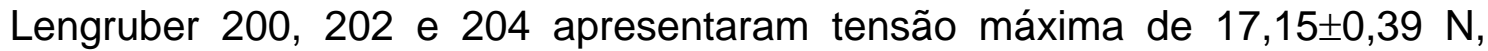
$46,94 \pm 0,68 \mathrm{~N}$ e $62,72 \pm 2,94 \mathrm{~N}$, respectivamente. As amostras da Thera-band $\AA$ vermelha e azul apresentaram valores de tensão máxima de 32,34 $\pm 1,96 \mathrm{~N}$ e $55,47 \pm 0,68 \mathrm{~N}$, respectivamente. Patterson et al. (2001) realizaram testes com amostras de tubos Thera-Band $®$ com deformação até $250 \%$ e obtiveram valores de tensão máxima para o de cor vermelha próximo de $25 \mathrm{~N}$ e para cor azul próximo de $50 \mathrm{~N}$, sendo que, tais valores estão de acordo como os descritos pelo fabricante (PAGE, 2004). Observa-se pelos gráficos da figura 32 , 
que com esta deformação (250\%) os nossos resultados são bastante próximos daqueles encontrados por Simoneau et al. (2001), sendo que, encontramos $29 \mathrm{~N}$ para a cor vermelha e $48 \mathrm{~N}$ para a cor azul. Os mesmos autores encontraram, ainda, diferenças nos valores tensionais entre as faixas e tubos elásticos de mesma cor. Nos experimentos deste trabalho não foi verificada a reprodutibilidade numérica da força para uma dada deformação para amostras de diferentes tipos de materiais elásticos (faixas ou tubos) de mesma cor. No entanto, pode-se afirmar que todas as cordas, sejam as nacionais ou as importadas, apresentam um comportamento muito parecido, além disso, os valores tensionais dos tubos 200, 202 e 204 intercalaram-se com os das Theraband vermelha e azul, o que amplia as opções de níveis de resistências para se utilizar durante a fase de fortalecimento muscular (tabela 5 e figura 32).

Embora estes valores sejam dependentes da espessura das cordas, nas condições de ensaio, não houve diferenças importantes entre as amostras, para a proposta de uso em fisioterapia, no que se refere a histerese, ou seja, a energia perdida de um ciclo de estiramento para outro. A figura 32 apresentou as curvas de tensão-deformação durante os ensaios das amostras da TheraBand ${ }^{\circledR}$ vermelha e azul e da Lengruber 200, 202 e 204. Nessas curvas, embora não possuam a mesma área, a força exigida para o seu estiramento e a histerese em cada ciclo do ensaio mecânico foram da mesma ordem para ambas as marcas de tubo de látex. Observa-se que, em todas as amostras ocorreu uma maior perda no primeiro ciclo do que nos demais, o que está relacionado com a viscoelasticidade da borracha que as compõe. Além disso, as curvas de tensão-deformação da figura 32 apresentaram um comportamento aproximadamente linear, com exceção do início do ciclo. Tais propriedades também foram descritas nas caracterizações mecânicas dos tubos e faixas elásticas analisados por Simoneau et al. (2001) e Patterson et al. (2001).

No entanto, são necessários, ainda, estudos complementares que visem analisar a durabilidade dos tubos em função das condições de armazenamento, a fim de se oferecer aos terapeutas uma melhor orientação relacionada ao tempo útil de uso dos tubos elásticos. Isto poderá proporcionar maior confiabilidade na prescrição de exercícios realizados com estes materiais. Simoneau et al. (2001) relata, também, que se deve explorar, para 
algumas formas de aplicação de exercícios, o fato de que a resistência gerada por uma corda elástica pode variar amplamente, dependendo do seu comprimento inicial.

Uma maneira de se minimizar as diferenças nas respostas da relação tensão-deformação da corda elástica entre as diversas formas de aplicação nos exercícios, foi utilizar um sistema mecânico de exercício (AZEVEDO et al., 2003). Alguns trabalhos mostraram a existência de diferenças importantes na geração de tensão pela corda elástica relacionadas a sua forma de aplicação bem como a posição adotada pelo indivíduo para a realização dos exercícios (SIMONEAU et al., 2001; HINTERMEISTER, 2001).

O sistema mecânico de exercício padroniza a utilização dos materiais elásticos para a realização de exercícios nos membros superiores e inferiores, eliminando as componentes de força de cisalhamento do material elástico, como ocorre quando se fixa uma extremidade da corda num determinado lugar e prende-se a outra no membro a ser exercitado. Além disso, permite a realização de exercícios com resistência constante e isométrico.

A fim de se verificar a manutenção das características das cordas, verificadas acima, nas condições de exercícios isotônicos, que são quase estáticas, foi realizado um ensaio complementar com uma amostra Lengruber 204 (figura 33). Os resultados obtidos foram similares aos apresentados na figura 32. Por meio deste experimento, foi possível obter a equação que define a tensão gerada por esta corda (equação 5), para deformações inferiores a 100\%, mostrando que este material elástico não obedece a Lei de Hooke.

Conforme citado anteriormente, um protocolo de fortalecimento muscular atinge bons resultados quando o profissional responsável respeita as necessidades e limitações dos indivíduos e os objetivos do tratamento e/ou treinamento e, também, quando o mesmo conhece e seleciona adequadamente os tipos de exercício, o tipo de resistência e o material utilizado para oferecer resistência e a posição que o indivíduo realizará o exercício.

Além desses aspectos, deve-se destacar a importância de se conhecer como é a resposta do músculo frente ao exercício, de acordo com o tipo de resistência utilizada e a posição do indivíduo, no que se diz respeito a sua geração de força e atividade mioelétrica. Assim, o objetivo principal deste 
trabalho foi quantificar a força interna do grupo muscular isquiotibial durante exercícios resistivos de flexo-extensão do joelho utilizando-se dois tipos de resistência, a fixa e a elástica, relacionando-a com a atividade eletromiográfica destes músculos.

Entretanto, para o desenvolvimento dos ensaios experimentais propriamente ditos e a realização do tratamento dos dados, foi necessária a definição do modelo biomecânico da atuação dos isquiotibiais e simulações do comportamento da força muscular.

As equações que definem o modelo biomecânico foram determinadas para quatro situações diferentes relacionadas com as possíveis posições que um indivíduo pode assumir para realizar os movimentos de flexo-extensão do joelho, ou seja, decúbito dorsal, decúbito ventral, decúbito lateral, em pé e sentado (tabela 6). Essas equações foram determinadas a partir da construção de diagramas de corpo livre para cada posição citada acima (figuras 35-39).

Quando se usa uma resistência elástica, a força aplicada na posição inicial é zero e aumenta progressivamente, o que não acontece com o peso fixo, cuja força aplicada é a mesma em toda extensão do movimento. Talvez, a principal diferença entre estes dois tipos de exercícios seja que, com a corda elástica, em algumas posições como por exemplo, em pé e em decúbito lateral, o exercício é iniciado com uma mínima força dos isquiotibiais.

Esta condição especial apresentada pela corda elástica pode ter importantes implicações fisiológicas. Pois, no início do movimento, as fibras musculares estão estendidas, e esta não é a condição mais favorável à produção de força. Por outro lado, o peso fixo exige no início do movimento a geração de força em condições desfavoráveis, correndo o risco de que a força necessária para que o exercício seja efetivo provoque danos à musculatura.

Com a determinação das equações que definem a força dos isquiotibiais em diferentes posições, tanto para corda elástica quanto para o peso fixo, foram realizadas simulações para definir as curvas de força muscular em função do ângulo de flexão do joelho. Os resultados destas simulações mostrados nas figuras de número 40 a 47 e permitem analisar as forças musculares de cada posição identificando suas características.

Em decúbito lateral e em pé, para iniciar o movimento, os isquiotibiais devem vencer apenas o torque aplicado pela força externa, pois a contribuição 
do peso da perna é nula quando o ângulo $\theta$ é igual a zero. Já em decúbito dorsal, ventral ou sentado, a contribuição do torque devido ao peso $\left(W_{p} L_{c m}\right)$ no início do movimento deve ser considerado.

Quando se usa a corda elástica a força muscular parte sempre de um valor mínimo e aumenta progressivamente e o formato da curva é o mesmo para qualquer número de cordas. Já para o peso fixo há uma ligeira variação no formato da curva, em função do peso, e uma mudança no valor da força no início da flexão. Na figura 42 observa-se a força dos músculos isquiotibiais no movimento de flexão do joelho, considerando o indivíduo na posição sentado. $\mathrm{Na}$ simulação sem força aplicada, ou seja, quando $\mathrm{F}_{\mathrm{a}}=0$, o músculo não tem ação, pois, o deslocamento se deve à força peso da perna. Já quando o peso fixo é utilizado, não se verifica grandes diferenças entre os valores inicias e finais da força muscular, e o exercício se inicia com a exigência de uma força de valor relativamente alto.

Observou-se que a principal vantagem da corda elástica, de proporcionar pequenas resistências no início do movimento deve ser combinada com o peso da perna escolhendo a posição do exercício. Em decúbito ventral, por exemplo, esta vantagem é bastante minimizada. Para a realização de ensaios experimentais foi adotado o decúbito dorsal, pois neste caso, tem-se a melhor diferenciação entre as forças geradas pelo músculo com o uso da corda elástica e com o uso do peso fixo. Houve este interesse de que as forças tivessem perfis distintos para facilitar a correlação entre força e sinal eletromiográfico. Outro fator determinante foi a questão de praticidade do sistema mecânico de exercício, que é maior nesta posição.

Ao propor a análise do sinal eletromiográfico gerado pela cabeça longa do bíceps femoral, além de procurar um entendimento de algumas diferenças fisiológicas exigidas pelos exercícios com peso e corda, buscou-se uma validação das simulações das forças musculares realizadas com o modelo biomecânico, já que estas não podem ser medidas diretamente. Neste caso, é importante conhecer a relação entre força muscular e eletromiografia.

No entanto, este é um tipo de relação que ainda envolve uma série de contradições (De LUCA, 1997; KELLIS, 1998). Mesmo assim, a eletromiografia de superfície tem sido largamente utilizada em estudos da função dos grupos musculares quadríceps e isquiotibiais durante diferentes tipos de atividades, 
principalmente, com o objetivo de se estabelecer uma relação entre força muscular e o sinal eletromiográfico (KELLIS, 1998).

Ao longo de uma contração não isométrica ocorrem várias modificações mecânicas, fisiológicas e anatômicas, as quais afetam significativamente a relação entre a amplitude do sinal e a força produzida pelo músculo (KELLIS, 1998; ONISHI et al., 2002; MOHAMED; PERRY; HISLOP, 2002). Por exemplo, a relação força-comprimento das fibras musculares varia não linearmente e as formas dos potenciais de ação que formam o sinal EMG são alteradas, pois a posição relativa do eletrodo fixo muda com respeito às fibras musculares em contração. Estes efeitos são agravados mais adiante se o deslocamento é acelerado devido o atraso entre o sinal e a força, podendo limitar o uso em algumas aplicações (De LUCA, 1997).

Além disso, a estimativa da amplitude do sinal EMG como uma função da força depende de fatores anatômicos e fisiológicos intrínsecos. Assim, um dos motivos para relação não ser linear, é que na maioria dos músculos, o volume de detecção do eletrodo é menor que o volume do músculo. Outro fator que pode afetar a relação EMG-força é a taxa de disparos e recrutamento das unidades motoras pelo sistema nervoso central, para controlar diferentes músculos (DE LUCA, 1997). Segundo De Lucca (1997), dentre outros critérios, para obter linearidade entre a amplitude do sinal de EMG e o nível de força muscular em exercícios dinâmicos, a força muscular deve ser muito menor que a força isométrica máxima e a velocidade deve ser pequena. No protocolo experimental procurou-se observar estes critérios.

Neste trabalho, ao analisar o comportamento da força gerada pelo grupo muscular isquiotibial comparando com o sinal eletromiográfico da cabeça longa do músculo bíceps femoral no exercício resistido com sobrecarga elástica e fixa, observou-se que as curvas do sinal eletromiográfico possuem um perfil muito próximo do apresentado pela curva de força muscular. No entanto, os valores máximos do sinal eletromiográfico ocorreram antes dos valores máximo da força.

Com relação ao padrão de ativação do sinal eletromiográfico entre as curvas provenientes dos exercícios, algumas diferenças podem ser observadas visualmente. O principal aspecto é que, com a corda elástica, o sinal inicia em zero, enquanto que, com o uso do peso isto não ocorre. Tal fato pode ser visto 
ao comparar os dados coletados com a corda elástica (figuras 48-54) e com os dados referentes ao uso do peso fixo (figuras 55 a 61). Observa-se, também, que, aparentemente, o sinal eletromiográfico nos exercícios com peso apresentou maiores flutuações e uma assimetria entre a flexão e extensão maior que a observada nos exercícios com a corda elástica.

A diferença notada no início das curvas de EMG era esperada já que, na posição escolhida, conforme pode ser observado nas curvas das simulações, o peso fixo proporciona uma maior sobrecarga logo no início da flexão do joelho, do que a corda elástica. Em ambos os casos, tanto a amplitude sinal do quanto os valores de força aumentam com o ângulo de flexão do joelho. A grosso modo, pode-se dizer que o perfil da curva de eletromiografia reproduz o perfil da curva de força muscular. A forma encontrada neste trabalho para verificar a relação entre a força e eletromiografia foi elaborar gráficos da força pela eletromiografia, conforme mostrado nas figuras 52 e 59 e nos apêndices B e C. Se o perfil do sinal eletromiográfico reproduzisse fielmente o perfil da curva de força muscular, o gráfico de força versus EMG seria uma reta com inclinação de 45 graus.

No entanto, observou-se que essas curvas: são lineares no inicio; a fase concêntrica é diferente da fase excêntrica, ou seja, as curvas são assimétricas; o valor máximo da força ocorre na fase concêntrica; a relação entre força e eletromiografia apresenta segmentos lineares com diferentes inclinações, sendo que, na maioria das vezes pode ser verificado uma região de transição; as curvas referentes aos exercícios com a corda elástica parecem apresentar uma continuidade, enquanto as curvas referente aos exercícios com peso fixo exibem as transições entre as regiões lineares de forma menos suaves.

As mudanças de inclinação podem estar associadas às diferenças na ação dos músculos que compõem o grupo dos isquiotibiais (ONISHI et al., 2002; MOHAMED; PERRY; HISLOP, 2003), visto que, as correlações foram realizadas entre a força do grupo muscular e o sinal eletromiográfico, o qual foi captado apenas da cabeça longa do bíceps femoral. No entanto, segundo Onishi et al. (2002), no início do movimento de flexão do joelho este é o principal músculo responsável pelo torque da perna. Assim, podemos relatar que a região linear no início da flexão do joelho se refere a ação da cabeça 
longa do bíceps, sendo mínima a interferência dos outros músculos. Com isso, a análise foi focada no início das curvas da relação força-EMG.

Se a relação entre força $(F)$ e intensidade do sinal eletromiográfico (IEMG) é linear, pode-se definir uma constante de proporcionalidade (IEMG/F = c). O valor desta constante foi avaliado pelo cálculo da inclinação inicial dos resultados mostrados nos apêndices $\mathrm{B}$ e $\mathrm{C}$, relativos as coletas experimentais feitas com corda elástica e peso fixo, respectivamente, para os dez voluntários. O valor médio encontrado para os exercícios com a corda não foi estatisticamente diferente, segundo o teste duplo $t$, do valor encontrado para os exercícios com peso fixo. De fato, este resultado era esperado, ou seja, a eletromiografia deveria ser proporcional à força muscular independente de sua forma de aplicação. Assim, para as condições experimentais deste trabalho foi encontrado que a constante de proporcionalidade entre a força e o sinal eletromiográfico da cabeça longa do bíceps é $\mathbf{3 , 6 \pm 1 , 7}$. Lembrando que, esta constante é referente à força normalizada pela força isométrica máxima do grupo muscular em 90 graus e a intensidade do sinal eletromiográfico gerado nesta condição.

Outro dado analisado foi o ângulo em que ocorreu a primeira mudança de inclinação, ou seja, o ponto onde há uma mudança de regime da curva. Nota-se, neste caso, uma diferença entre os valores observados nos exercícios com a corda elástica daqueles observados com o peso fixo. No caso do exercício usando corda elástica, o valor encontrado foi de $\mathbf{2 4 \pm 7 , 4}$ graus, enquanto que, para o peso fixo o valor foi de $15 \pm 6,3$ graus. Na amostra experimental, encontrou-se que estes valores são considerados estatisticamente diferentes $(p=0,016)$ pelo teste duplo $t$ com um nível de significância $p<0,05$.

Este resultado, adicionado com a análise da curva, pode indicar que no caso do exercício com peso fixo, os músculos do grupo muscular são solicitados de forma diferente. Do ponto de vista do modelo biomecânico a principal diferença é que a corda elástica proporciona uma força que varia continuamente de zero até um valor máximo enquanto o peso proporciona uma força que inicia de um valor relativamente alto e varia pouco. Ao fazer esta análise, embora de forma não conclusiva, pode-se dizer que o exercício com a 
corda elástica faz uma solicitação mais harmônica do conjunto e exige que a cabeça longa do bíceps femoral atue numa extensão maior durante o arco de movimento.

É comum encontrar estudos que correlacionam o sinal eletromiográfico com o torque do grupo muscular, principalmente em exercícios isocinéticos, talvez devido à facilidade de cálculo desta grandeza (KELLIS, 1998; ONISHI et al., 2002; MOHAMED; PERRY; HISLOP, 2003). Nos resultados, as figuras 53 e 60 e os apêndices B e C, apresentam os gráficos de EMG versus torque, em que não são observadas diferenças relevantes em relação aos gráficos de força. Este resultado, a princípio decepcionante, poderia estar relacionado com erros experimentais ou erros provenientes do tratamento dos dados. No entanto, o trabalho de Onishi et al (2002) traz uma explicação adequada para este resultado. Em estudos do perfil de ativação motora em exercícios isocinético, esses autores, verificaram a atividade elétrica individual dos quatro músculos isquiotibiais pela eletromiografia de fio. Observa-se em seus resultados, que o perfil da curva de EMG da cabeça longa do bíceps femoral é o mesmo do torque gerado pelo grupo muscular. Para ilustrar a relação linear entre EMG e torque, construiu um gráfico do sinal eletromiográfico versus torque, ambos obtidos dos resultados de Onishi et al. (2002) (figura 62).

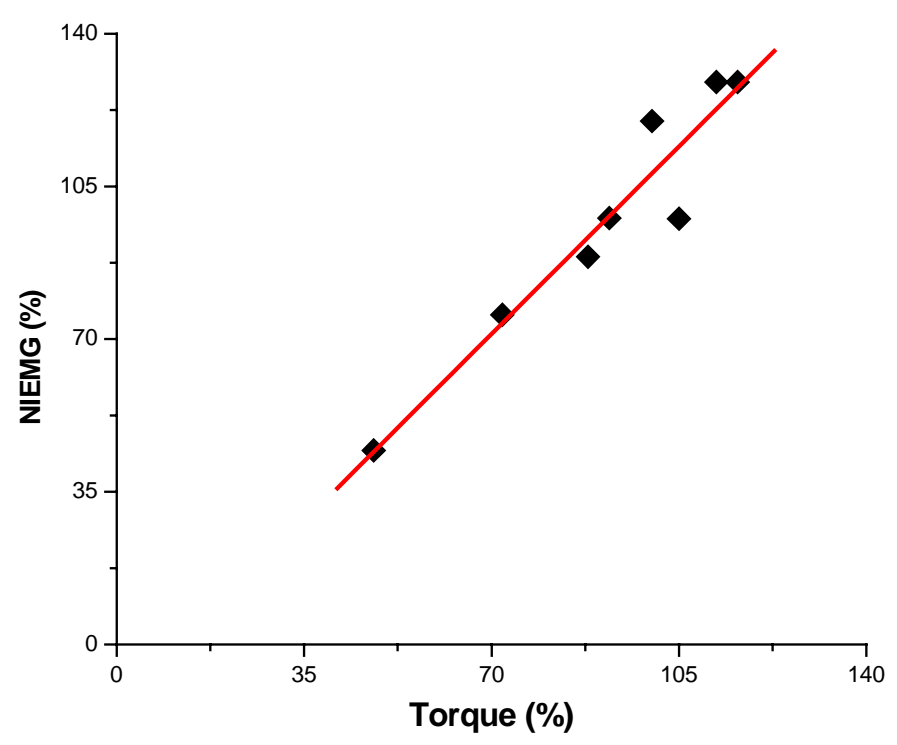

Figura 62. Relação NIEMG-Torque durante flexão do joelho (Adaptado de Onishi et al. (2002)). 
Portanto, os resultados deste trabalho estão de acordo com os resultados de Onishi et al. (2002), mostrando que é uma característica da cabeça longa do bíceps femoral, durante a flexão isocinética do joelho, apresentar uma ação eletromiográfica com um perfil que coincide com o do torque do conjunto muscular dos isquiotibiais em toda extensão conforme ilustra a figura 62. Este fato justifica o fato das curvas de torque versus EMG parecerem mais lineares que as curvas de força versus EMG. 


\section{CONCLUSÃO}

Com a realização do presente trabalho, buscou-se analisar o comportamento mecânico dos tubos elásticos de fabricação nacional, os quais são adaptados para exercerem a função de sobrecarga externa nos protocolos de fortalecimento muscular.

Após a caracterização mecânica, foi possível concluir que os tubos elásticos analisados, ou seja, as cordas elásticas nacionais (referências 200, 202 e 204) e os tubos Thera-Band (cores vermelha e azul), possuem um comportamento similar quando estirados. Não há diferenças significativas na relação tensão-deformação entre estas amostras, sendo que, os dados encontrados estão compatíveis com o encontrado na literatura e as características fornecidas pelo fabricante dos tubos elásticos Thera-Band. Assim, os tubos de látex nacionais podem ser utilizados com segurança durante os exercícios realizados com resistência elástica.

Além disso, este tipo de material não obedece a Lei de Hooke, pois, encontrou-se que a força tensora produzida pela corda elástica obedece a função: $F c=1 \lambda A\left(\Delta L / L_{0}\right)^{n}$, nos quais $\lambda A$ é igual a 44,7 e $n$ é igual a 0,5 , para a corda elástica Lengruber 204, determinados no ensaio mecânico estático no sistema mecânico de exercício. Ressalta-se que esta relação é observada quando a deformação não ultrapassa $100 \%$ e que se obedecesse a Lei de Hooke teríamos $\mathrm{n}$ igual 1.

As simulações permitem concluir que a otimização da escolha do tipo de resistência, baseada na resposta de força muscular, depende também da escolha da posição adotada pelo indivíduo para a realização do exercício de flexo-extensão dos isquiotibiais. Por exemplo, quando se aplica exercícios com a corda elástica com o indivíduo em decúbito ventral não se obtem uma força muscular próxima de zero no início do arco de movimento. Portanto, nesta posição, para o músculo isquiotibial, o uso da corda elástica não proporciona a sua principal vantagem.

Além disso, a relação entre a força da cabeça longa do bíceps femoral e o sinal EMG para os indivíduos analisados foi independente do tipo de 
sobrecarga utilizada. O sinal EMG proveniente dos exercícios realizados com peso é menos harmônico e o músculo age numa extensão de movimento menor. O torque gerado pelos isquiotibiais, por sua vez, é proporcional ao sinal eletromiográfico captado da cabeça longa do bíceps femoral durante os exercícios de flexão do joelho realizados no sistema mecânico de exercício, tanto para os utilizados com resistência constante quanto para os realizados com resistência elástica.

Por fim, com a realização deste trabalho, fica possível oferecer informações aos profissionais responsáveis pelos protocolos de fortalecimento muscular, tanto dos programas de reabilitação quanto dos programas de treinamento, as quais podem otimizar a aplicação dos mesmos. Principalmente, no que se diz respeito à posição adotada pelo indivíduo para exercícios resistidos de flexão do joelho com peso fixo e corda elástica e que provavelmente a resistência elástica proporciona um exercício seguro durante ação conjunta do grupo muscular. 


\section{REFERÊNCIAS BIBLIOGRÁFICAS*}

ALMEIDA, M. A. F. (1997). Filtragem Digital de Sinais Biomédicos, Florianópolis, SC. 116p. Dissertação (Mestrado), PGEEL, Universidade Federal de Santa Catarina, Florianópolis, 1997.

AMADIO, A. C. (1996). Fundamentos biomecânicos para a análise do movimento humano. São Paulo: EEFE-USP.

AZEVEDO, F. M.; NEGRÃO FILHO, R. F.; CARVALHO, A. C. A. (1999). Atividade elétrica do músculo bíceps braquial em diferentes ângulos e resistências. Revista de Fisioterapia da Universidade de São Paulo, v. 6, suplemento, p. 36.

AZEVEDO, F. M. (2003). Estudo da força e da atividade elétrica gerada pelo músculo quadríceps femoral submetido a exercícios com resistência elástica, São Carlos, SP. 90p. Dissertação (Mestrado), Escola de Engenharia de São Carlos, Universidade de São Paulo, São Carlos, 2003.

AZEVEDO, F.M; BENATTI, L.N; ALVES, N.; NEGRÃO FILHO; R.F. (2003). Avaliação biomecânica e proposta para utilização de um sistema de tração baseado em resistência elástica para a realização de exercícios dinâmicos no músculo bíceps braquial. Revista Brasileira de Biomecânica, São Paulo, n. 6, ano 4, p. 49-54, maio.

BALTZOPOULOS, V. A. (1995). Videofluoroscopy method for optical distortion correction and measurement of knee-joint kinematics. Clinical Biomechanics, v. 10, n. 2 , p. $85-92$.

BARBANTI, V. J. (1992). Teoria e prática do treinamento desportivo. São Paulo: Editora Manole.

BARBANTI, V.J. (2002). Manifestações da força motora no esporte de rendimento. In: BARBANTI, V.J.; AMADIO, A.C.; BENTO, J.O.; MARQUES, A.M. Esporte e Atividade Física: Interação entre rendimento e saúde. São Paulo: Editora Manole, 2002, p.13-25.

BAUMANN, W. (1995). Procedimentos para determinar as forças internas na biomecânica do ser humano - aspectos da carga e sobrecarga nas extremidades inferiores. In: CONGRESSO BRASILEIRO DE BIOMECÂNICA, 4., 1995, Brasília. Anais... Brasília: Sociedade Brasileira de Biomecânica.

BENATTI, L.N; FANTON, M.; AZEVEDO, F.M.; ALVES, N.; NEGRÃO FILHO, R.F. (2003). Propriedades materiais dos tubos de látex nacionais utilizados em protocolos de reabilitação. In: CONGRESSO BRASILEIRO DE BIOMECÂNICA,

\footnotetext{
* De acordo com:

ASSOCIAÇÃO BRASILEIRA DE NORMAS E TÉCNICAS. NBR 6023. Informações e documentação: referências: elaboração: Rio de Janeiro, 2002.
} 
10., 2003, Ouro Preto. Anais... Ouro Preto: Sociedade Brasileira de Biomecânica. v. 2, p. 368-371.

BIODEX MEDICAL SYSTEM. Disponível em http://www.biodex.com/rehab/system3/system3 feat.htm. Acesso em: 25 Jan 2005.

BOSCO, C.; VIITASSALO, J.; KOMI, P.V.; LUHTANEN, P. (1982). Combined effect elastic energy and myoelectrial potentiation during stretch-shortening cycle. Acta Physiologica Scandinavia, v. 114.

CICCOTTI, M. G., KERLAN, R. K., PERRY, J., PINK, M. (1994). An electromyografic analysis of the knee during functional activities. II. The anterior cruciate ligament-deficient and reconstructed profiles. American Journal of Sports Medicine. v. 22, p. 651-658.

De LEVA, P. (1996). Adjustments to Zatsiorsky-Seluyanov`s segment inertia parameters. Journal of Biomechanics, v. 29 n. 9, p. 1223-1230.

DE LUCA, C. (1979). Physiology and Mathematics of Myoelectric Signals. Transactions on Biomedical Engineering, v. BME-26, n.6, p. 313-325.

De LUCA, C. J. (1997). The use of surface electromyography in biomechanics. Journal of Applied Biomechanics, v.13, p.135-163, 1997.

DVIR, Z. (2002). Isocinética: Avaliações musculares, interpretações e aplicações clínicas. São Paulo: Editora Manole, $1^{\mathrm{a}}$ Edição.

ELLIS, M.I; et al. (1979). Forces in the knee joint while rising from normal and motorised chairs. Eng. Med. v. 8, p. 33-40.

FLECK, S. J.; KRAEMER, W. J. (1995). Fundamentos do treinamento de força muscular. Porto Alegre: Artmed Editora, $2^{a}$ edição.

FOSS, M. L.; KETEYIAN, S. J. (2000). FOXI Bases fisiológicas do exercício e do esporte. Rio de Janeiro: Editora Guanabara.

FRONTERA, W.R.; DAWSON, D.M.; SLOVIK, D.M. (2001). Exercício físico e reabilitação. Porto Alegre: Artmed Editora.

GLITSCH, U.; BAUMANN, W. (1997). The three-dimensional determination of internal loads in the lower extremity. Journal of Biomechanics, v. 30, n. 11/12, p.1123-1131.

GUEDES, L. A. (1972). Electrodes and the Measurement of Bioelectric Events. New York: Wiley.

HERMENS, H. J. et al. (2002). The SENIAM Project: Surface electromyography for non-invasive assessment of muscle. In: Congresso ISEK., Áustria, CDRom... 
HERMENS, J. H.; FRERIKS, B., DISSELHORST-KLUG, C.; RAU, G. (2000). Development of recommendations for SEMG sensors and sensor placement procedures. Journal of Electromyography and Kinesiology. v. 10, p. 361374.

HERZOG, W.; READ, L. (1993). Lines of action and moment arms of the major force-carrying structures crossing the human knee joint. Journal of Anatomy, v. 182, p. 213-30.

HINTERMEISTER, R., BEY, M. J.; LANGE, G. W.; STEADMAN, J. R. (1998). Quantification of elastic resistence knee rehabilitation exercises. Journal of Orthopaedic \& Physical Therapy, v. 28, n. 1, jul.

HISLOP, H.; PERRINE, J.J. (1967). The isokinetic concept of exercise. Phisical Therapy, v.47, p.114 - 117.

HOLLMANN, W.; HETTINGER, T. (1989). Medicina do esporte. São Paulo: Editora: Manole.

HOUAISS, A.; VILLAR, M.S.; DE MELLO FRANCO, F.M. (2001). Dicionário Houaiss da Língua Portuguesa. Rio de Janeiro: Instituto Antônio Houaiss de Lexicografia, Editora Objetiva, p. 1283.

KALUND, S., SINKAJAER, T., ARENDT-NIELSEN, L., SIMONSEN, O. (1990). Altered timing of hamstring muscle action in anterior cruciate ligament deficient patients. American Journal of Sports Medicine, v. 18, p. 245-8.

KAPANDJI, I.A. (2000). Fisiologia Articular. Rio de Janeiro: Editora Guanabara, v. 3.

KELLIS, E. (1998). Quantification of quadriceps and hamstring antagonist activity. Sports Medicine, v. 25, n. 1, p. 37-62, jan.

KELLIS, E.; BALTZOPOULOS, V. (1999). In vivo determination of the patella tendon and hamstrings moment arms in adult males using videofluoroscopy during submaximal knee extension and flexion. Clinical Biomechanics, v. 14, p. $118-124$.

KENDALL, F. P.; McCREARY, E. K.; PROVANCE, P. G. (1995). Músculos, provas e funções. $4^{a}$ edição. São Paulo: Editora Manole.

KISNER, C.; COLBY, L. A. (1998). Exercícios terapêuticos: fundamentos e técnicas. $3^{a}$ ed. São Paulo: Editora Manole.

LI, G.; RUDY, T.W.: SAKANE; M.; KANAMORI, A.; MA, C. B.; WOO, S. L.-Y. (1999). The importance of quadriceps and hamstrings muscle loading on knee kinematics and in situ forces in the ACL, Journal of Biomechanics, v. 32, p. $395-400$.

LINDSTRÖN, L.; KADEFORS, R.; PETERSEN, I. (1970). Muscular fatigue and action potential conduction velocity changes studies with frequency analysis of EMG signals. Electromyography. v.10, p. 341-356. 
LIU, W.; MAITLAND, M. E. (2000). The effect hamstring muscle compensation for anterior laxity in the ACL-deficient knee during gait. Journal of Biomechanics, v. 33, p. 871-879.

MOHAMED, O.; PERRY, J.; HISLOP, H. (2002). Relationship between wire EMG activity, muscle length, and torque of the hamstrings. Clinical Biomechanics. v.17, p. 569-579.

MOHAMED, O.; PERRY, J.; HISLOP, H. (2003). Synergy of medial and lateral hamstrings at three positions of tibial rotation during maximum isometric knee flexion. The Knee. v. 10, p. 277-281.

MOORE, K.L. (1994). Anatomia orientada para a clínica. $3^{a}$ Edição. Rio de Janeiro: Guanabara Koogan, p. 378-83.

MORITANI, T.; HERBERT, A. (1978). Rexamination of the relationship between the sufarce integrated electromyogram (IEMG) and force of isometric contraction. American Journal of Physical Medicine, v. 57, n. 6, p. 263-277.

NETTER, F.H. (1999). Atlas interativo de anatomia humana. Porto Alegre: Artmed Editora, CD-Rom...

NISELL, R. (1985). Mechanics of the knee: a study of joint and muscle load with clinical applications. Acta Orthop Scand, v. 56, p. 1-42.

ONISHI, H.; YAGI, R.; MOMOSE, K.; IHASHI, K.; HANDA, Y. (1999). Relationship between EMG signals and force in human vastus lateralis muscle using multiple bipolar wire electrodes. Journal of Electromyography and Kinesiology, v. 10, p. 59-67.

ONISHI, H.; YAGI, R.; OYAMA, M.; AKASAKA, K.; IHASHI, K.; HANDA, Y. (2002). EMG-angle relationship of the hamstrings muscles during maximum knee flexion. Journal of Electromyography and Kinesiology. v. 12, p. 399406.

PAGE, P. (2004). Developing resistive exercise programs using Thera-Band elastic bands e tubing. Thera-Band $\AA$ and Associated Colors are trademarks of the Hygenic Corporation. (C2004.

PATTERSON, M.; JANSEN, C. W. S.; HOGAN, H. A. NASSIF, M. D. (2001). Material properties of thera-band tubing. Physical Therapy, v. 81, n. 8, agos.

PEREIRA, M.C.V.; AZEVEDO, F.M. (2002). Análise para um ajanelamento adequado para sinais bioelétricos. In: CONGRESSO BRASILEIRO DE ENGENHARIA BIOMÉDICA, 18, 2002, São José dos Campos, CD-Rom...

PERRIN, D. (1993). H. Isokinetic exercise and assessment. U.S.A: Humam Publishers, 1993, 211p.

POZZO, M.; FARINA, D.; MERLETTI, R. (2004). Electromyography: Detection, Processing, and Applications. In: MOORE, J.; ZOURIDAKIS, G. Biomedical Techology and Devices. Handbook. USA/Flórida: CRC Press, p. 1-66. 
POWERS, S. K., HOWLEY, E. T. (2000). Fisiologia do exercício. $3^{a}$ edição, São Paulo: Editora Manole.

PRIMAL PICTURES. (2003). Anatomic Pictures [on line]. Disponível: http:// www. primalpictures.com. Acesso em: 11 mar, 2003.

ROBINSON, A. J. (2001). Fisiologia do músculo e do nervo. In: ROBINSON, A. J.; SNYDER-MARCKLER, L. Eletrofisiologia clínica. Eletroterapia e teste fisiológico. $2^{\text {a }}$ Edição. Porto Alegre: ArtMed Editora, p. 85 - 118.

SIMONEAU, G.G.; BEREDA, S. M.; SOBUSH, D. C.; STARSKY, D.C. STARSKY, A. (2001). Biomechanics of elastic resistive in therapeutic exercise programs. Journal of Orthopaedic \& Physical Therapy, v. 31, n. 1, p. 16-24.

SMIDT, G.L. (1973). Biomechanical analysis of knee flexion and extension. Journal of Biomechanics, v. 6, p. 79-92.

SOLOMONOW, M., BARATTA, R., ZHOU, B.H., SHOJI, H., BOSE, W., BECK, C. D'AMROSIA, R. (1987). The synergistic action of the unstable anterior cruciate ligament and thigh muscles in maintaining joint stability. American Journal of Sports Medicine, v. 15, p. 207-13.

VLACK, L. H. V. (1970). Princípios da ciência dos materiais. São Paulo: Edgard Blücher.

WEBSTER, J. G. (1998). Medical Instrumentation: Application and Design. $3^{\mathrm{a}}$ edição, New York.

WEINECK, J. (1991). Biologia do esporte. São Paulo: Editora Manole.

WRETENBERG, P. NeMETH, G., LAMONTAGNE, M. et al., (1996). Passive knee muscle moment arms measured in vivo with MRI. Clinical Biomechanics, v. 11, p. 439-46.

YAMAGUCHI, G.T., ZAJAC, F.E. (1989). A planar model of the knee joint to characterize the knee extensor mechanism. Journal of Biomechanics, v. 22, p. 1-10.

YANAGAWA, T. SHELBURNE, K. SERPAS, F. PANDY, M. (2002). Effect of hamstrings muscle action on stability of the ACL-deficient knee in isokinetic extension exercise. Clinical Biomechanics, v. 17, p. 705-712. 


\section{APÊNDICE A - Termo de consentimento}

\section{ESTUDO DA FORÇA GERADA PELO GRUPO MUSCULAR ISQUIOTIBIAL EM EXERCÍCIOS RESISTIDOS.}

As informações aqui contidas e fornecidas por LEANDRA NAVARRO BENATTI, aluna do Programa de Pós-Graduação Interunidades em Bioengenharia - EESC/ FMRP/IQSC USP/São Carlos, têm por objetivo firmar acordo escrito com o voluntário que participa da pesquisa, autorizando sua participação com pleno conhecimento da natureza dos procedimentos que irá se submeter.

1. Os voluntários não serão submetidos a riscos durante o período experimental. O protocolo de coleta consiste em exercícios resistidos com corda elástica e peso fixo. A primeira parte do experimento consiste na geração de força máxima com o joelho posicionado em $90^{\circ}$. Em seguida, realizam-se repetições do movimento de flexo-extensão com uma resistência elástica. Depois de um período de repouso o voluntário será orientado a realizar repetições do movimento de flexo-extensão com resistência fixa. Ambas as resistências estarão fixas junto ao sistema mecânico de exercício. Os valores das sobrecargas serão determinados como $50 \%$ da força gerada na contração voluntária isométrica máxima, em $90^{\circ}$. Os equipamentos que serão utilizados: eletrogoniômetro, célula de carga, anilhas (peso fixo) tubo de látex e eletrodos de superfície para EMG, não oferecem possibilidade de risco, visto que a metodologia aplicada não é do tipo invasiva.

2. O voluntário pode fazer qualquer pergunta ou esclarecimento de dúvidas a respeito dos procedimentos e outros assuntos relacionados com a pesquisa, tendo, ainda a liberdade de retirar seu consentimento a qualquer momento e deixar de participar do estudo.

3. Os procedimentos foram elaborados de acordo com as diretrizes e normas regulamentadas de pesquisa envolvendo seres humanos atendendo à resolução n. 196, de 10 de outubro de 1996, Conselho Nacional de Saúde do Ministério da Saúde - Brasília - DF.

4. Os pesquisadores asseguram a privacidade dos voluntários quanto aos dados confidenciais e envolvidos na pesquisa.

5. A pesquisa será desenvolvida no Laboratório de Fisioterapia Aplicado ao Movimento Humano da FCT/UNESP, Departamento de Fisioterapia, localizado à Rua Roberto Simonsen, 305 - Presidente Prudente, SP. Os telefones para contato são: Prof. Dr. Neri Alves (018) 2295300- UNESP; Leandra Navarro Benatti (18) 229 -5388 (ramal 5416).

$\mathrm{Eu}$, , após a leitura e compreensão destas informações, entendo que minha participação é voluntária, e que posso sair a qualquer momento do estudo, sem prejuízo algum. Confirmo que recebi uma cópia deste termo de consentimento, e autorizo a execução do trabalho de pesquisa e a divulgação dos dados obtidos neste estudo.(Telefone para contato: 


\section{APÊNDICE B}

Resultados individuais dos experimentos com corda elástica 
VOLUNTÁRIO 1 (Corda elástica)
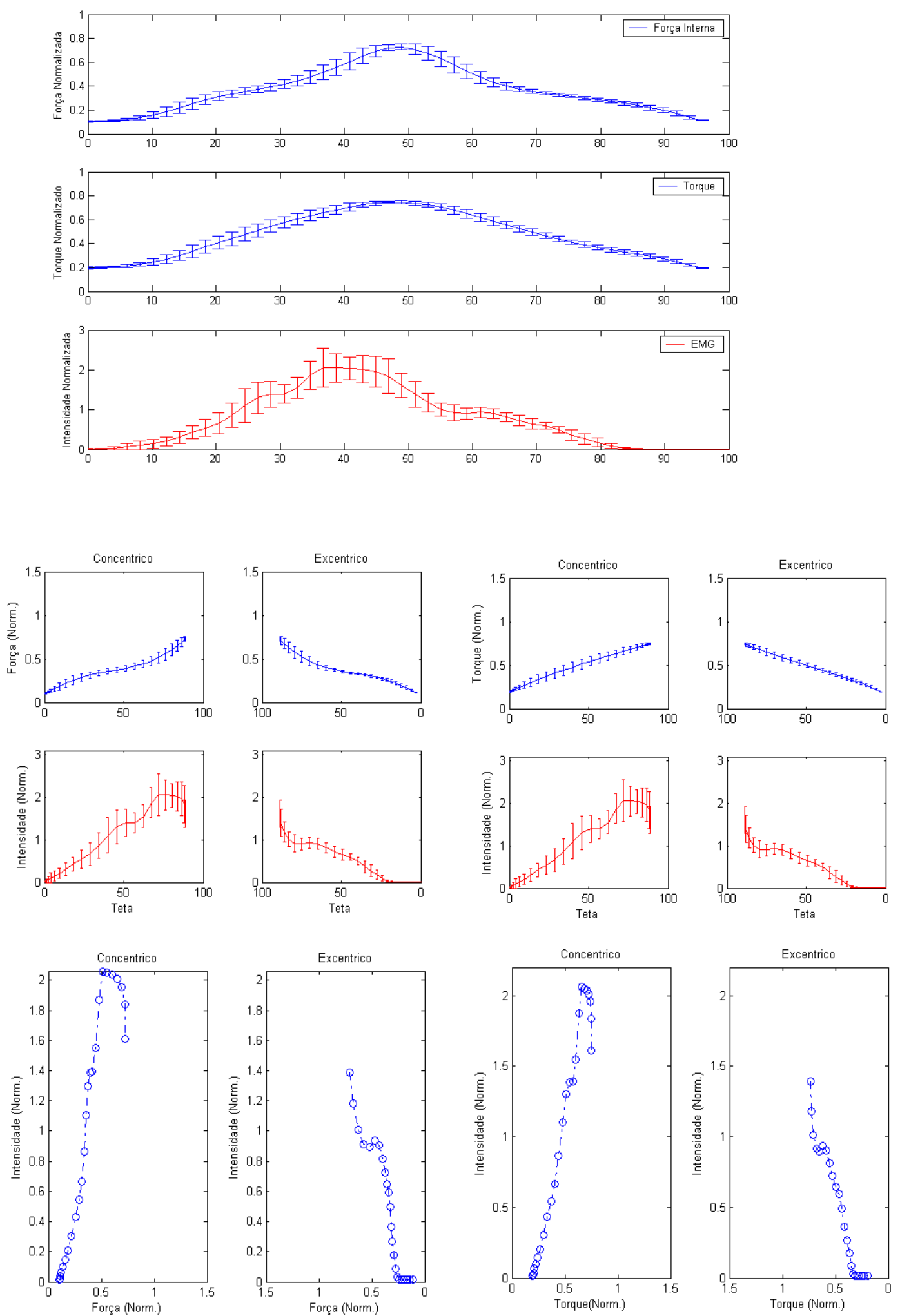
VOLUNTÁRIO 2 (Corda elástica)
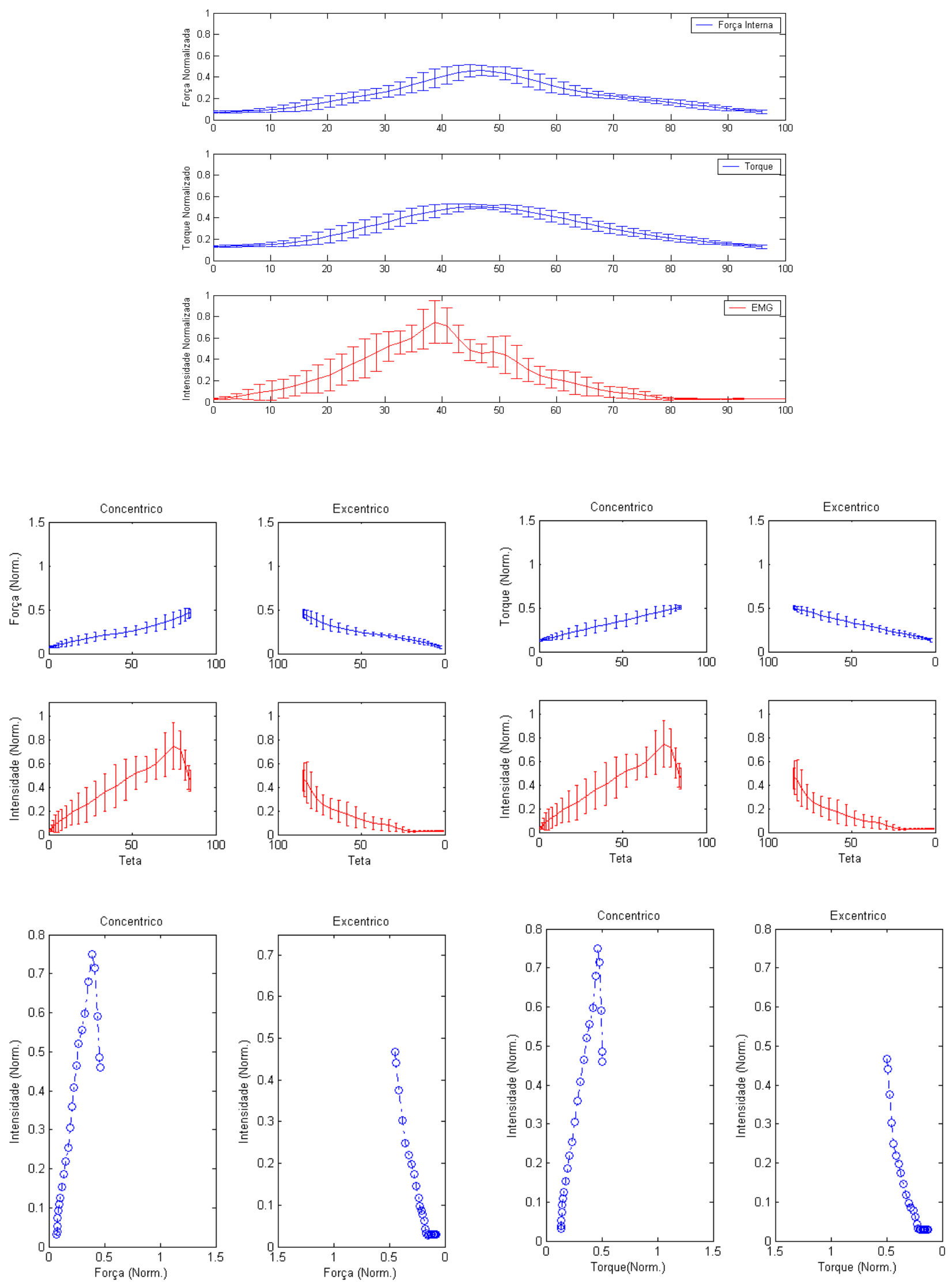
VOLUNTÁRIO 3 (Corda elástica)
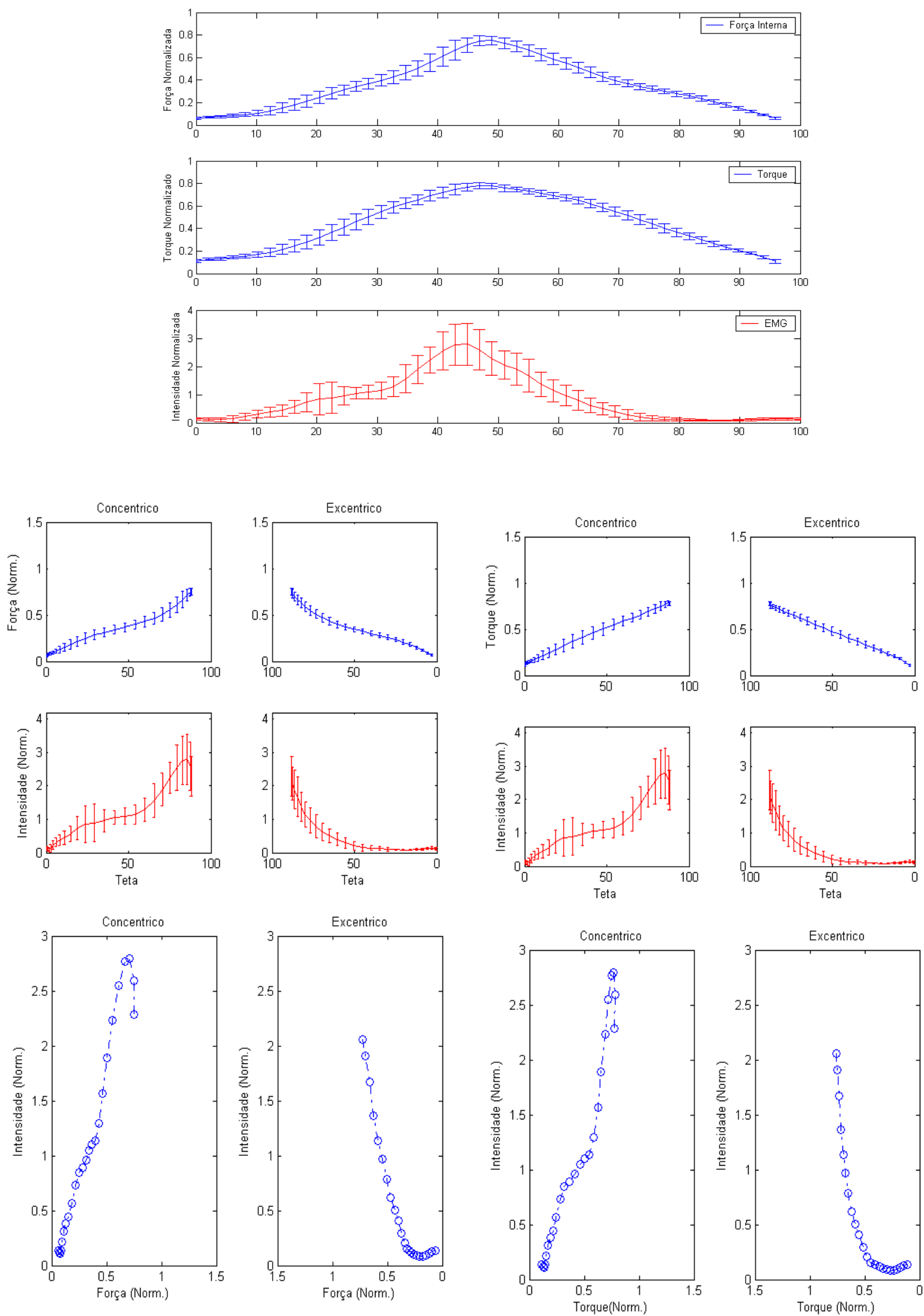
VOLUNTÁRIO 4 (Corda elástica)
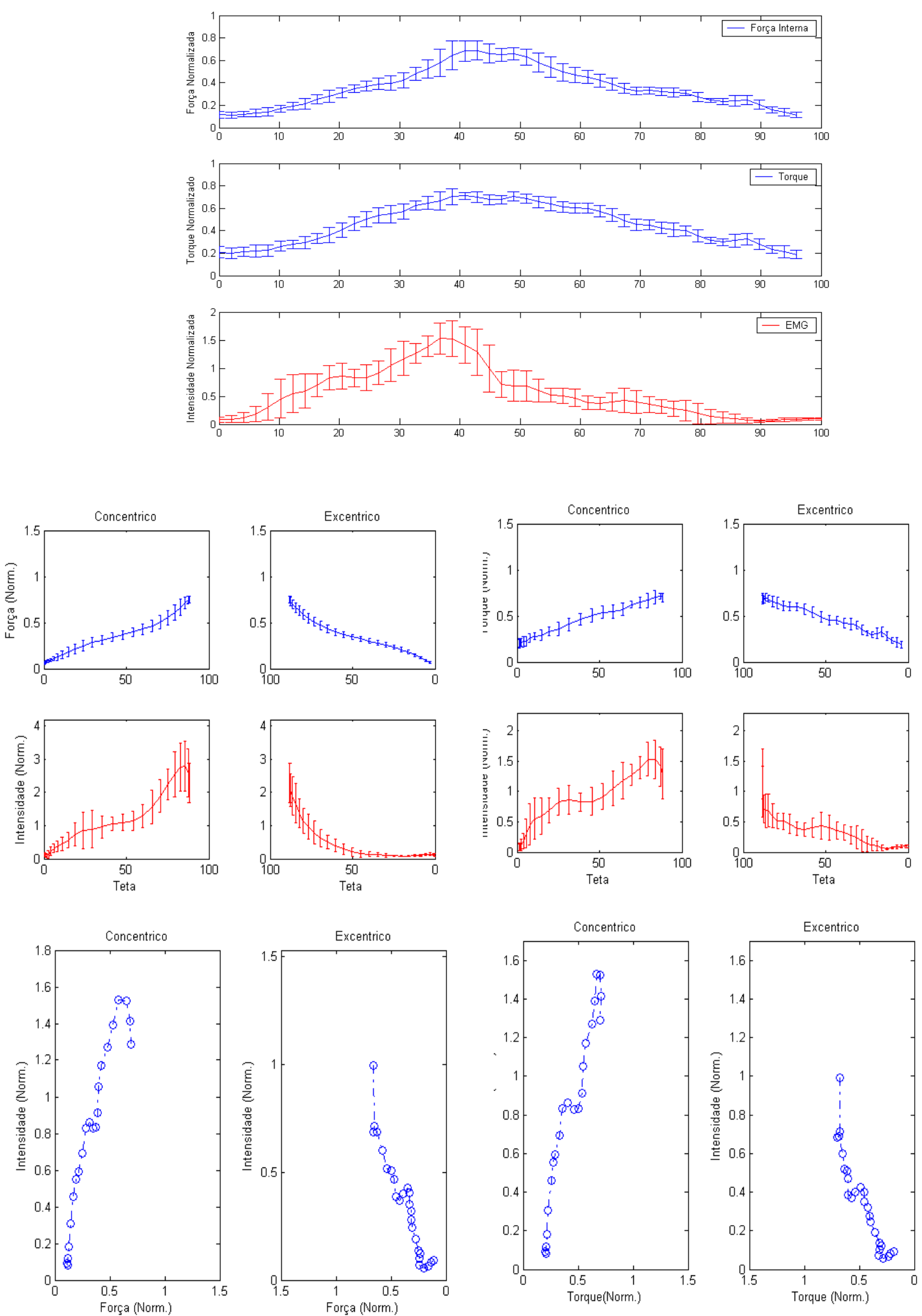
VOLUNTÁRIO 5 (Corda elástica)
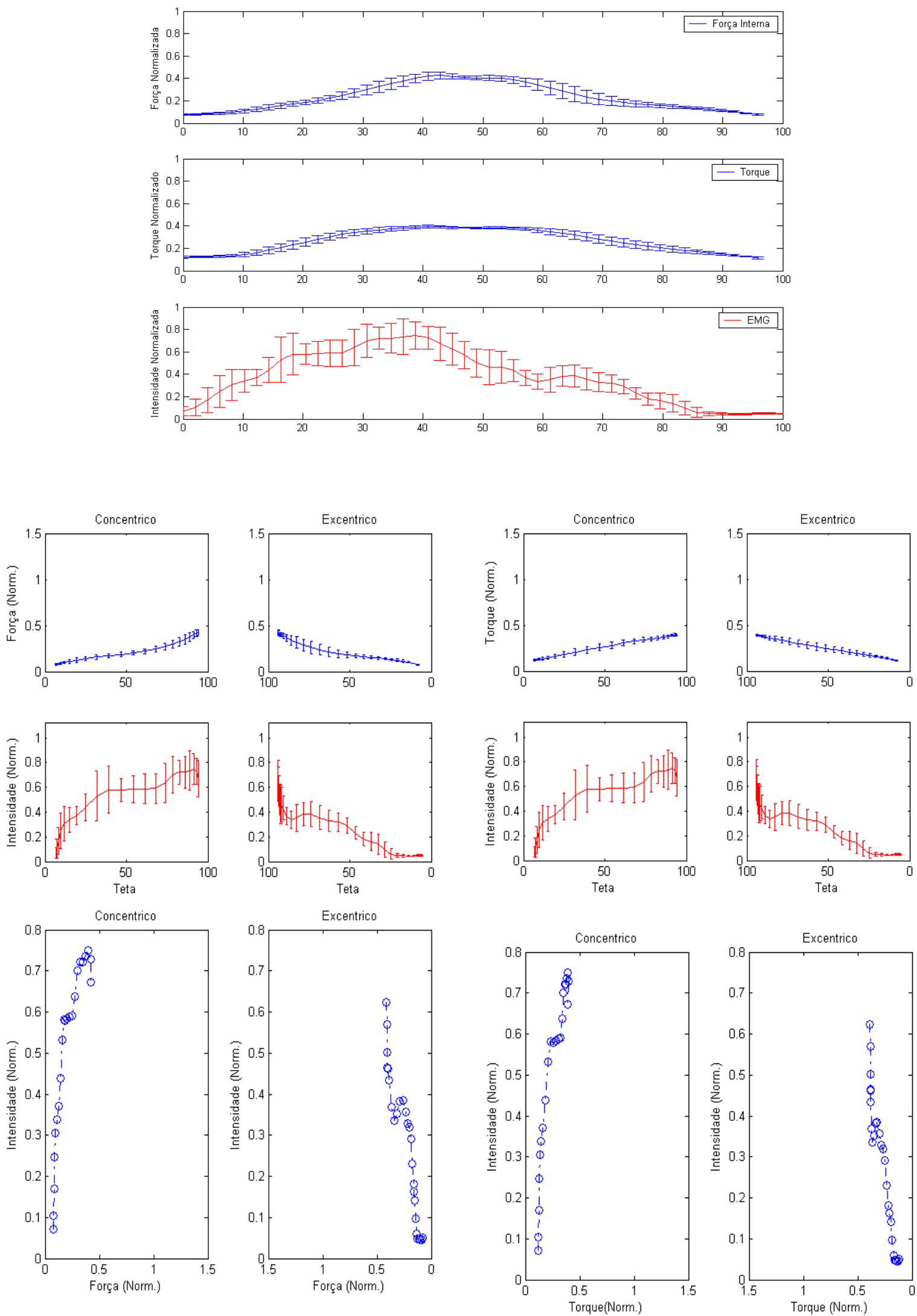
VOLUNTÁRIO 6 (Corda elástica)
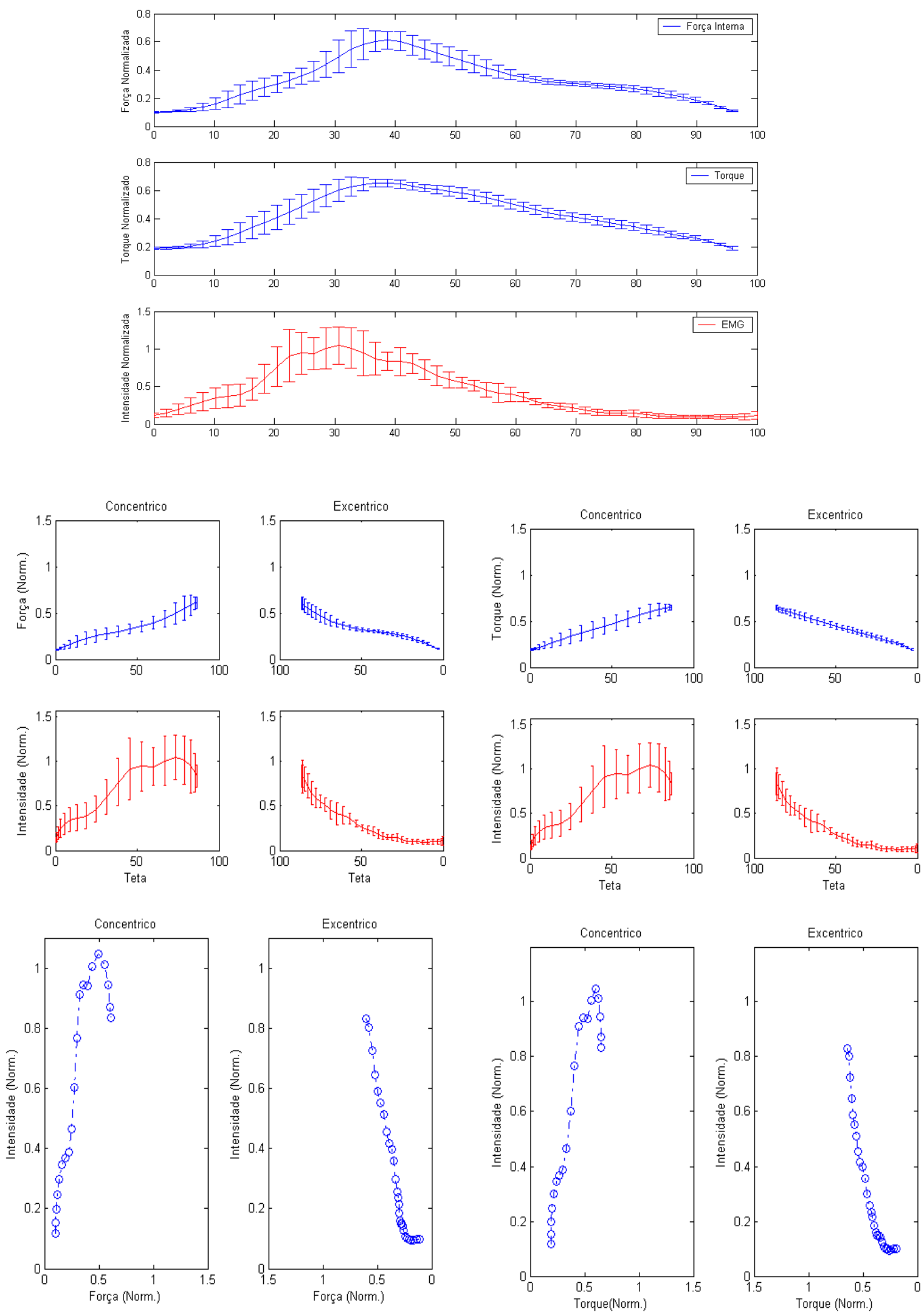
VOLUNTÁRIO 7 (Corda elástica)
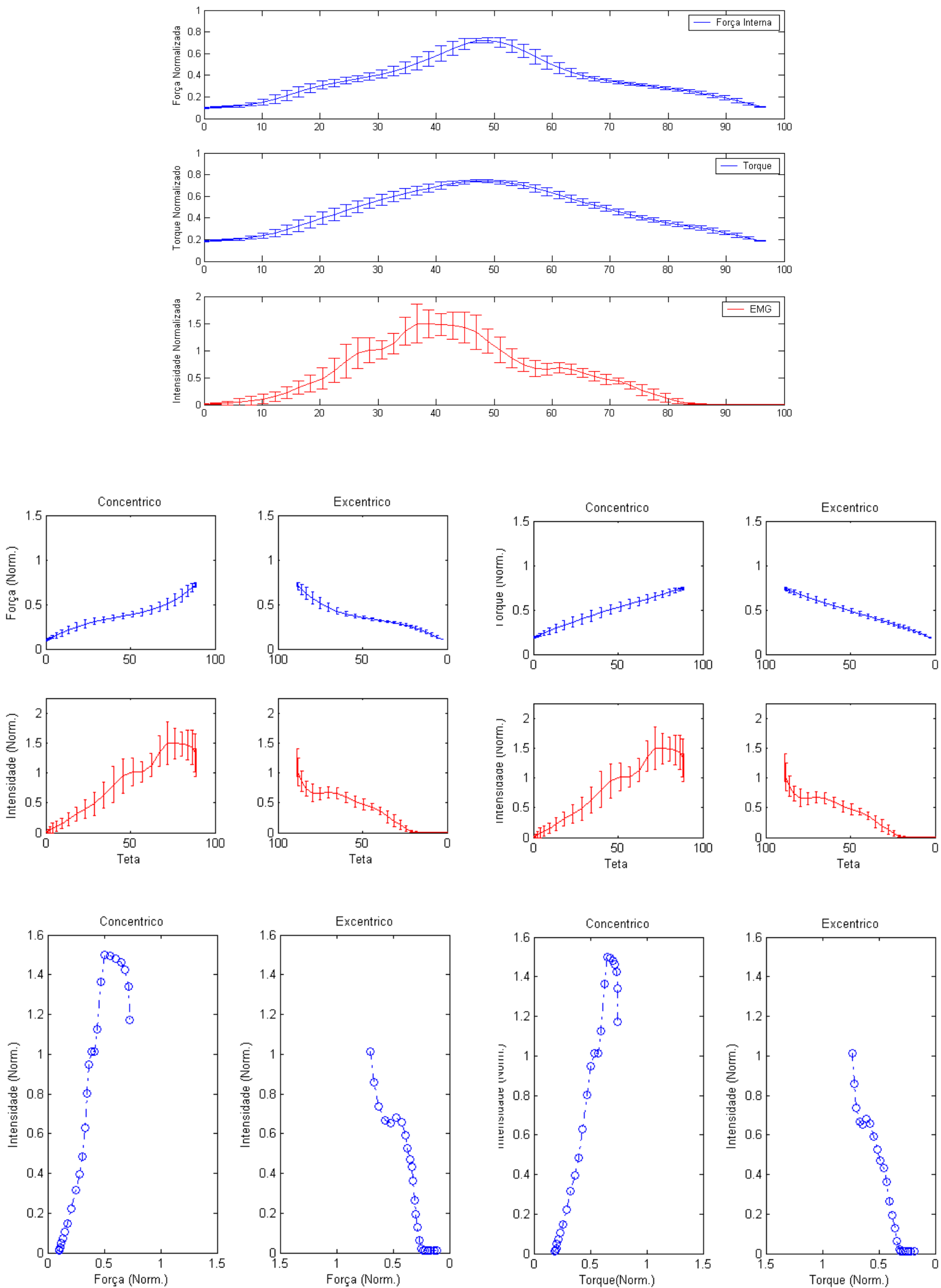
VOLUNTÁRIO 9 (Corda elástica)
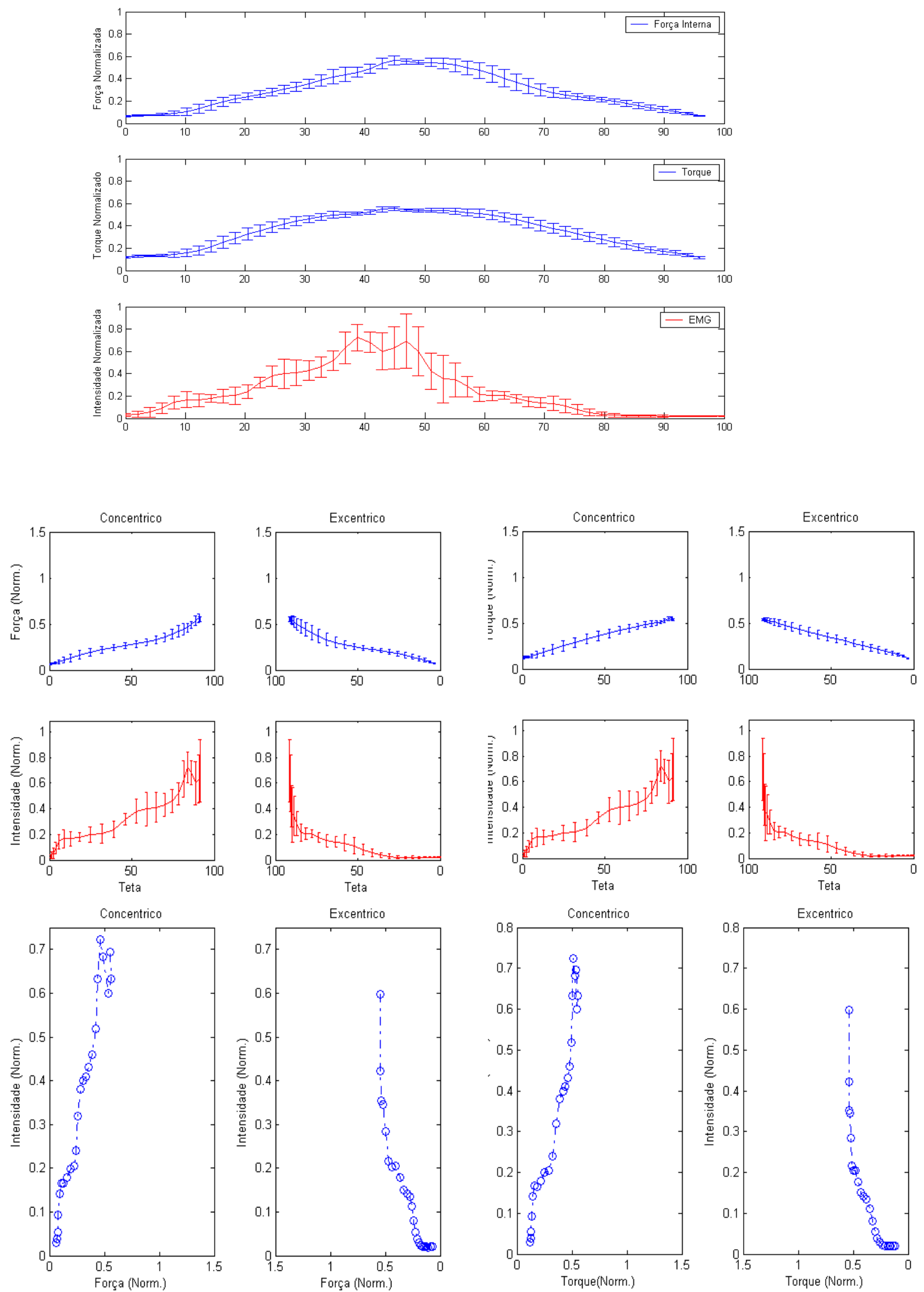


\section{APÊNDICE C}

Resultados individuais dos experimentos com peso fixo. 
VOLUNTÁRIO 1 (Peso fixo)
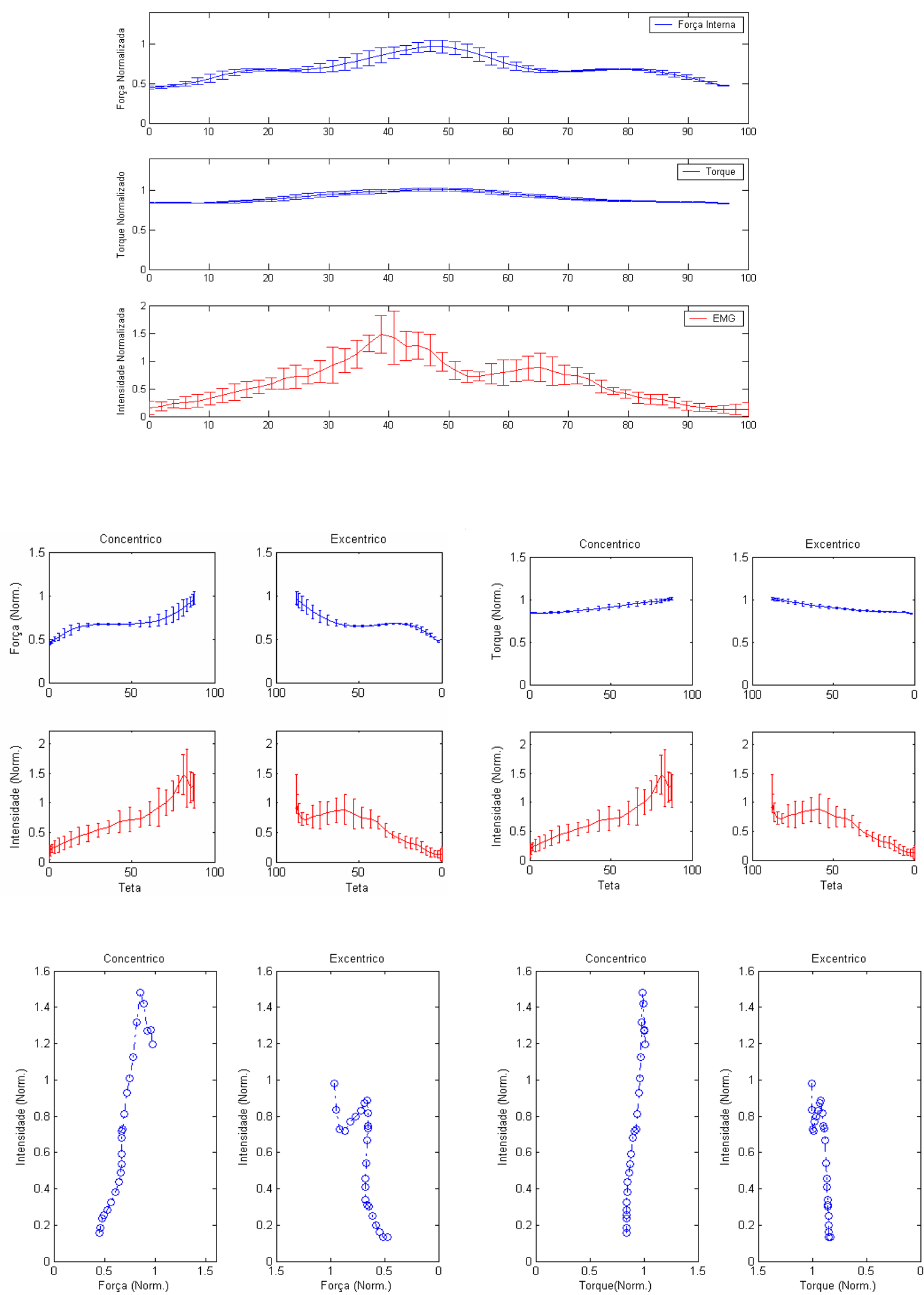
VOLUNTÁRIO 2 (Peso fixo)
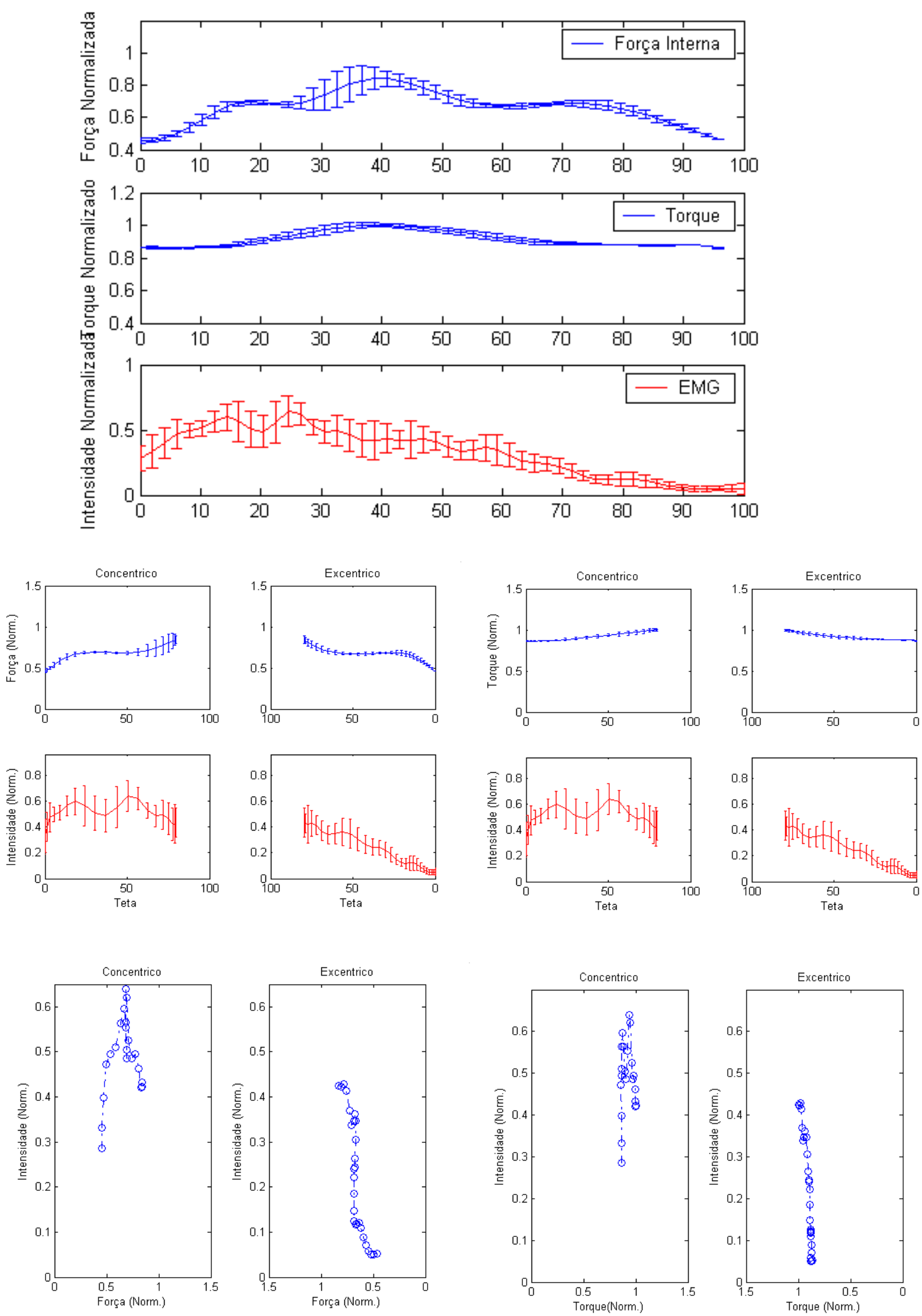
VOLUNTÁRIO 3 (Peso fixo)
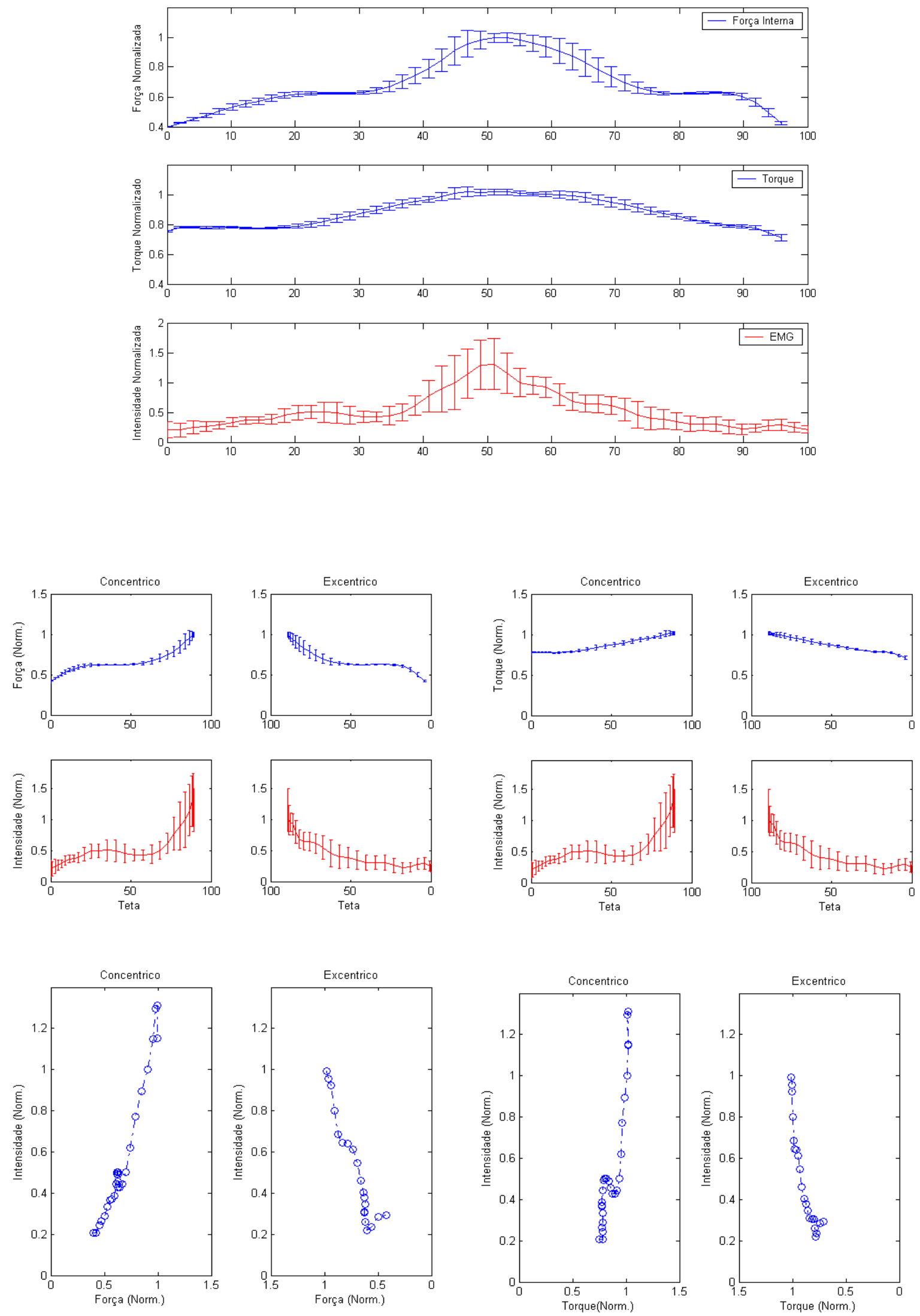
VOLUNTÁRIO 4 (Peso fixo)
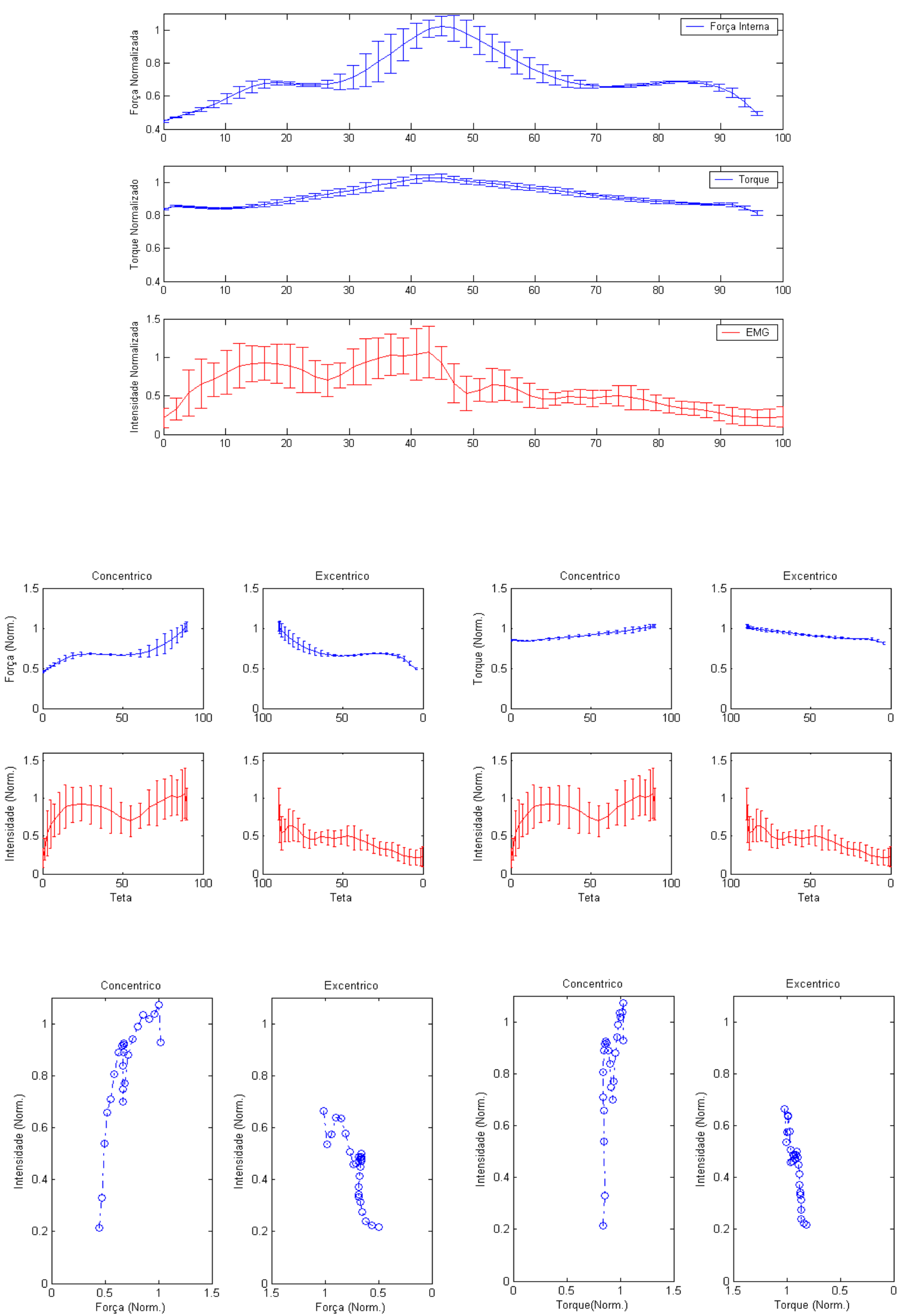
VOLUNTÁRIO 5 (Peso fixo)
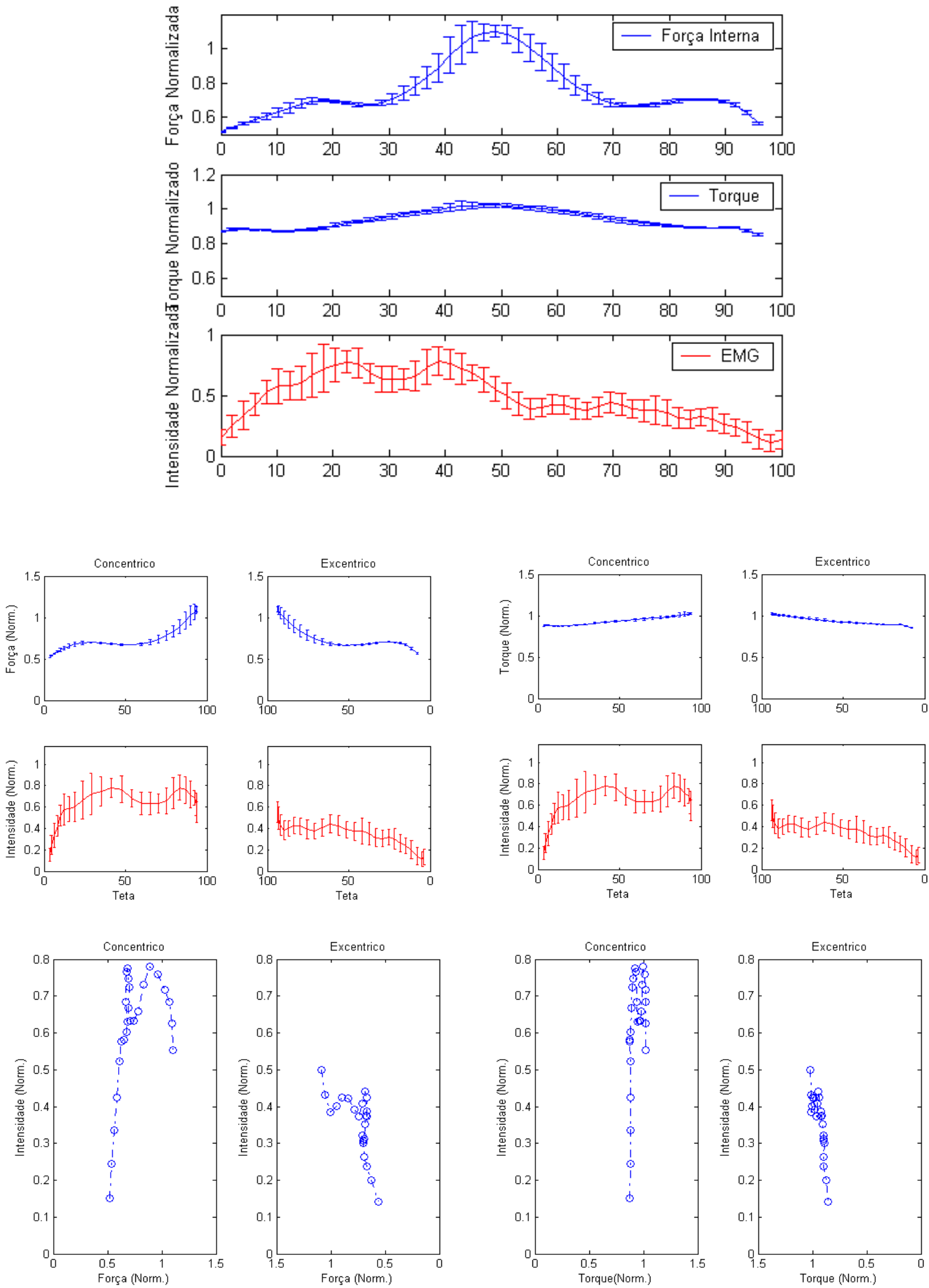
VOLUNTÁRIO 6 (Peso fixo)
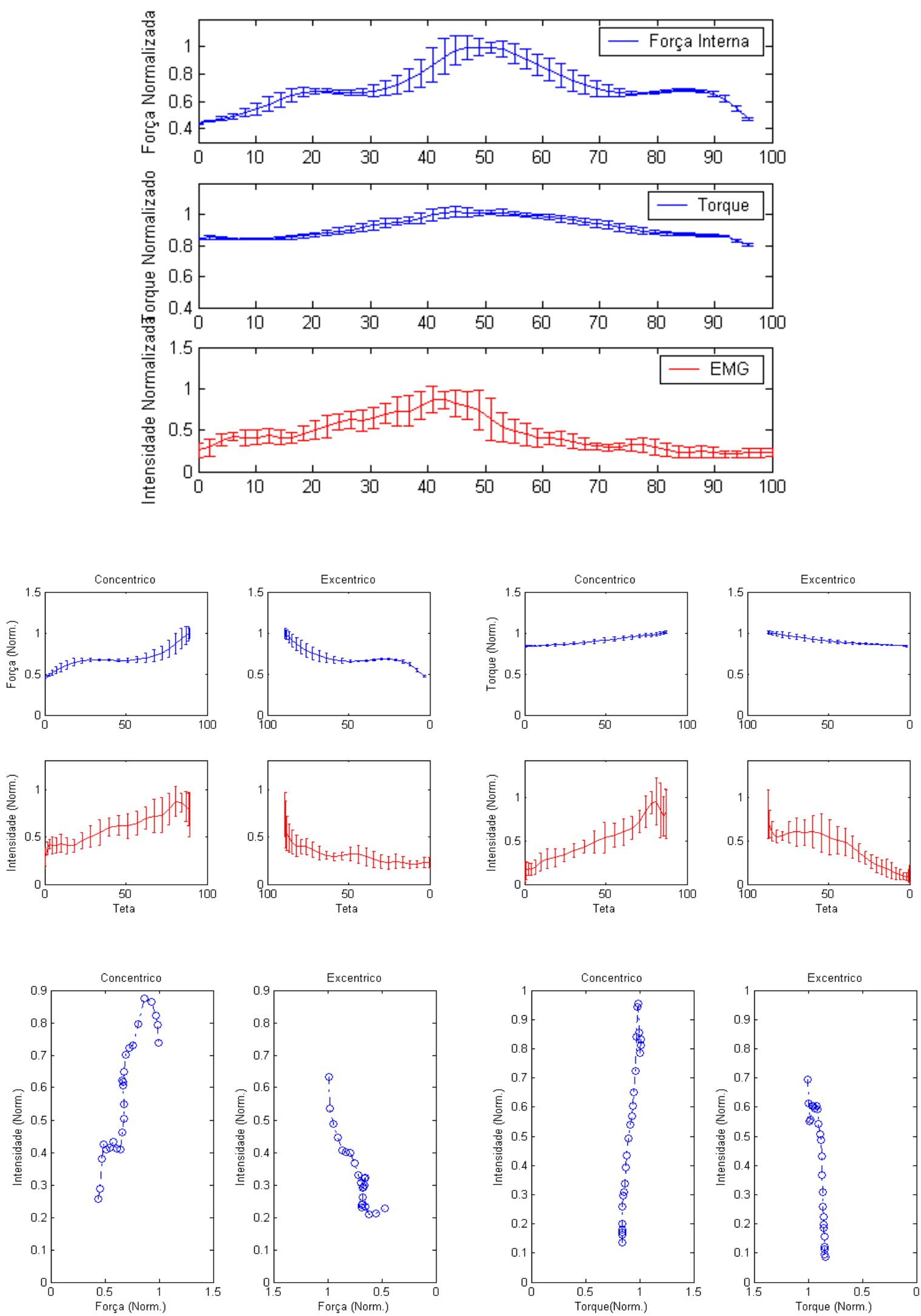
VOLUNTÁRIO 7 (Peso fixo)
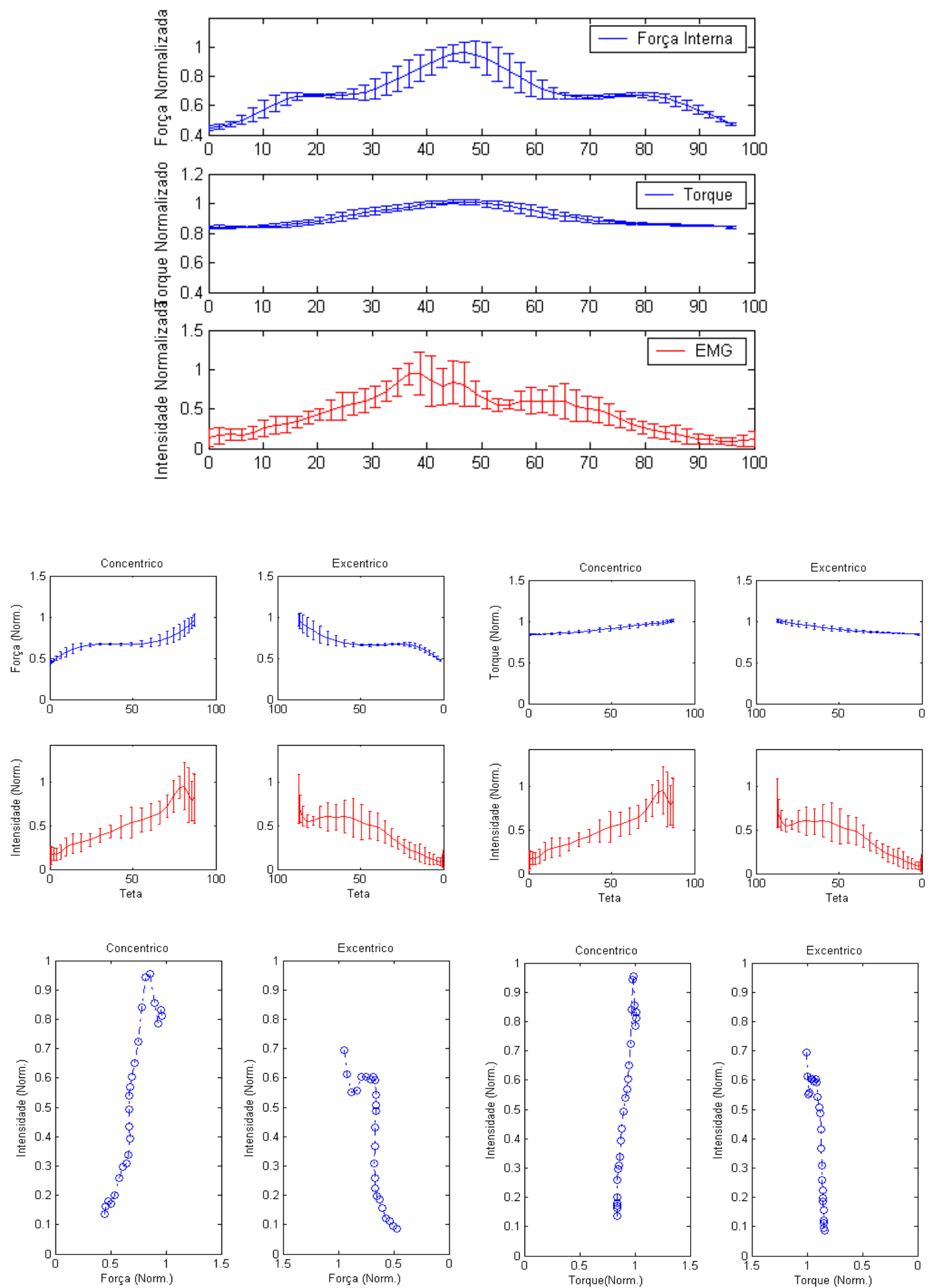
VOLUNTÁRIO 8 (Peso fixo)
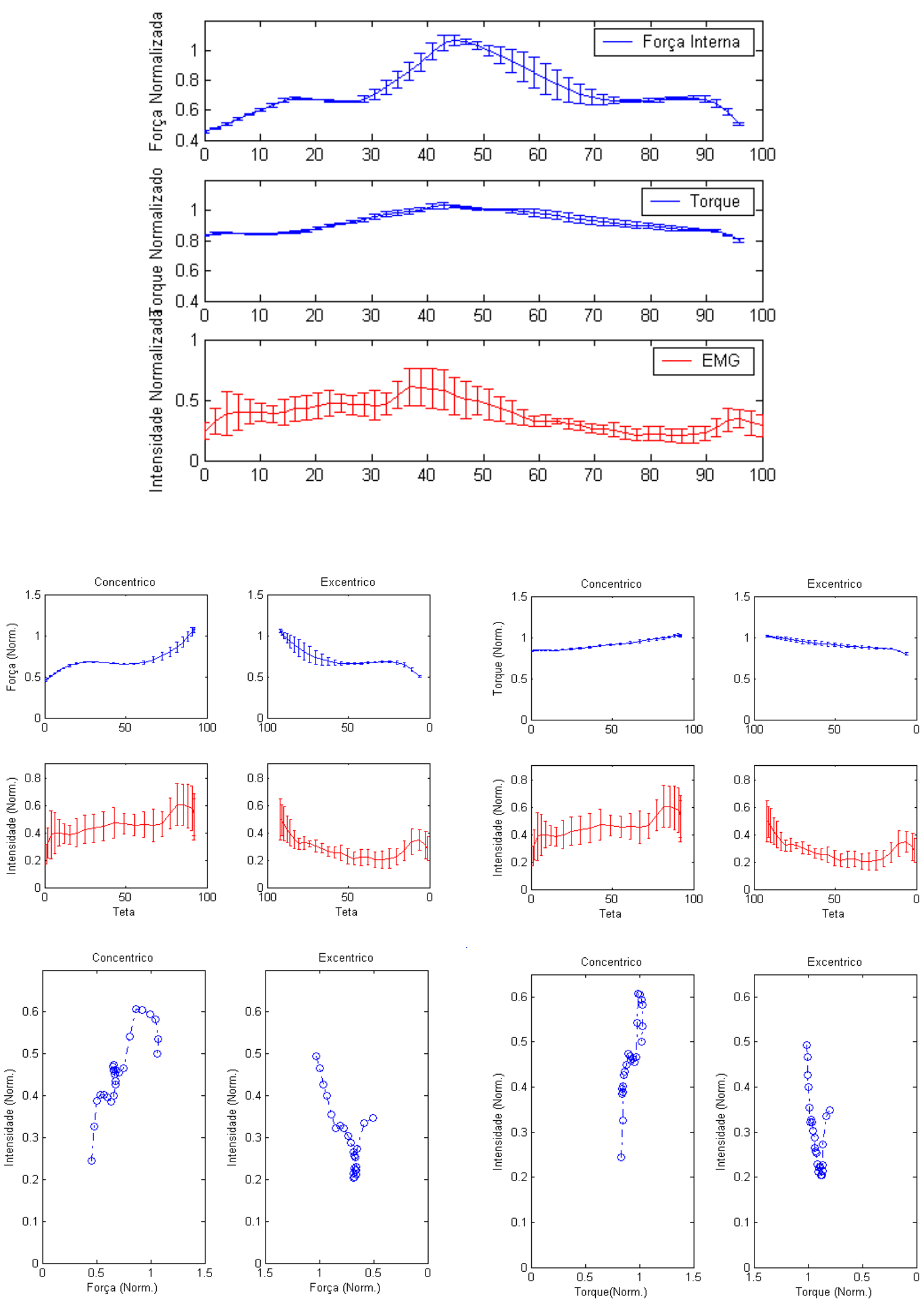
VOLUNTÁRIO 10 (Peso fixo)
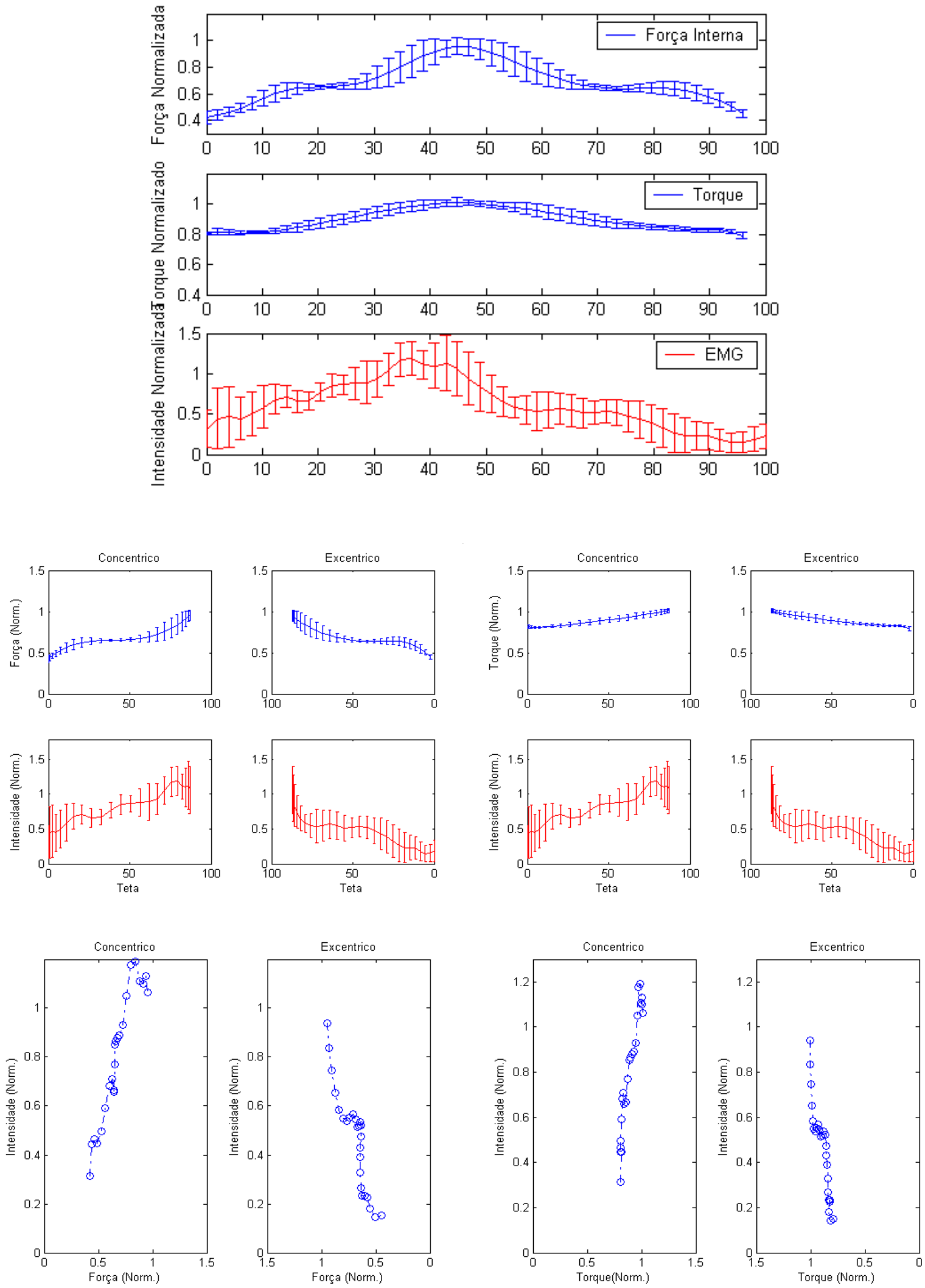